\title{
MIXING REQUIREMENTS FOR THE LIMITING FUEL-COOLANT \\ INTERACTIONS IN LIQUID METAL FAST BREEDER REACTORS
}

by

William F. Lenz, Jr.
This report was preporicE

This report was prepared as an account of work sponsored by the United States Government. Neither Research and Devel nor the Uniled States Energy their employees, nor any of their, nor any of subcontractors, or their employees contractors, warrenty, express or implied, or assumes any leat Lubity or responsibility for the accuracy, completeness or usefulnes of any information, apparatus, product or process disclosed, ot represents that its use would not

\begin{abstract}
November, 1976
Department of Nuclear Engineering

Massachusetts Institute of Technology

77 Massachusetts Avenue

Cambridge, Massachusetts 02139
\end{abstract}

Approved

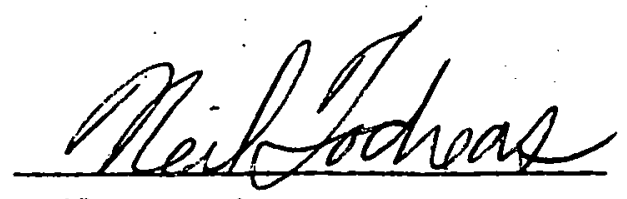

Neil E. Todreas

Principal Investigator

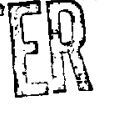




\section{DISCLAIMER}

This report was prepared as an account of work sponsored by an agency of the United States Government. Neither the United States Government nor any agency Thereof, nor any of their employees, makes any warranty, express or implied, or assumes any legal liability or responsibility for the accuracy, completeness, or usefulness of any information, apparatus, product, or process disclosed, or represents that its use would not infringe privately owned rights. Reference herein to any specific commercial product, process, or service by trade name, trademark, manufacturer, or otherwise does not necessarily constitute or imply its endorsement, recommendation, or favoring by the United States Government or any agency thereof. The views and opinions of authors expressed herein do not necessarily state or reflect those of the United States Government or any agency thereof. 


\section{DISCLAIMER}

Portions of this document may be illegible in electronic image products. Images are produced from the best available original document. 
Reports and Papers Pubitished under. MIT Fuei-Coolant Interaction Project

(This project was funded until June 30,1975 by ANL and reports issued as 31-109--38-2831-XX; starting July 1 , 1975 reports were issued as $\mathrm{COO}-2781-\mathrm{XX}$ )

Progress Reports (Available from National Technical Information Service, U.S. Department of Commerce, Springfield, Va. 2215i)

W.F. Lenz, G. Shiralker and N. Todreas, Fuel Coolant Thermal Interaction Project UC 79P, COO-2781-1, Nov. 1975.

W.F. Lenz, G. Shiralker and N. Todreas, Fuel Coolant Thermal Interaction Project UC 79P, Coo-2781-2, Feb. 1976.

G. Shiraiker, W.F. Lenz and M. Corradini, Fuel Coolant Thermal Interaction Project UC 79P, COO-2781-3, April 1976.

G. Shiralker, W.F. Lenz and M. Corradini, Fuel Coolant Thermal Interaction Project UC 79P, COO-2781-5, Oct. 1976.

G. Shiralker, W.F. Lenz and M. Corradini, Fuel Coolant Thermal Interaction Project UC 79P, COO-2781-10, Dec. 1976. 


\section{Reports Issued under this contract}

Topical Reports (Available from National Technical Information Service, U.S. Department of Commerce, Springfield, va. 22151)

Pujid S. Kazimi, "Theoretical Studies on Some Aspects of Molten Fuel-Coolant Thermal Interaction," 31-109-38-283i-lTR, MITNE-155, May 1973.

Charles E. Watson, "Transient Heat Transfer Induced Pressure Fluctuations in the Fuel-Coolant Interaction," 31-109-38-2831-. 2TR, MITISE-I56, August 1973.

Trond A. Bjornard, "An Experimental Investigation of Acoustic Cavitation as a Fragmentation Fiechanism of Molten Tin Droplets in water," 31-109-38-2831-3TR, MITNE-163, May 1974.

Glen Bjorkquist, "An Experimental Investigation of the Fragmentation of Molten Metals in Water," 31-109-38-2831-4TR, June 1975.

Roland B. Knapp, "Thermal Stress Initiated Fracture as a Fragmentation Mechanism in the $\mathrm{UO}_{2}$-Sodium Fuel-Coolant Interaction," 31-109-38-2831-5TR, May 1975 .

Michael Corradini, "Prediction of Minimum UO2 Particle Size Based on Thermal Stress Initiated Fracture Model," COO-2781-4TR, August 1976.

7i. Kazimi, C. Watson, D. Lanning, W. Rohsenow, N. Todreas, "Acoustic Cavitation as a Mechanism of Fragmentation of Hot Molten Droplets in Cool Liquids," COO-2781-6TR, November. 1976.

Gautam S. Shiralkar, "An Investigation of the Fragmentation of Molten Metals Dropped into Cold vater," COO-2781-7TR, November 1976.

William F. Lenz, Jr. "Mixing Requirements for the Limiting Fuel-cooiant Interactions in ílouid fetal Fast Breeder Reactors, "c00-2781-3TR, November 1976

M. Corradini, A.A. Sonin, N. Todreas, "A Proposed Heat Transfer Model for the Gas-Liquid Heat Transfer Effects Observed in the Staniord F.esearch Institute Scaled Tests," COO-2781-9TR, December. 1976. 


\section{Reports Issued under this Contract}

Papers and Summaries

Y.S. Kazimi, N.E. Todreas, D.D. Lanning and U.M. Rohsenow, "A Criterion for Free-Contact Fragmentation of Hot Molten Materials in Coolants," Transactions of the American Nuclear. Society, Vol. 5, No. 2, p. 835, November 1972 .

N.S: Kazimi, N.E. Todreas, W.M. Rohsenow and D.D. Lanning, "A. Theoretical Study of the Dynamic Growth of a Vapor Film Around a Hot Sphere in a Coolant," Fifth International Heat Transfer. Conference, Tokyo; 1974.

T.A. Bjornard, W.M. Rohsenow and N.E. Todreas, "The Pressure Behavior Accompanying the Fragmentation of Tin in Water," Transactions of the American Nuclear Society, Vol. 19, pp. 247248,1974 .

R. Knapp and $\mathrm{N}$ : Todreas, "Thermal Stress Initiated Fracture as a Fragmentation Mechanism in the $\mathrm{UO}_{2}$-Sodium Fuel-Coolant Interaction," Nuclear Engineering and Design 35, pp. 69-85, 1975 . 
"This report was prepared as an account of Government-sponsored work. Neither the United States, nor the Energy .Research and Development Administration, nor any person acting on behalf of the Commission

A. Makes any warranty or representation, expressed or implied, with respect to the accuracy, completeness, or usefulness of the information contained in this report, or that the use of any information, apparatus, method, or process disclosed in this report may not infringe privately owned rights; or

B. Assumes any liabilities with respect to the use of, or for damages resulting from the use of, any information, apparatus, method, or process disclosed in this report.

As used in the above, 'person acting on behalf of the Commission' includes any employee or contractor of the Administration or employee of such contractor, to the extent that such employee or contractor prepares, disseminates, or provides access to, any information pursuant to his employment or contract with the Administration or his employment with such contractor." 
MIXING REQUIREMENTS FOR THE LIMITING FUEL-COOLANT

INTERACTIONS IN LIQUID METAL FAST BREEDER REACTORS

\section{ABSTRACT}

An estimation of the mixing requirements for the limiting fuelcoolant interactions in two specific liquid metal cooled fast reactors, the Fast Flux Test Facility (FFTF) and the Clinch River Breeder Reactor (CRBR), has been undertaken. The mixing requirements were represented in terms of the limiting mixing time constants. These constants were determined with the Argonne parametric FCI Computer Model for a range of core involvements. Specifically, fuel masses used ranged from as low as one-seventh of the core to a fuli core involvement. In general, conservative values for additional FCI input parameters were assumed such that the results would be conservative.

With the results in hand, several mechanisms were investigated to determine what limiting effects they could have on the mixing rates of the fuel and coolant during an FCI. The energy requirements for mixing were investigated. The results, however, provided no limiting effects. A solidification limited fragmentation model was also investigated. Although this model provided no absolute limiting effects, it did show that fuel particle sizes of a certain size could indeed limit the fuelcoolant mixing rates. Additionally, the limiting effects were found to be much less significant for UC fuel. The third mechanism that was investigated concerned the limiting effects of the finite fuel release. rates as a result of TOP accidents in the FFTF. Equivalent mixing time constants based on the fuel release rates were shown to be greater than the limiting values. Thus, this mechanism was shown to be limiting for the particular accident sequence investigated. 


\section{ACKNOWLEDGEMENTS}

I wish to thank those who provided the encouragement and support that I needed throughout the course of my graduate work. I would like to thank Professor Neil E. Todreas for not only the overall technical. direction of my thesis, but also for the encouragement and understanding which were essential to the completion of my work:

For their companionship, friendship, and encouragement, I thank Ed Griffor and Mike Corradini. Their help in the final stages of my thesis after I left MIT was greatly appreciated. For their constant encouragement and willingness to aid me in my thesis work, I thank Drs. Michael Grolmes and Dae Cho of Argonne National Laboratory.

I thank my typist, Cindy Polansky, for her diligence and willingness. to accept the extra work of numerous corrections and changes.

And I wish to thank my family for their overall support of my efforts.

My thanks go to the Nuclear Engineering Department for their financial support of my graduate education at MIT. 
TABLE OF CONTENTS

Page

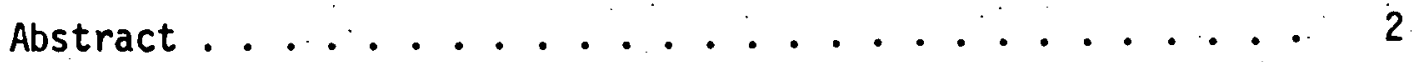

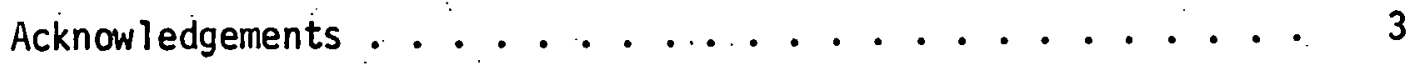

List of figures . . . . . . . . . . . . . 6

List of Tables................... . . 8

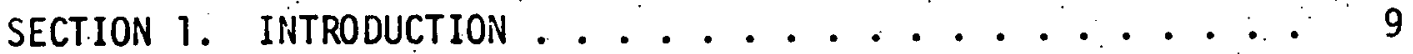

SECTION 2. OVERALL APPROACH

2.1 Limiting Case FCI ............ 13

2.2 Work Potential ............ 15

2.3 Mixing Requirements .......... 16

SECTION 3. LIMITING MIXING REQUIREMENTS

3.1 Conservative Model Inputs . . . . . . . . 18

3.2 Results ................ . . 23

SECTION 4. RATE LIMITING MECHANISMS FOR

FUEL-COOLANT MIXING : . . . . . . . . . . . . 28

4.1 Introduction . . . . . . . . . . . 28

4.2 FCI Energy Requirements . . . . . . . . . 29

4.3 Solidification Limited Fragmentation Model ..... 34

4.4 Incoherent Fuel Release Effects ......... 48

SECTION 5. CONCLUSION AND RECOMMENDATION ......... 57

References .................. . 6 62

APPENDIX A. ANL Parametric Fuel-Coolant Interaction Model

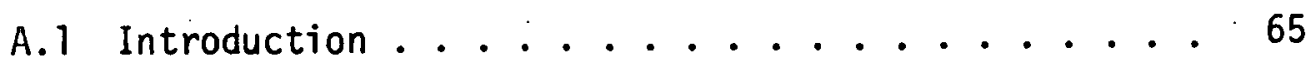

A.2 Model Formulation ............ 66

A.2.1 Physical Model and General Formulation ... . 67

A.2.2 Equation of State for Cool ant Mixing Zone . . 71

A.2.3 Heat Transfer Approximations ...... 72

A.2.4 One-Dimensional Model of Constraint .... 76 
A.3 ANL Parametric Model Input . . . . . . 79

A.3.1 Introduction ............. 79

A.3.2 Case Dependent Input Parameters ..... 81

A.3.2.1 FCI Mixing Zone Height ....... 81

A.3.2.2 Vessel Flow Area ........ 86

A.3.2.3 Fuel/Sodium Mass Ratios ..... 87

A.3.2.4 Mixing Time Constants ..... 89

A.4 Code Output ...................... 89

A.5 Code listing . . . . . . . . . 90

References to Appendix A . . . . . . . 109

APPENDIX B. Solidification Calculations ........... 111

APPENDIX C. Lower Bound on Final Fuel Particles Size

C.1 Introduction ............. 118

C.2 Translating the Finest Particle Size Distribution to a Single Particle Size ......... 123

C.3 Discussion . . . . . . . . . . . 129

References to Appendix C . . . . . . . 130

APPENDIX D. High Temperature Thermophysical Fuel Properties 131

References to Appendix D ........... 132

APPENDIX E. Hydrodynamic Breakup of a Molten Fuel Jet

E.1 Introduction ........... 133

E.2 Fuel Squirting Velocities......... 134

E.3 Critical Fuel Particle Sizes . . . . . . . . 136

E.4 Discussion ................... 141

References to Appendix E............ 145

APPENDIX F. Fuel-Coolant Interface Temperatures

F.1 Introduction .............. 146

F.2 Results ............... 147

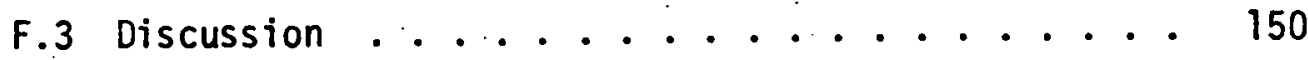

F.4 Derivation of Fuel Coolant Temperature Distribution 152

References to Appendix F . . . . . . . 164

APPENDIX G. ANL Computer Code Run Tabulation ....... 165 
1. Potential at slig impact as a function of fuel-sodium mass ratio for the CRBR

2. Finest particle size distribution (from Ref. 14).

3. Mixing time constant requirements for a $\mathrm{UO}_{2}-\mathrm{Na} \mathrm{FCI}$ having a work potential at slug impact equal to the containment capability of the FFTF ( $40 \mathrm{MW}-\mathrm{sec})$.

4. Mixing time constant requirements for a $\mathrm{UO}_{2}-\mathrm{Na} \mathrm{FCI}$ having a work potential at slug impact equal to the containment capability of the CRBR (70 MN-sec).

5. Mixing time constant requirements for an FCI having work potential at slug impact equal to the containment capability of the:CRBR (70 MW-sec).

6. Spherical representation of solidifying fuel drop.

7. Solidification and fragmentation of molten sphere drop.

8. Comparison between actual ratio of surface area to total surface area and exponential approximation.

9. Approximate mixing time constants for $\mathrm{UO}_{2}$ solidification.

10. Approximate mixing time constants of $\mathrm{UO}_{2}$ solidification for various final particle fragmentation layer sizes.

11. Comparison of approximate mixing time constants for $\mathrm{UO}_{2}$ and UC solidification (particle breakoff).

12. Limiting initial $U_{2}$ particle radii for FFTF and CRBR. 46

13. Fuel channel failure versus time in the FFTF for beginning 53 of life cycle Transient Overpower Accident.

14. Fuel channel failure versus time in the FFTF for beginning of cycle 4 Transient Overpower Accident.

15. Fuel channel failure versus, time in the FFTF for end of Cycle 4 Transient Overpower Accident.

16. Mixing time constant requirements for a $\mathrm{UO}_{2}-\mathrm{Na} \mathrm{FCI}$ having a work potential at slug impact equal to the containment capability of the FFTF ( 40 MW-sec). 
Page

17. Sensitivity of work potential at slug impact for a varia- 60 tion of FCI input parameters.

A. 1 One-dimensional model used in ANL FCI parametric model. 67

A.2 Effect of heat loss to uncovered fission-gas plenum; work 69 done for large-scale interaction.

A.3 Fuel channel dimensions in the FFTF and the CRBR. 83

A. 4 Work potential at slug impact for the FFTF varying the 88 sodium mass.

C. 1 Combination of final fuel radii and mixing time constants that produce the limiting work potential capability of the FFTF at slug impact.

C.2 Finest particle size distribution.

C. 3 Mizuta's finest fuel particle distribution.

E. 1 Hydrodynamic breakup model of idealized fuel jet.

E.2 Molten fuel jet velocity versus overall pressure differ137 ence $\Delta P$.

E.3 Stable fuel particle radi i followign hydrodynamic breakup 139 of a molten fuel jet.

E.4 Pin and FCI-Zone pressure history.

E.5 FFTF and:CRBR fuel pin geometry.

E.6 Comparison of impact time and splitting-up time for molten 144 fuel jet.

F.i Fuel-coolant interface temperatures:

1. Range of sodium critical temperatures;

2. Range of sodium spontaneous nucleation temperatures.

F.2 Liquid-liquid fuel-sodium interface temperatures.

F.3 Solid-liquid fuel-sodium interface temperatures.

F.4 Fuel-coolant temperature distribution. 


\section{LIST OF TABLES}

Page

1. Examples of Vapor Explosions.

2. List of Conservative Model Input Parameters.

3. Mixing Energy Requirements for Limiting Mixing Time

4. Fuel Release Constants.

5. Base Case Input Parameters for the Sensitivity Analysis.

A.1 Summary of Pertinent Equations.

A.2 Major Input Parameters to the ANL FCI Parametric Model. 82

A. 3 Core Flow Areas.

B.1 Approximate Mixing Time Constants for $\mathrm{UO}_{2}\left(T_{f}=2800^{\circ} \mathrm{C}\right)$. 111

B.2 Approximate Mixing Time Constants for UC $\left(T_{f}=2530^{\circ} \mathrm{C}\right) . \quad 112$

B.3 Approxinate Mixing Time Constants for UN $\left(T_{f}=2860^{\circ} \mathrm{C}, \quad 112\right.$ $R_{f}=0.0064 \mathrm{~cm}$ ).

C. 1 Finest Fuel Particle Sizes.

F.1 Fuel-Coolant Interface Temperatures.

F.2 Sodium Properties. 


\section{INTRODUCTION}

During the course of a hypothetical core disruptive accident (HCDA) in a liquid metal fast breeder reactor (LMFBR), some fraction of the fuel will melt, mix, and may interact with the sodium coolant. This is known as a fuel-coolant interaction (FCI). Whether or not this interaction will be energetic enough to cause significant damage to the primary containment boundary will depend upon how rapidly the fuel's thermal energy can be converted to mechanical work energy. The large number of uncertainties involved makes the prediction of the actual energy transfer difficult. These uncertainties, however, can be divided into two groups (1).

The first group concerns the initial conditions at the time of contact between the molten fuel and sodium. This includes the amount of interacting fuel. and sodium, the physical states of the fuel and sodium, and their mode of mixing. The second group involves the inherent mechanisms of heat transfer and interdispersion of the fuel and sodium. The first group, in general, will determine what mechanisms are operative and therefore will affect the possible consequences. Because of the safety implications of such uncertainties in LMFBR designs, much attention has been directed towards resolving both groups of uncertainties.

The initial conditions of the fuel and sodium following an HCDA have been addressed, in the last few years, by the emergence of a mechanistic approach to the analysis of HCDAs (2). This mechanistic approach analyzes the step-by-step progression of accident sequences using cause and effect 
relationships. The first step to this approach is the choice of those initiating events and/or range of events that are to be analyzed. A postulated failure of the plant protection systems (PPS) designed to protect the plant from any off-normal conditions is assumed to occur simultaneously with the proposed initiating events. The two types of HCDAs that are currently evaluated for the design assessment of LMFBRs are the Transient Overpower Accident (TOP) and the Loss of Flow Accident (LOF).

The mechanisms for heat transfer and interdispersion of fuel and sodium among other materials have been under investigation for a number of years, in nuclear as well as non-nuclear industries, due to occurrence of vapor explosions in these industries (see Table 1). A host of models have been developed to predict the experimental results of reactor materials. Such models include fragmentation models (3), heat transfer models, and in recent cases, overall models that attempt to dynamically characterize the overall heat transfer and mixing of the fuel and sodium. At this time, however, no single model is capable of predicting the entire range of experimental results. Therefore, in the design assessment of LMFBR containment capabilities, qualitative arguments have been used to assess the possibility of occurrence for a large scale coherent FCI. In the case of the $\mathrm{UO}_{2}-\mathrm{Na}$ system, used in the Fast Flux Test Facility (FFTF) and the Clinch River Breeder Reactor (CRBR), the general opinion is that energetic FCIs having significant damage potential are not possible (4). It is believed that mechanisms responsible for thermal interactions of 
TABLE 1. Examples of Vapor Explosions

Related Areas

Hot Fluid
Cold Fluid

Nuclear

SPERT-1; SL-1, BORAX-1

Al uminum

Water

Non-Nuclear

Foundry Industry

Steel

Water

Al uminum Industry

Al uminum

Water

Kraft Paper Industry

Smelt. $\left(\mathrm{Na}_{2} \mathrm{CO}_{3}\right.$ and $\mathrm{Na}_{2} \mathrm{~S}$ )

LNG Industry

Water

LNG

Submarine Explosion-

Volcanic (Krakatoa, etc.)

Lava

Water 
oxide fuel and sodium are sufficiently slow that they are not of concern in damage evaluation but are still of interest in describing accident. behavior (4). How rapid these mechanisms must be is important in assessing the energetics of $F C I s$ under different initial conditions and modes of mixing.

With this in mind, work was undertaken to establish the fragmentation and mixing requirements for limiting case FCIs. in the small-sized oxide fueled fast reactors such as the FFTF and the CRBR. Additionalliy, some work has been performed for an advanced LMFBR fuel, UC, assumed to replace the mixed-oxide fuel in the CRBR.

With these results, several possible mechanisms were investigated regarding their ability to limit the actual mixing rates of an FCI in oxide fueled fast reactors. For instance, in the Transient Overpower Accident in the FFTF, fuel release rates derived from the mechanistic analysis of the TOP accident are shown to limit the energetics of a TOP induced FCI. Other mechanisms that were investigated are the energy requirements for large-scale mixing of $\mathrm{UO}_{2}$ fragments in sodium, and the solidification of the fuel following fuel release into the sodium coolant. 


\section{OVERALL APPROACH}

To describe more completely the method used in determining the mixing requirements for limiting cases of energetic $\mathrm{FCIs}$, three items need clarification: the definition and characterization of a limiting case FCI; the description of the calculational tool that is employed including its major assumptions; and how the above two items are combined to yield the mixing requirements for the limiting case.

\subsection{Limiting Case FCI}

In short, a limiting case $\mathrm{FCI}$ is defined to be that interaction that will provide work energies at slug impact that equal the containment capability for the reactor system. Specifically, the integrity of the reactor cooling system should not be breached due to the mechanical loadings on the vessel structures as a result of the work potential at slug impact from the limiting FCI.

To describe completely the damage potential of an HCDA in which substantial vapor pressures are generated, a detailed determination of the dynamic response of the primary system is required. This is a complex problem. Calculations must include not only the response of the containment structures but also the propagation of shock waves, interaction of fluid and structures, loads imposed on components and structures adjacent to the core, and the damage produced by these loads (5). 
The actual sequence of events that will determine the deformation of the reactor vessel and its internal structures may be stated as follows. As the sodium vapor expands, it first deforms the core surrounding structures. As it expands further, it pushes the core support structure downward, deforming the core barrel and the vessel wall radially and accelerating, in the upward direction, the liquid sodium slug above the core. Once the sodium slug has moved through the free volume of the cover gas, it impacts upon the reactor cover exerting an impact force on the cover and the upper vessel wal1. Depending on the exerted force, the head hold down bolts and upper vessel wall may subsequently be deformed plastically. Finally, the system regains dynamic equilibrium. As can be seen, an accurate description of these events and the different damage mechanisms is quite involved. For current HCDA analyses, the primary containment code, REXCO-HEP, developed at Argonne National Laboratory, is used (5). Because of the time and effort involved in using this tool, a simpler means of determining the damage potential of an FCI resulting from a hypothetical core meltdown is used here.

There are two simple ways to describe the energetics of an FCI. The most frequently used method uses the expansion work of the heated coolant in the mixing zone calculated for an expansion down to $1 \mathrm{~atm}$. The other method utilizes the expansion work calculated for an expansion up to the time of slug impact.

of the various damage mechanisms mentioned above, the sodium slug impact on the reactor head provides the most serious. threat to the primary 
containment and has the most influence on containment design (6). For example; the HCDA analysis using the REXCO-HEP Computer model predicts that incipient failure of certain reactor seals may result from slug impact $(7,8)$. Therefore, the second method of describing an FCI is used. Consequently, the upper limit to the vapor expansion work at slug impact was employed to describe the containment capabilities of the FFTF and the CRBR. The values used in this analysis were $40 \mathrm{MW}-\mathrm{sec}$ and $70 \mathrm{MW}-\mathrm{sec}$ for the FFTF and the CRBR, respectively $(9,10)$.

\subsection{Calculation of Work Potential}

The calculation of the work potential at slug impact of an FCI is accomplished with the ANL parametric FCI computer model (11-13). This model comprehensively treats many of the various rate limiting processes. These include the fragmentation and mixing of the molten fuel and coolant in a mixing zone, heat transfer from the fuel to the coolant and the expansion of the heated coolant against the system constraints. Input variables generally define the two groups of uncertainties mentioned earlier.

One group of input variables describes the initial conditions of the fuel and coolant. The second group of variables describes the inherent mechanisms of heat transfer and interdispersion of the fuel and coolant. In particular, two input variables, the final fuel particle size and the mixing time constant, are used to describe the extent and 
rate of the fragmentation and mixing of the fuel and coolant.

Given the above input information, the model predicts the transient thermodynamic behavior of the fuel and sodium in the interaction zone and describes the dynamic properties of the coolant slug above the core, the position and velocity of the slug with time. The expansion work potential at slug impact is determined by allowing the sodium slug to move through a distance equal to the height of the cover gas region. At the point of impact, the corresponding output value: of the expansion work is determined directly from code output values.

The cover gas regions in the FFTF and the CRBR are different sizes even: though the reactor vessels of each have approximately the same radial

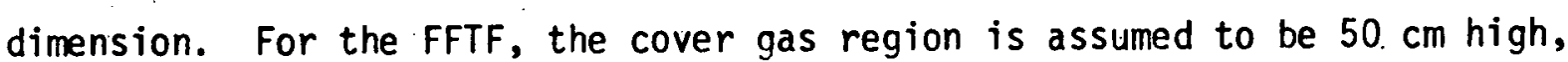
which is equivalent to that used in other models of the FFTF (12). For the CRBR, a cover gas height of $70 \mathrm{~cm}$ was used. This number was determined by dividing the cover gas volume in the CRBR vessel by the cross-sectional area of the vessel.

\subsection{Mixing Requirements}

The mixing requirements of the molten fuel and coolant that produce limiting work potential weredetermined by iterative calculations. This was performed by choosing mixing time constants (code input) that produce expansion work values which equal the limiting values for the structural integrity. If, for instance, the result of an interaction was a value 
higher than the limiting value, a larger mixing time constant would be chosen and another case would be calculated. This would indicate that the mixing occurred over a longer period of time thus reducing the rate of energy transfer and the subsequent pressurization. When two values for the work potential are obtained which bound the work potential, a graphical interpolation of the assumed mixing time constants is used to determine the time constant associated with the limiting value for the work potential.

This procedure was employed for a range of initial conditions. From this, a locus of points is established that represents the mixing requirements for the limiting work potential as a function of the mass of fuel participating in the interaction. 


\section{LIMITING MIXING REQUIREMENTS}

\subsection{Conservative Model Inputs}

To limit the number of parametric cases that could have been calculated, certain input parameters were chosen such that they would provide conservative results in calculating the: work potentials. A list of these conservative input parameters can be found in Táble: 2

The fuel temperatures were chosen to be close to the boiling points of the fuels at atmospheric pressures. These unusually high values are also a result of accounting for the latent heat of the fuel. In the ANL parametric model, solidification was not assumed; therefore, the latent heat of fusion was accounted for by adding an equivalent amount of sensible heat to the fuel. This had the result of raising the fuel temperature by approximate 1 y $560^{\circ} \mathrm{C}(12)$.

The sodium temperatures for the different reactor systems regardless: of the fuel type were taken to be the upper limit to the normal operating sodium temperatures of the particular system, namely $840^{\circ} \mathrm{K}$ and $808^{\circ} \mathrm{K}$ for the FFTF and the CRBR.

The fuel/sodium mass ratios were chosen depending upon the fuel type. For this analysis, it was determined that fuel/sodium mass ratios do not show an optimum value for which the highest work potential would be attained as was noted in an earlier analysis (12). In fact, the larger the mass ratio, the higher the work potential. This effect was examined, 
TABLE 2. List of Conservative Model Input Parameters

Fue?

Reactor System

Fuel Temperature $\left({ }^{\circ} \mathrm{K}\right)$

Sodium Temperature $\left({ }^{\circ} \mathrm{K}\right)$

Fuel/Sodium Mass Ratio

Final Fuel Particle Radius : ( $\mu \mathrm{m})$
$(\mathrm{U}, \mathrm{Pu})_{2} \quad(\mathrm{U}, \mathrm{Pu}) \mathrm{O}_{2} \quad U C$ FFTF CRBR CRBR

$4000 \quad 4000 \cdot 5000$

$\begin{array}{lll}840 & 808 & 808\end{array}$

$11-13 \ldots 11-13 \quad 15$

64

64

64 
showing that increasing the mass ratio provided increased work potentials. These results are shown in Figure 1. Therefore, the fuel mass/ sodium mass ratios in the reactor core were used as the upper limits. The UC value for the mass ratio was assumed to be higher due to the increased density of the UC fuel as compared with $\mathrm{UO}_{2}$.

The final fuel particle size was primarily based on a $\mathrm{UO}_{2}$ particle size distribution that had been determined to be the finest particle size distribution found in the U.S. and Japanese experiments (14). Figure 2 shows the different distributions and the solid line of the log-normal particle distribution that was fitted to the data to represent the finest distribution. A surface area-to-volume mean was used to determine a single fuel particle size to represent this distribution. This is known as the Sauter mean radius and can be calculated using the following form:

$$
R_{v s}=\frac{1}{\sum_{i} \frac{y_{i}}{R_{i}}} \text {, }
$$

where $y_{i}$ represents the mass fraction of particles having a diameter $D_{i}$. The resulting value for the mean is $64 \mu \mathrm{m}$. (Appendix $C$ ). This number was used throughout the analysis to represent the smallest particle size for $\mathrm{UO}_{2}$ that would be expected.

Although sufficient data was not available to make a similar determination for a lower bound on the UC particle size, results of a recent study (15) predict smaller particle sizes for UC than for $\mathrm{UO}_{2}$. However, no adjustment was made for this for the UC cases. 


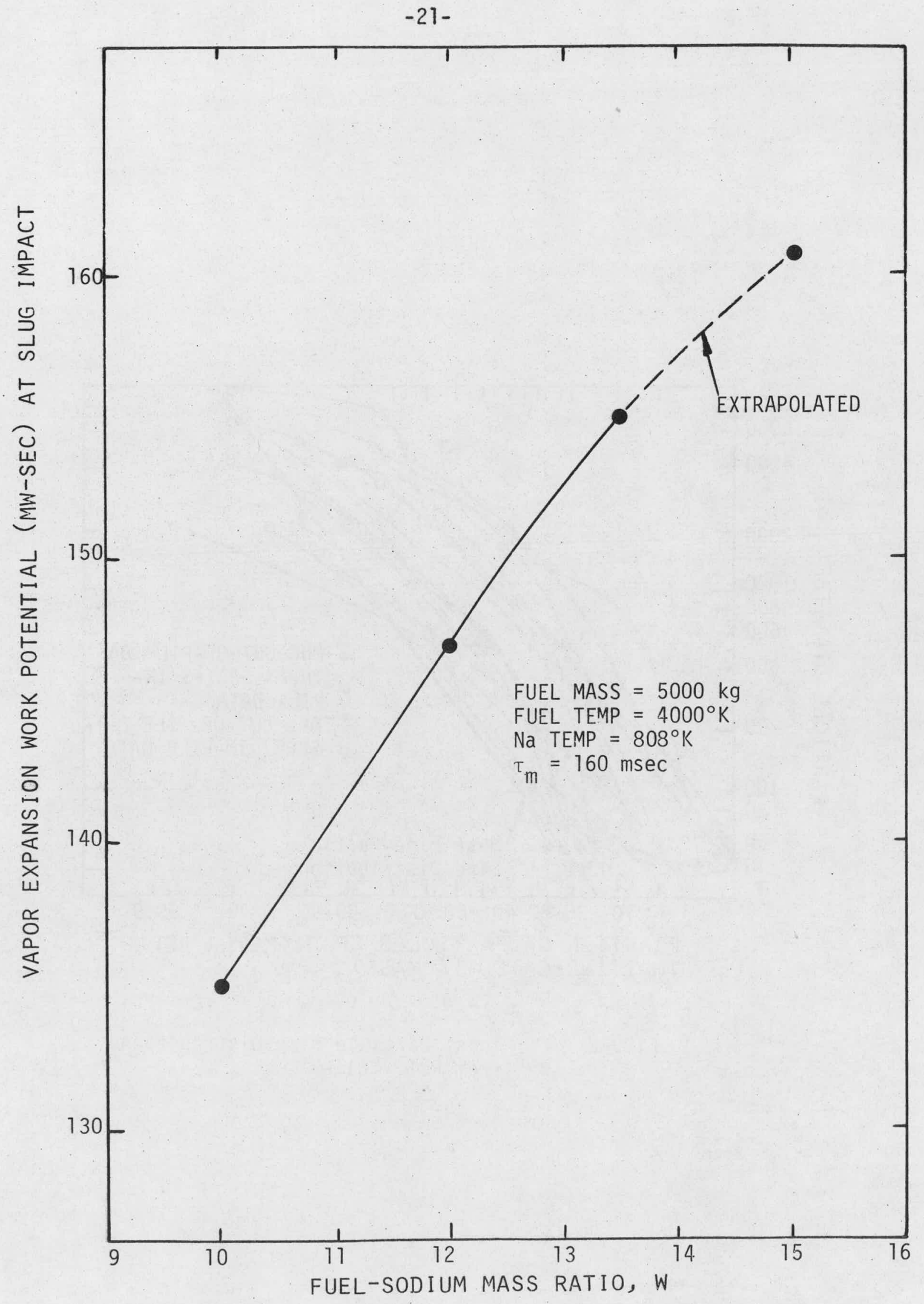

FIGURE 1. Potential at Slug Impact as a Function of Fuel-Sodium Mass Ratio for the CRBR 


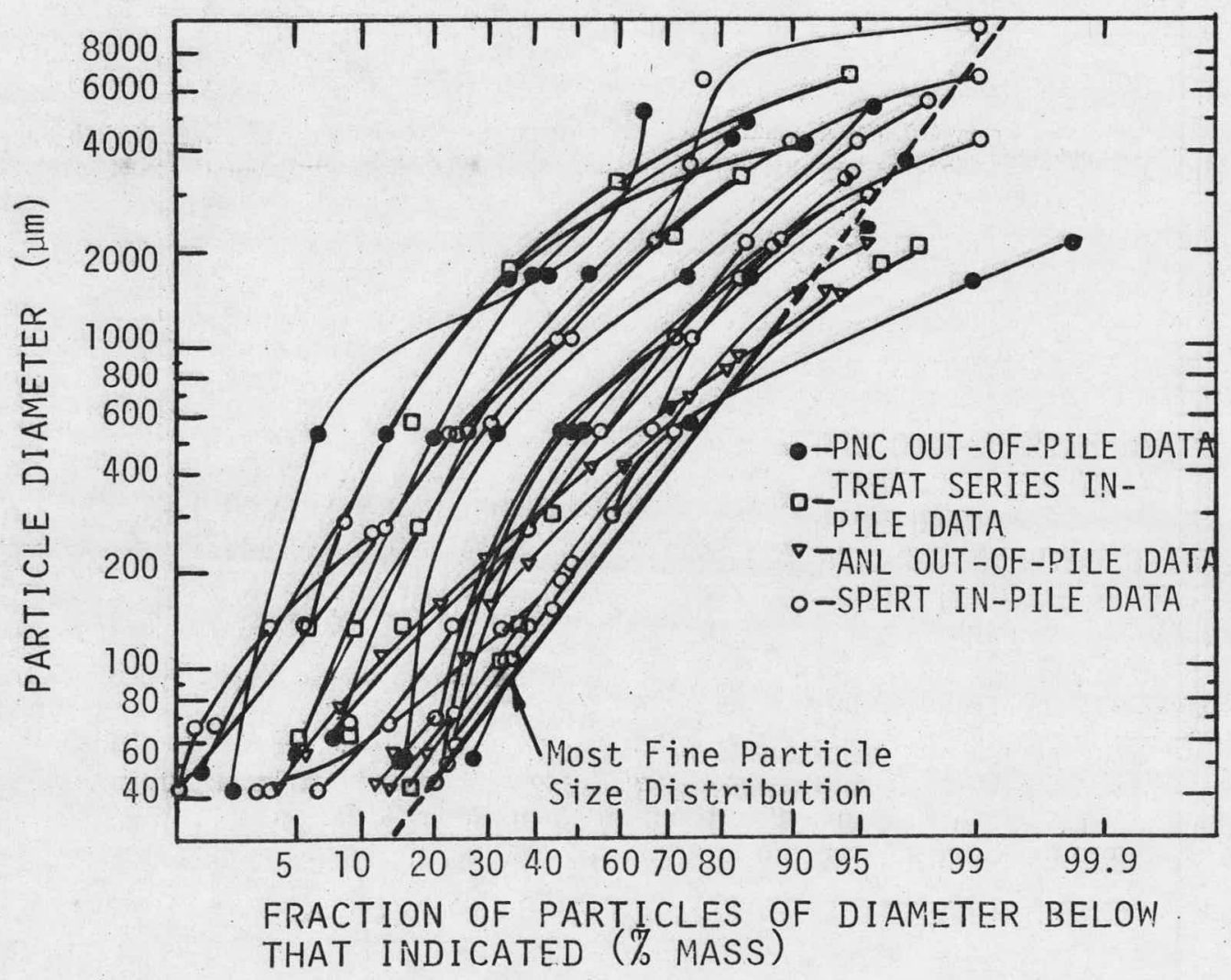

FIGURE 2. Finest Particle Size Distribution (from Ref. 14). 


\subsection{Results}

The oxide results for the limiting mixing requirements for the FFTF and CRBR are presented in Figures 3 and 4. The different mixing requirements obtained for the CRBR and FFTF reflect two major differences between the two systems, the sodium slug height and the cover gas region size. The dashed lines in both figures represent an extrapolation of the curves. Cases could not be run at these lower values because the numerical analysis in the ANL computer model is unstable at the lower values for the mass of fuel.

The carbide results for the CRBR are presented in Figure 5. For comparison purposes the oxide results for the CRBR are included in this figure for the same final particle size. It is clearly seen that the carbide mixing requirements are almost an order of magnitude less severe than the oxide results. This large discrepancy can be understood in terms of the differences in the heat transfer rate. The particular heat transfer model used in the ANL parametric model uses the following definitions for the heat transfer rate:

$$
\frac{d Q}{d t}=h A\left(T_{f}-T_{c}\right)
$$

where the heat transfer coefficient is defined as

$$
h=\frac{k_{f}}{\sqrt{\pi \alpha_{f} t}}+\frac{k_{f}}{R} .
$$

The main differences between the carbide and oxide fuels that produce the differing results are the differences in the thermal conductivities 
and initial fuel temperatures. The carbide fuel has a thermal conductivity of $0.053 \mathrm{cal} / \mathrm{sec}-\mathrm{cm}^{\circ} \mathrm{C}$, ten times that of $\mathrm{UO}_{2}$. This increases the value of the heat transfer coefficient substantially. In addition the initial fuel temperature is assumed to be $1000^{\circ} \mathrm{C}$ higher for UC than $\mathrm{UO}_{2}$. 


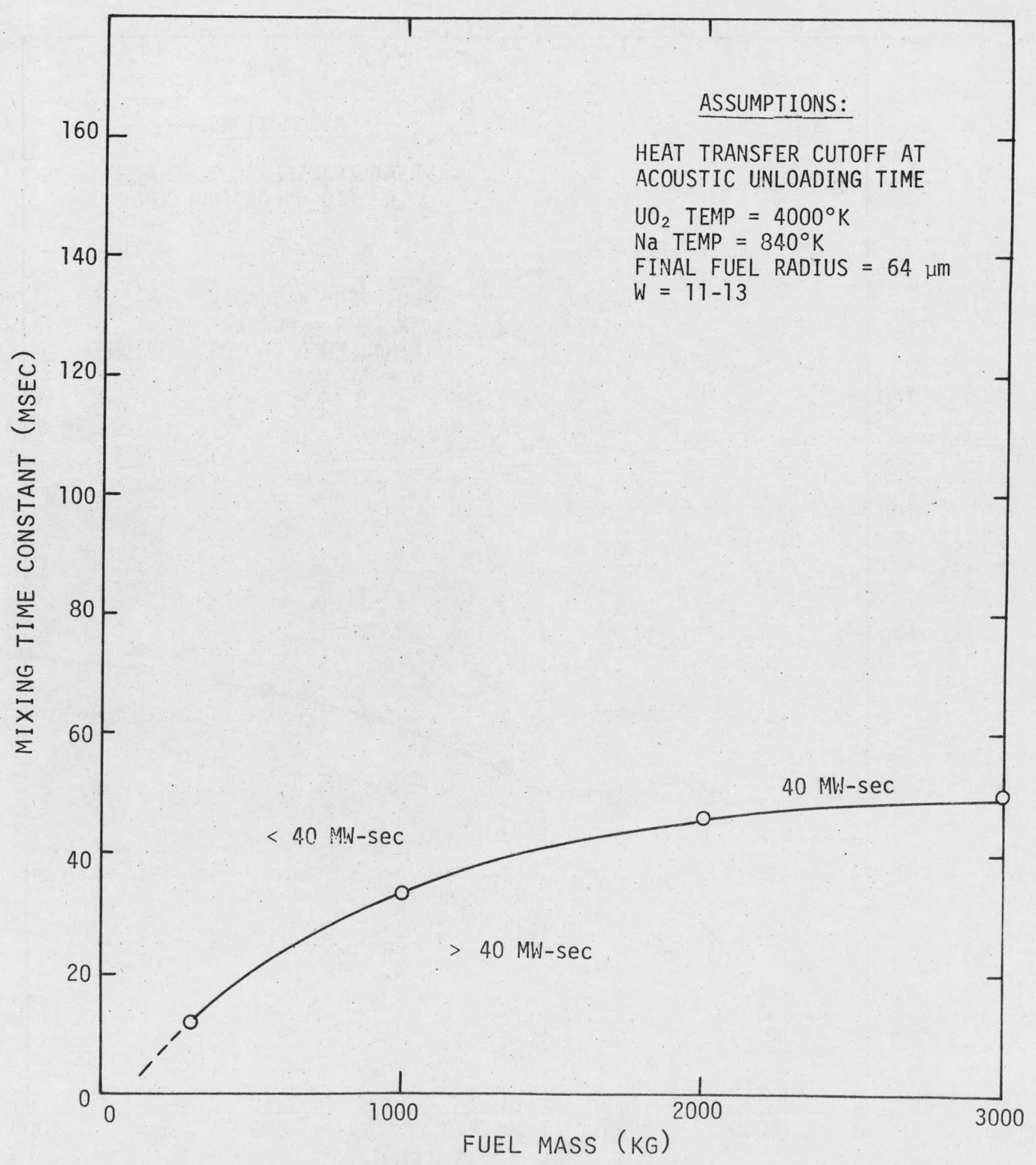

FIGURE 3. Mixing Time Constant Requirements for a $\mathrm{UO}_{2}-\mathrm{Na}$ FCI Having a Work Potential at Slug Impact Equal to the Containment Capability of the FFTF $(40 \mathrm{MH}-\mathrm{sec})$ 


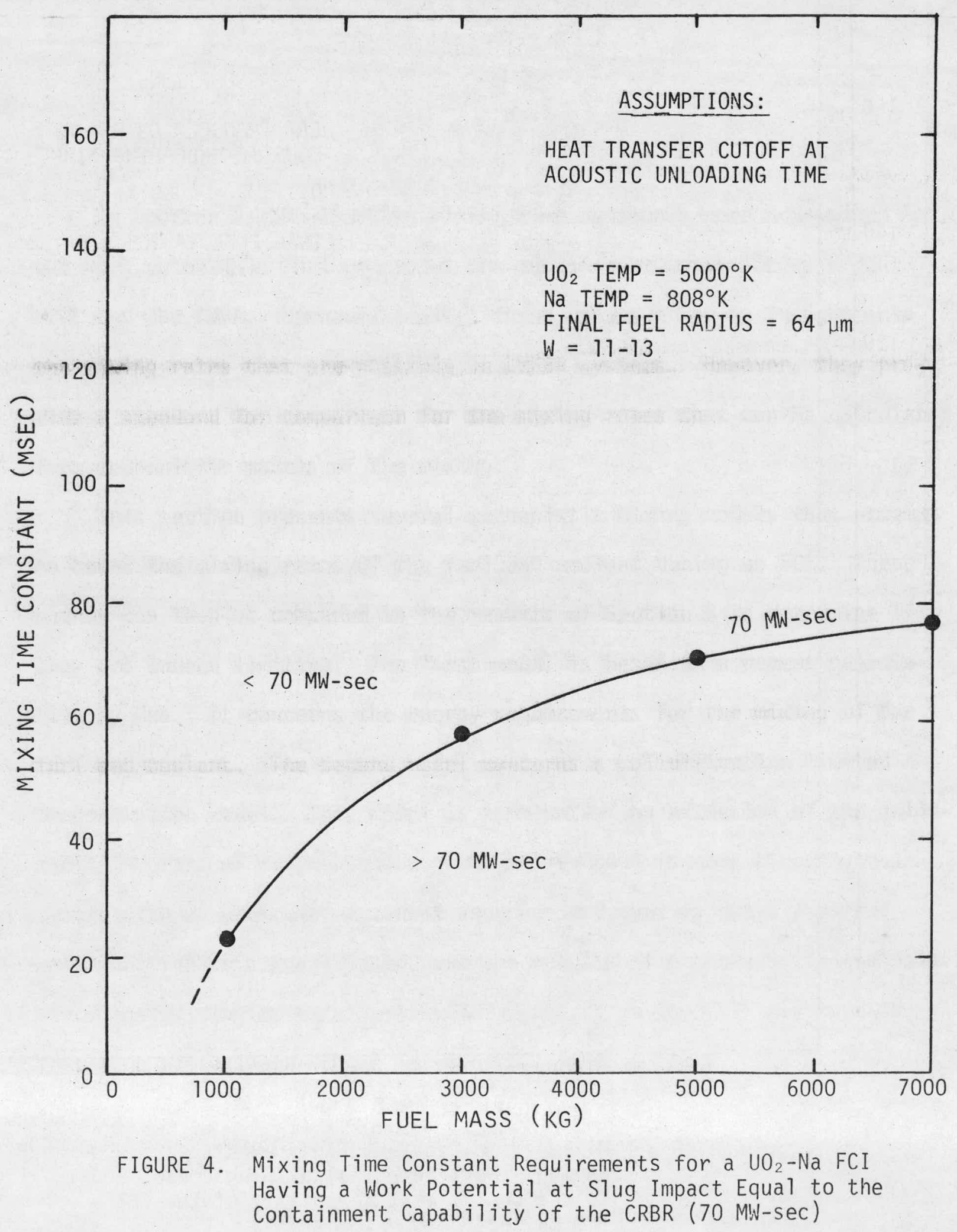




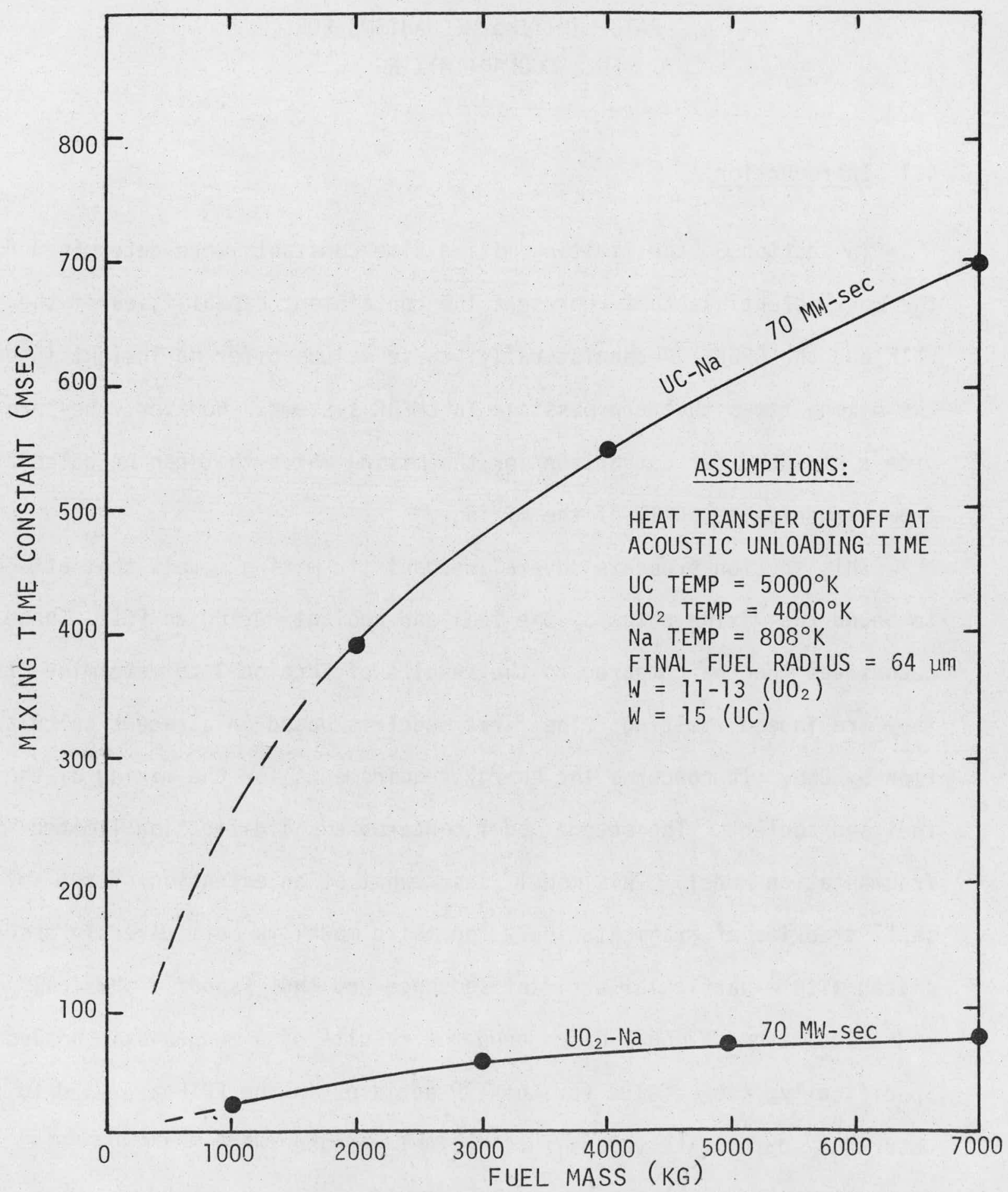

FIGURE 5. Mixing Time Constant Requirements for an FCI Having Work Potential at Slug Impact Equal to the Containment Capabilities of the CRBR (70 MW-sec) 


\section{RATE LIMITING MECHANISMS FOR FUEL-COOLANT MIXING}

\subsection{Introduction}

In Section 3, the limiting mixing time constants were determined for the work potentials that represent the containment capabilities of the FFTF and the CRBR. Mechanistically, these values offer no insight into the mixing rates that are possible in LMFBR systems. However, they provide a standard for comparison for the mixing rates that can be calculated from mechanistic models of the mixing.

This section presents several mechanistic mixing models that attempt to bound the mixing rates of the fuel and coolant during an FCI. These bounds can then be compared to the results of Section 3 to determine if they are indeed limiting. The first model is based on a recent calculation by Cho. It concerns the energy requirements for the mixing of the fuel and coolant. The second model concerns a solidification limited fragmentation model. This model is somewhat of an extension of the solidshell theories of fragmentation. The third model is more directly associated with a particular accident sequence and thus is not a physical model but rather a model based upon the results of a mechanistic analysis. Specifically, the results for the TOP accident in the FFTF are used to determine approximate values for the fuel release rates. 


\subsection{FCI Energy Requirements}

In the calculational tool used for the analysis in Section 3 , the ANL parametric model, it is assumed that the mixing zone consists of finely fragmented fuel particles spread homogeneously through the liquid coolant. The degree and rate of mixing are governed by the input parameters of the fuel particle size and the mixing time constant. These input parameters, however, do not present a model for the mixing. To investigate the mixing requirements, Cho $(16,17)$ has made an order of magnitude estimate of the energy required to break up and disperse the fuel particles in a finite volume representing the mixing zone of fuel and sodium.

Cho considered the energy requirements for the surface energy breakup (molten state), the kinetic energy of the particle movement, and the energy dissipated during the movement of the fuel particles. The surface energy can be determined by

$$
\text { Surface Energy }=N\left(4 \pi R_{f}^{2}\right) \sigma_{f}
$$

where $N$ is the number of particles and can be described as

$$
N=\frac{V_{f}}{\frac{4}{3} \pi R_{f}^{3}}
$$

Using this in Eq. (4), we get

$$
\text { Surface Area }=\frac{3 V_{f}}{R_{f}} \sigma_{f} .
$$


The kinetic energy can be calculated with

$$
\text { Kinetic Energy }=N\left(\frac{4}{3} \pi \rho_{f} R_{f}{ }^{3}\right) \rho_{f} \frac{u_{M}{ }^{2}}{2}=v_{f} \frac{\rho_{f} u_{M}^{2}}{2} \quad,
$$

where $u_{M}$ is the mixing velocity. The frictional dissipation energy can be calculated by

$$
\text { Frictional Dissipation }=N\left(C_{D} \frac{\rho_{N a} U_{M}^{2}}{2}\right) \pi R^{2} L_{M},
$$

where $C_{D}$ is the drag coefficient and $L_{M}$ is the characteristic length of the mixing zone. Assuming the drag coefficient to be equal to one, the result is:

$$
\text { Frictional Dissipation }=V_{f}\left(\frac{3}{8} \rho_{N a} u_{M}^{2}\right) \frac{L_{M}}{R} \text {. }
$$

This can be further, reduced to an equation in terms of $V_{f}$ and $t_{m}$, the mixing time (Note: not to be confused with the mixing time constant $\tau_{m}$ ) if the following substitutions are made for $L_{M}$ and $u_{M}$ :

$$
\begin{gathered}
L_{M}=V_{f}^{1 / 3} . \\
u_{M}=v_{f}^{1 / 3} / t_{m} .
\end{gathered}
$$

The final result is

$$
\text { Frictional Dissipation }=\frac{3}{8} \frac{\rho_{c} V_{f}^{2}}{t_{m}{ }^{2} R} .
$$

It was recognized that for cases of practical interest, the mixing energy 
is due primarily to the frictional dissipation as a result of the fuel particle movement, therefore eliminating the other two energy terms.

Two cases were investigated for the mixing energy. The first case is that of a one-step mixing energy,

$$
\left(E_{M}\right)_{\text {one-step }}=\frac{3}{8} \frac{\rho_{c} V_{f}{ }^{2}}{t_{m}{ }^{2} R_{f}} \quad \therefore
$$

The second case assumes progressive breakup and intermixing of fuel particles. The mixing energy for this case was derived by Cho as

$$
\begin{array}{r}
\left(E_{M}\right)_{\text {progressive,min }}=1.81 \rho_{c} V_{f}\left(\frac{V_{f}^{2 / 3}}{t_{m}^{2}}\right)\left(1-\frac{R_{f}^{2}}{V_{f}^{2 / 3}}\right) \\
\times \ln \frac{V_{f}^{\frac{1}{2}}}{R_{f}},
\end{array}
$$

where the above equation represents a minimum for a particular number of steps, $n$.

In an illustrative calculation (16), Cho assumed that $1 \%$ of the fuel's thermal energy corresponding to a $3000^{\circ} \mathrm{C}$ temperature difference was used to determine the mixing volume. Assuming a mixing time constant of $1 \mathrm{msec}$, the result using Eq. (14) was a $950 \mathrm{~cm}^{3}$ mixing volume, small compared to the necessary mixing volumes required in a large-scale HCDA. This method was applied to the results of Section 3 for the FFTF. The limiting mixing time constants with their respective fuel masses were used in Eq. (14) to determine the nixing energy. This was then compared to the total thermal energy in the fuel to assess how likely it was that this energy could be 


\section{TABLE 3. Mixing Energy Requirements for Limiting}

Mixing Time Constants in the FFTF

$\begin{array}{cccccccc}\begin{array}{c}M_{f} \\ (\mathrm{~kg})\end{array} & \begin{array}{c}V_{f} \\ \left(10^{5} \mathrm{~cm}^{3}\right)\end{array} & \begin{array}{c}{ }_{T_{\mathrm{m}}} \\ (\mathrm{msec})\end{array} & \begin{array}{c}t_{\mathrm{m}} \\ (\mathrm{msec})\end{array} & \begin{array}{c}\mathrm{R}_{\mathrm{f}} \\ (\mu \mathrm{m})\end{array} & \begin{array}{c}{ }^{*}\left(E_{M}\right)_{\mathrm{p}} \\ (\mathrm{cal})\end{array} & \begin{array}{c}{ }^{*}{ }^{*} E_{T} \\ (\mathrm{cal})\end{array} & \begin{array}{l}\text { Percent } \\ \text { Fraction }\end{array} \\ 500 & 0.51 & 25 & 115 & 64 & 191 \times 10^{2} & 1.9 \times 10^{8} & 1.0 \times 10^{-4} \\ 1000 & 1.0 & 34 & 157 & 64 & 315 \times 10^{4} & 3.8 \times 10^{8} & 0.8 \times 10^{-4} \\ 2000 & 2.0 & 47 & 216 & 64 & 527 \times 10^{4} & 7.6 \times 10^{8} & 0.7 \times 10^{-4} \\ 3000 & 3.1 & 51 & 235 & 64 & 925 \times 10^{4} & 11.5 \times 10^{8} & 0.8 \times 10^{-4}\end{array}$

${ }^{*}{ }_{M}$ is the limiting mixing time constant as obtained from Figure 2.

**From Eq. (14)

$* \star E_{T}$
${ }^{*} M_{f} C_{f} \Delta T \quad$ (where $C_{f} \Delta T$ is the equivalent energy content per unit mass from molten
fuel temperatures through solidification to the reference sodium temperature) 
expended for the mixing process. To analyze the energy requirements correctly, the mixing time constants, $\tau_{m}$, should be translated to the mixing time, $t_{m}$. This is accomplished by taking $t_{m}$ to be the time at which $99 \%$ of the fragmentation and mixing has taken place. Using the exponential form with the above assumption, the surface area ratio is

$$
\frac{A}{A_{0}}=1-e^{-t_{m} / \tau_{m}}=0.99 .
$$

The relationship between $t_{m}$ and $\tau_{m}$ can then be described by

$$
t_{m} / \tau_{m}=4.605
$$

Using the FFTF limiting mixing time constants, translations were made for the specific cases calculated as indicated in Table 3 . The results in Table 3 indicate that the mixing energy requirements for the four cases investigated are very small. This conclusion differs somewhat from Cho's, primarily due to the difference between the mixing times chosen. In effect, Cho used a mixing time of $1 \mathrm{msec}$ for illustrative purposes only. The mixing times used in our analys is were based on the limiting mixing time constants of Section 3 without specifying a particular mixing mechanism. For our case, if the energy requirements had been substantial, this would effectively move the curves in Figs. 3 and 4 to the right. In essence, larger fuel masses would have to be postulated to give the same expansion work potential because some portion of the energy in the original fuel mass would be used to mix the fuel and coolant rather than to simply heat the sodium coolant. 


\subsection{Solidification Limited Fragmentation Model}

The solidification of molten fuel (outside the cladding) during an HCDA is an important consideration for the safety analyses in LMFBRs. It can affect not only the accident sequence but the overall consequences of an accident. In a macroscopic sense, it can affect how rapidiy reactor shutdown is accomplished following a release of molten fuel. For example, fast reactor shutdown is facilitated during a TOP accident by a sweepout of the fuel material into the upper plenum region (18). If; on the other hand, molten fuel solidifies close to the release area, it is possible that there will be a net positive reactivity insertion until some other mechanism can shut down the reactor, such as the disassembly and dispersion of the core materials. In a microscopic sense, solidification is an important consideration regarding proposed fuel fragmentation mechanisms (19). The physical state of the fuel surface within the breakup period is important to the analysis of the fragmentation mechanics. Solidification, itself, has been demonstrated analytically to be a plausible fragmentation mechanism of fuel (19-21). This mechanism is referred to as the solid shell theory of fragmentation or the thermal-stress induced fracture mechanism.

Solidification rates of fuel are analyzed to determine what possible limiting effects they could have on overall fuel fragmentation rates. Of course, the results of this investigation and their applicability is contingent upon the assumption that the fuel fragmentation takes place as a result of the proposed thermal stress mechanism and the particular model. 
In short, this model for the thermal stress mechanism requires that only the solidified fuel will fragment. In essence, molten fuel cannot fragment significantly before solidifying. Therefore, the solidification rate will bound the fragmentation rate. This model is acceptable for the $\mathrm{UO}_{2}-\mathrm{Na}$ system or the UC/UN-Na systems in which solidification will begin immediately (< $1 \mathrm{msec}$ ) upon contact with the liquid sodium (22).

To provide what would be considered the limiting values for the solidification rates and subsequent fragmentation rates, a fixed interface temperature boundary condition is used. Previous analyses (23) have shown that this boundary condition provides the fastest solidification rate when compared with other modes of heat transfer. A spherical geometry was assumed for these calculations.

To determine the progress of the solidification front within the molten spherical droplet (see Figure 6), the Fourier heat conduction equation must be solved. Assuming constant thermophysical properties, the form of this equation in spherical coordinates is

$$
\frac{\partial^{2} T(r, t)}{\partial r^{2}}+\frac{2}{r} \frac{\partial T(r, t)}{\partial r}=\frac{1}{\alpha} \frac{\partial T(r, t)}{\partial t}
$$

The spherical fuel droplet is assumed to be initially at its melting temperature

$$
T(r, 0)=T_{M}
$$

At the solidifying front, there are two conditions that must be met: 


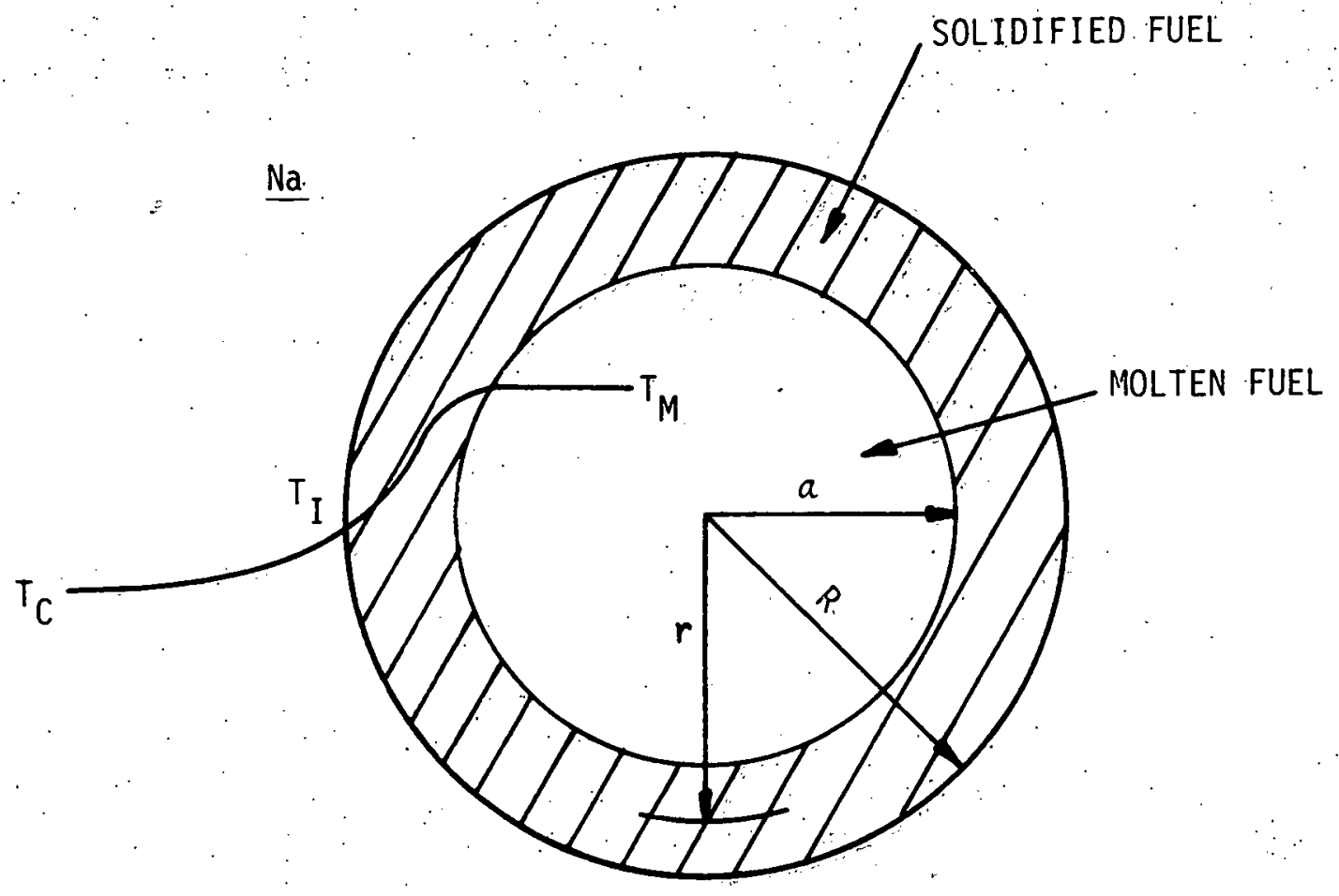

FIGURE 6. Spherical Representation of Solidifying Fuel Drop 


$$
\left.k \frac{\partial \dot{T}(r, t)}{\partial r}\right|_{r=a}=\rho L \frac{d a}{d t}
$$

and

$$
T(a, t)=T_{M} .
$$

The only other condition that must be satisfied is a fixed surface temperature at the originat fuel-sodium interface,

$$
T(R, t)=T_{I}
$$

Unlike the derivation of the temperature distribution in slab geometry, the non-linearity of Eq. (19) presents a problem in solving the above formulation exactly. For spherical geometry, only a limited number of analytic solutions are available (19). Of these, the Adam's solution was used in this analysis. This method of solution was developed by transforming the partial differential boundary value problem into an integral equation and solving by successive approximations (19). With this method, the freezing rate can be determined by:

$$
\frac{d a}{d t}=\frac{2 a C_{p}\left(T_{M}-T_{I}\right)}{L a\left(1-\frac{a}{R} z\right)} \text {, }
$$

where

$$
z=1+\left[1+\frac{4}{3} \frac{R C_{P}}{\alpha L}\left(T_{M}-T_{I}\right)\right]^{\frac{3}{2}} .
$$

The above form for $\mathrm{da} / \mathrm{dt}$ can be integrated directly to give the position of the solidification front.with time. 


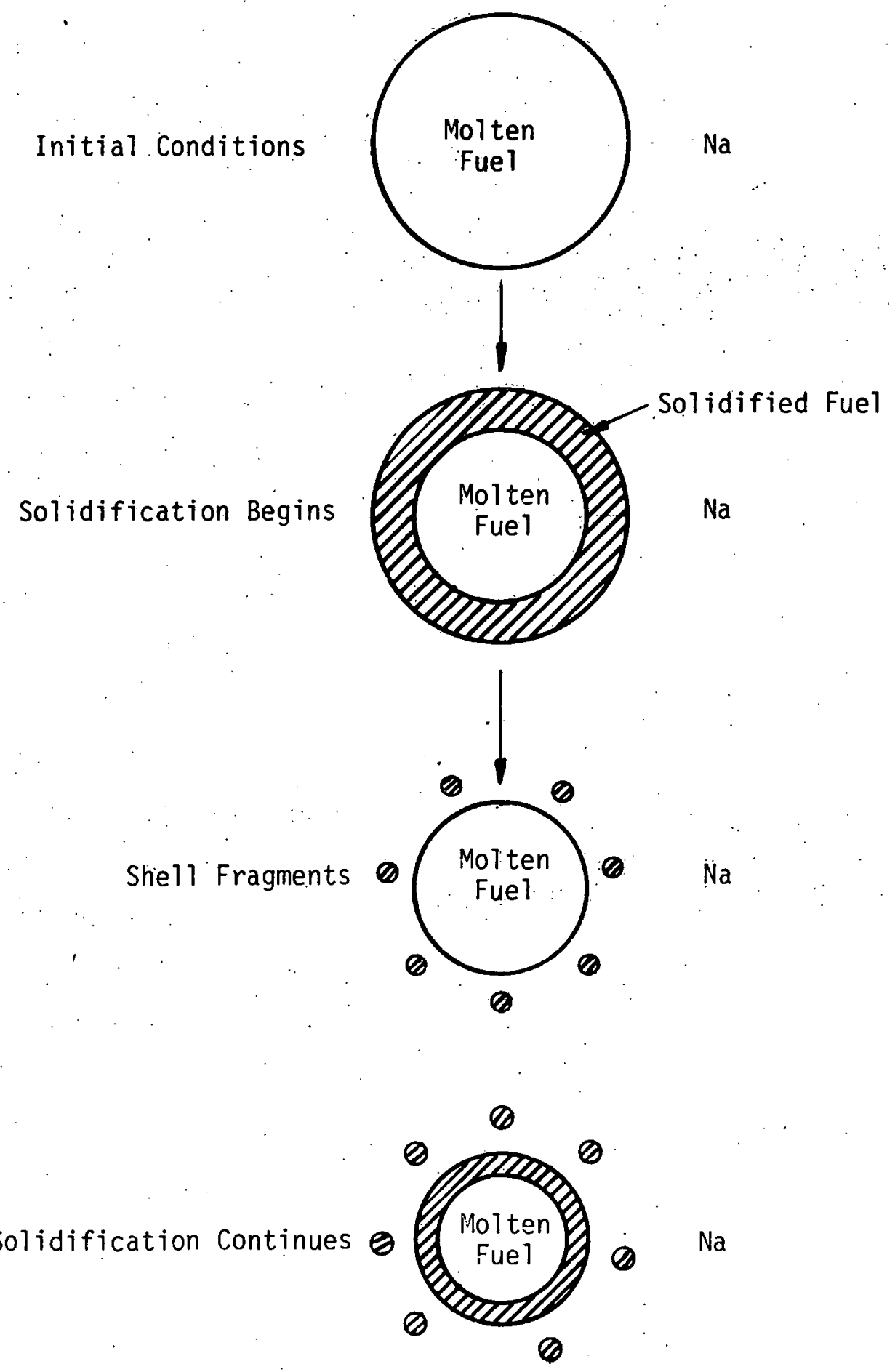

FIGURE 7. Solidification and Fragmentation of Molten Sphere Drop 
Two general solidification modes were considered in these calculations; the solidification of a molten sphere assuming the droplet geometry remains intact and the solidification of a molten sphere assuming fuel particle breakoff. The second mode is perhaps more realistic in that it represents a molten droplet that is successively solidifying with the intermittent fragmentation and/or shedding of a frozen shell of fuet. A graphical representation of the second mode is shown in Figure 7 . This calculation assumes that once a certain solidified shell thickness is achieved (i.e., thick enough to fragment), the initial interface temperature is re-established on the smaller molten sphere. No delay time is assumed for re-establishing the interface temperature. The progressive solidifying and fragmenting of the molten sphere will provide the fastest rate at which the entire sphere can fragment with the proposed model. From these solidification rates, approximate mixing time constants were established that could be used to relate the solidification or fragmentation rate to the results for the limiting mixing requirements as developed with the ANL parametric FCI model.

The mixing time constants were determined by comparing two curves. The first curve is that of the surface area generated with time, A, divided by the final surface area, $A_{0}$. This surface area pertains to the surface area that would be exposed as the spherical droplet solidifies and fragments. The second curve represents an exponential approximation of the first curve. The form for the exponential curve is 
FIGURE 8. Comparison Between Actual Ratio of Surface Area to Total Surface Area and Exponential Approximation.

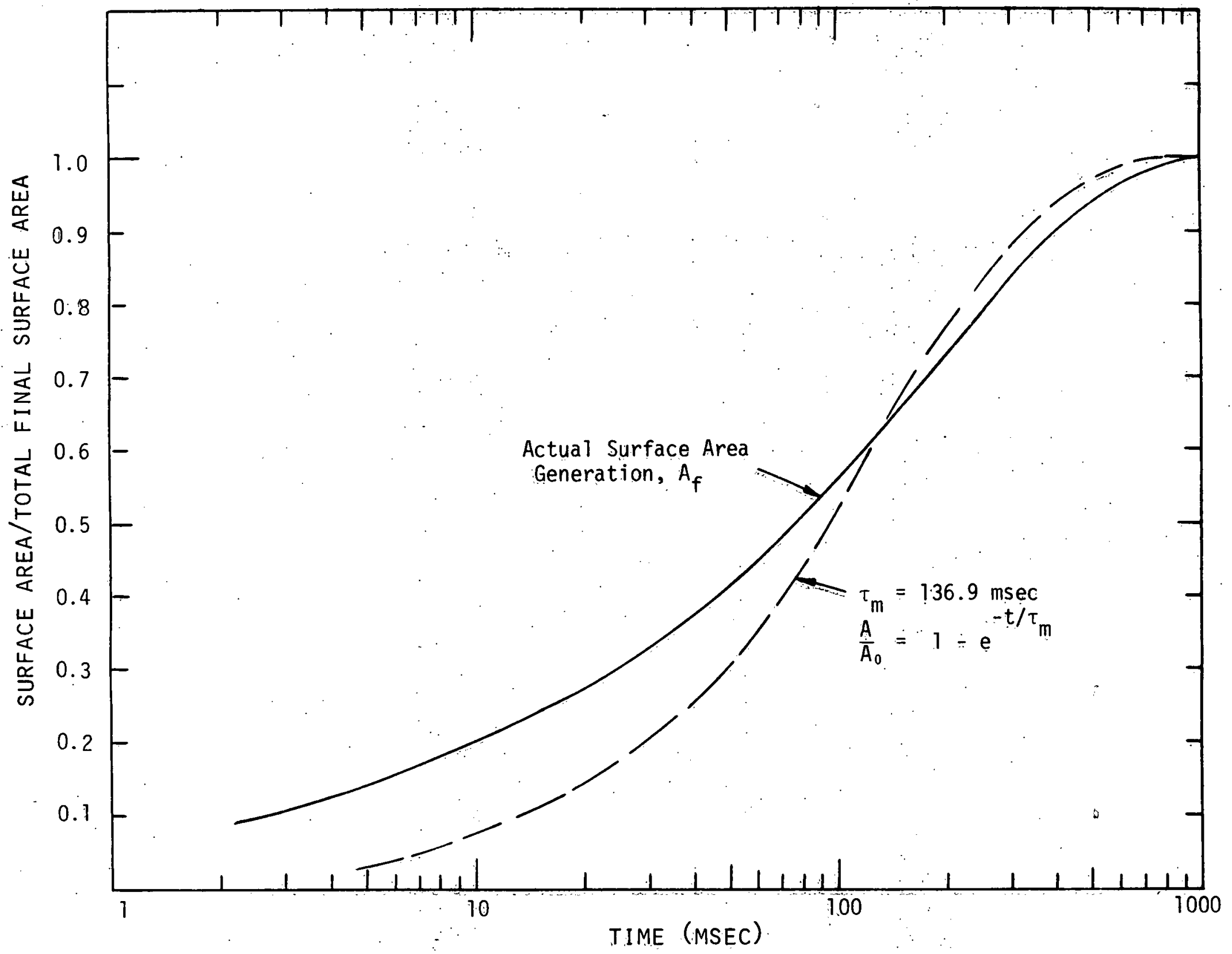




$$
\frac{A}{A_{0}}=1-e^{-41-},
$$

where ${ }^{\prime}{ }_{m}$ is the mixing time constant. This equation is identical to that used in the parametric model. Therefore, if a mixing time constant can be chosen suitably to approximate the actual curve, $\tau_{m}$ can be compared to the results for limiting mixing requirements. Figure 8 is an example of the two curves, the expected ratio of the surface area generated to the final surface area and the exponential approximation, for the case of particle breakoff.

For simplicity, the mixing time constants were chosen such that the values of the approximation and the actual curve would be equal when $A / A_{0}$ equals 0.632 . Comparing the two curves on Figure 8 , this method appears to provide an adequate representation for the case of particle breakoff. Two fuels were investigated in this analysis, $\mathrm{UO}_{2}$ and UC. The solidification rates and the surface area generation for these fuels were determined for a range of initial fuel droplet sizes. Figure 9 represents. the results for $\mathrm{UO}_{2}$. The different interface temperatures represent the interface temperatures calculated assuming the fuel to be initially at its melting point with the range of normal sodium operating temperatures in the FFTF and the CRBR. The interface temperatures were determined from the results in Appendix F.

From Figure 9, it can be seen that varying the interface temperature does not have a large effect on the resultant mixing time constants as compared to the difference between the behavior of an intact versus a 
$-42-$

FIGURE 9. Approximate Mixing Time Constants for $\mathrm{UO}_{2}$ Solidification

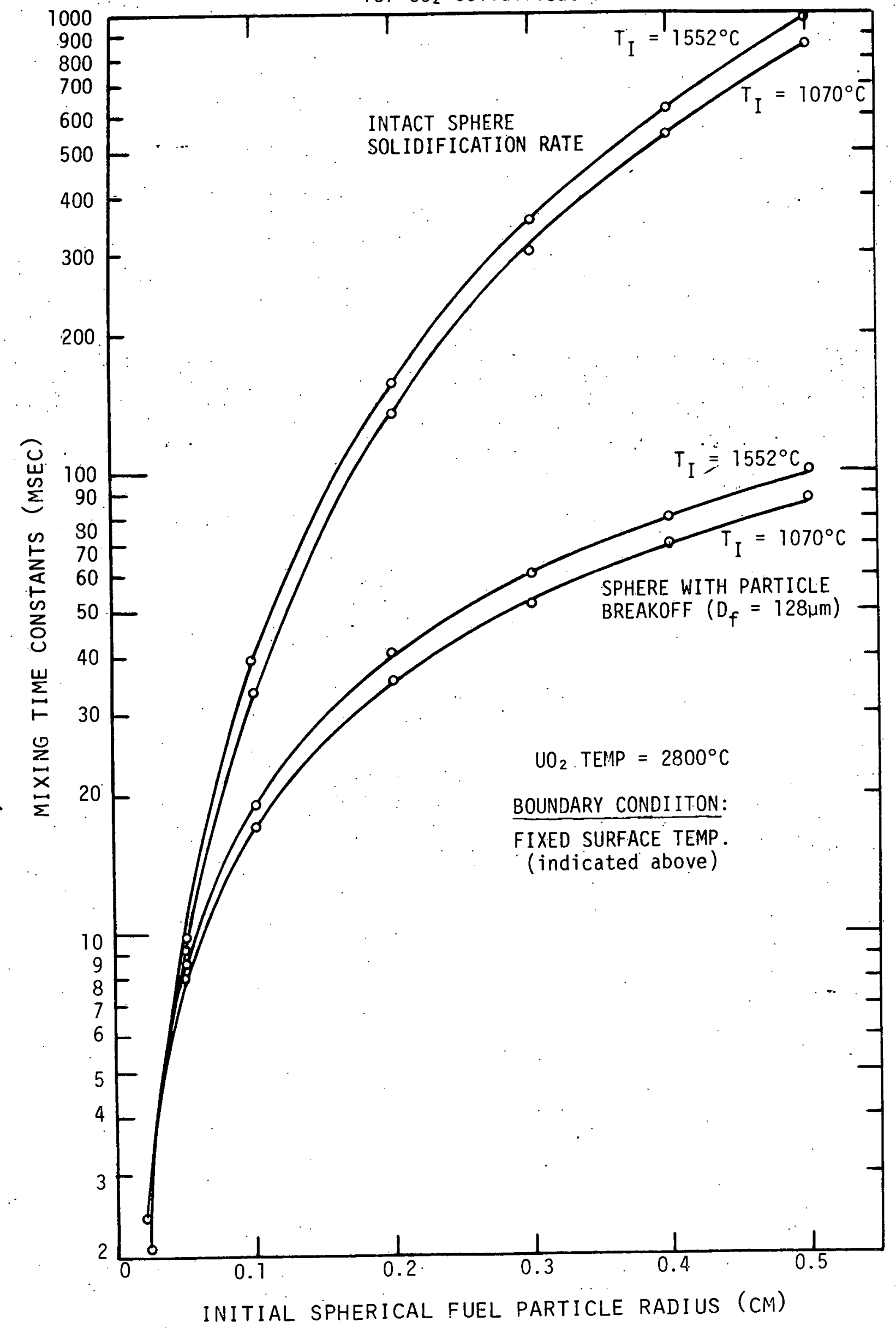


$-43-$

FIGURE 10. Approximate Mixing Time Constants of $\mathrm{UO}_{2}$ Solidification for Various Final Particle Fragmentation Layer Sizes.

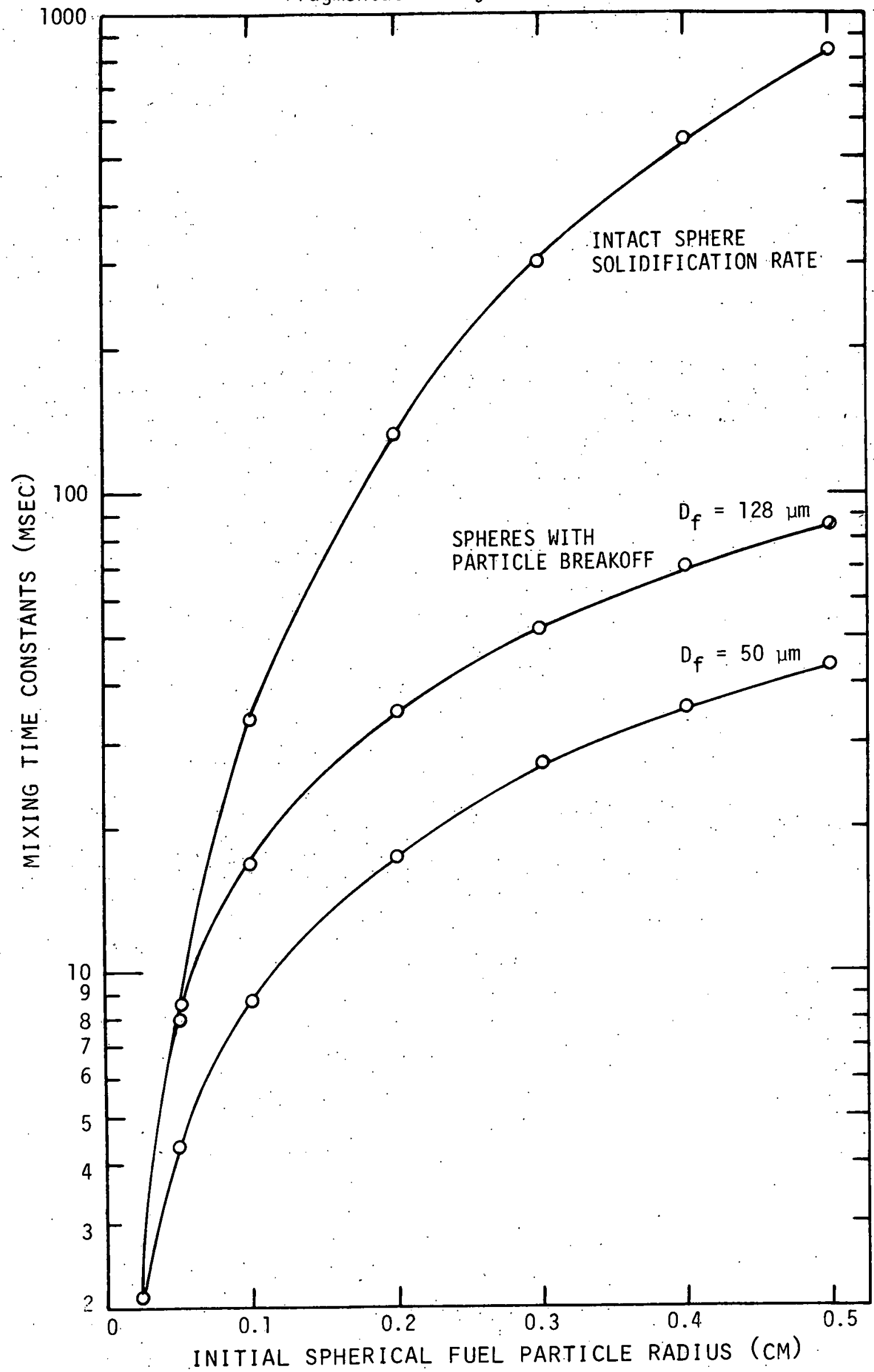


continuously fragmenting sphere. The solidified shell thickness in this figure is assumed to be 128: $\mathrm{mm}$ (i.e., equal to the final fuel particle diameter assumed for the mixing requirement analysis:). The effect of choosing even smaller final fuel particle sizes for the breakoff of the solidified layer can be seen in Figure 10. In this figure, a layer: breakoff thickness of $50 \mathrm{\mu m}$ shows expectedly a faster solidification rate and smaller mixing time constant. Although this presents a more conservative (faster). solidification rate, the 128 um size should be? adequate for several reasons. First of all, this fuel particle diameter was based upon the finest experimental fuel particle size distribution: Furthermore, the method used in determining this equivalent fuel particle size provides a smaller value than a simple diameter-volume average of the fuel particle size distribution:

In Figure 11, the mixing time constants for the advanced fuel, UC, are compared with those of. $\mathrm{UO}_{2}$. Again, the fuel is assumed to be at its melting temperature. The interface temperatures for the UC-Na system were calculated based on the inlet sodium temperature in the CRBR, which provides the fastest solidification rate and the smallest mixing time constants.

Whether or not these calculations provide us with any significant limiting mechanism is dependent upon the results of Section 3 . For the case of $\mathrm{UO}_{2}$, the limiting mixing time constants have been compared with results of this section. Figure 12 represents the initial fuel particles' radii that represent the limiting work potential of the FFTF and the CRBR, considering the particle breakoff mode. This curve was generated by choosing 


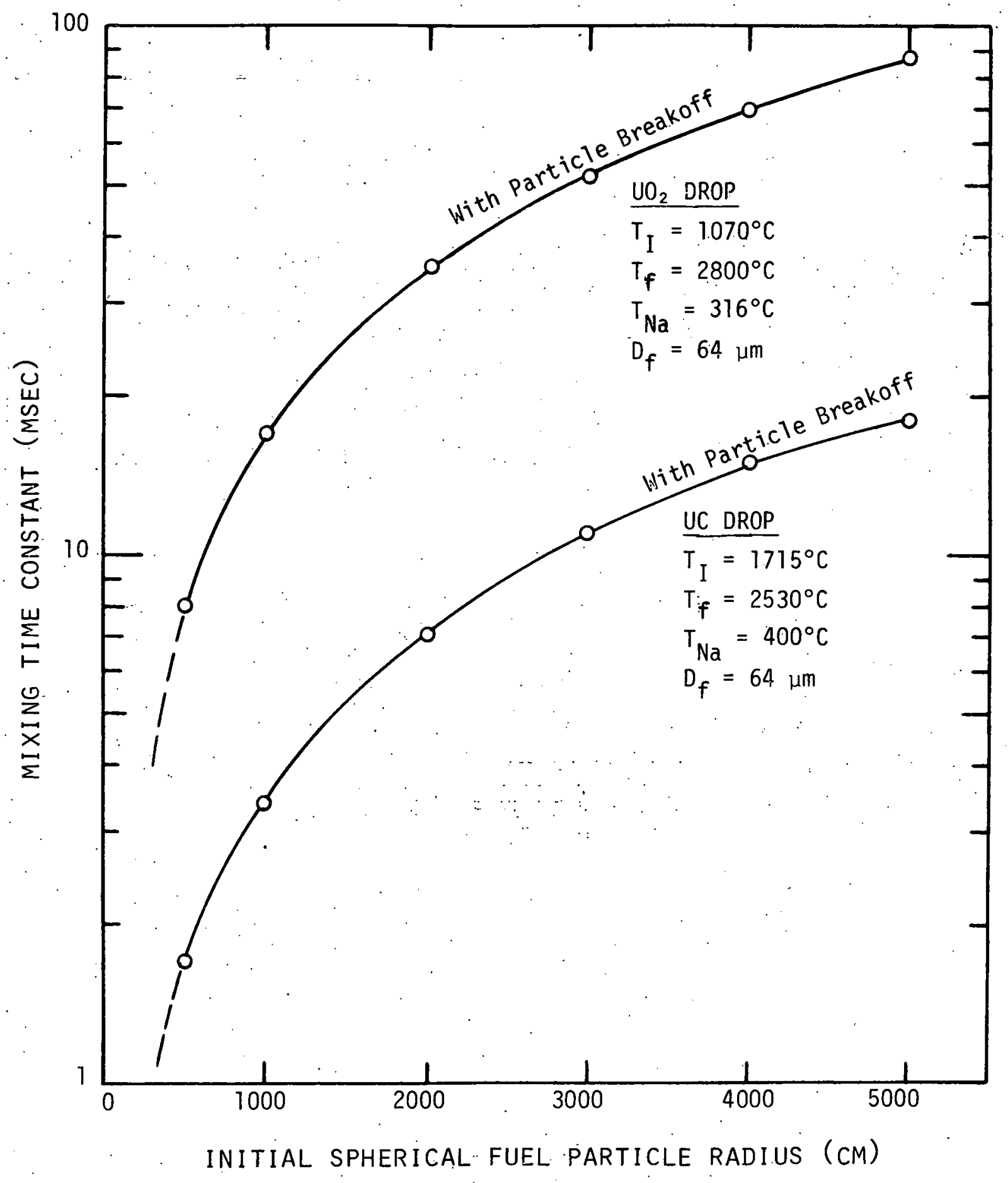

FIGURE 11. Comparison of Approximate Mixing Time Constants for $\mathrm{UO}_{2}$ and UC Solidification (Particle Breakoff) 


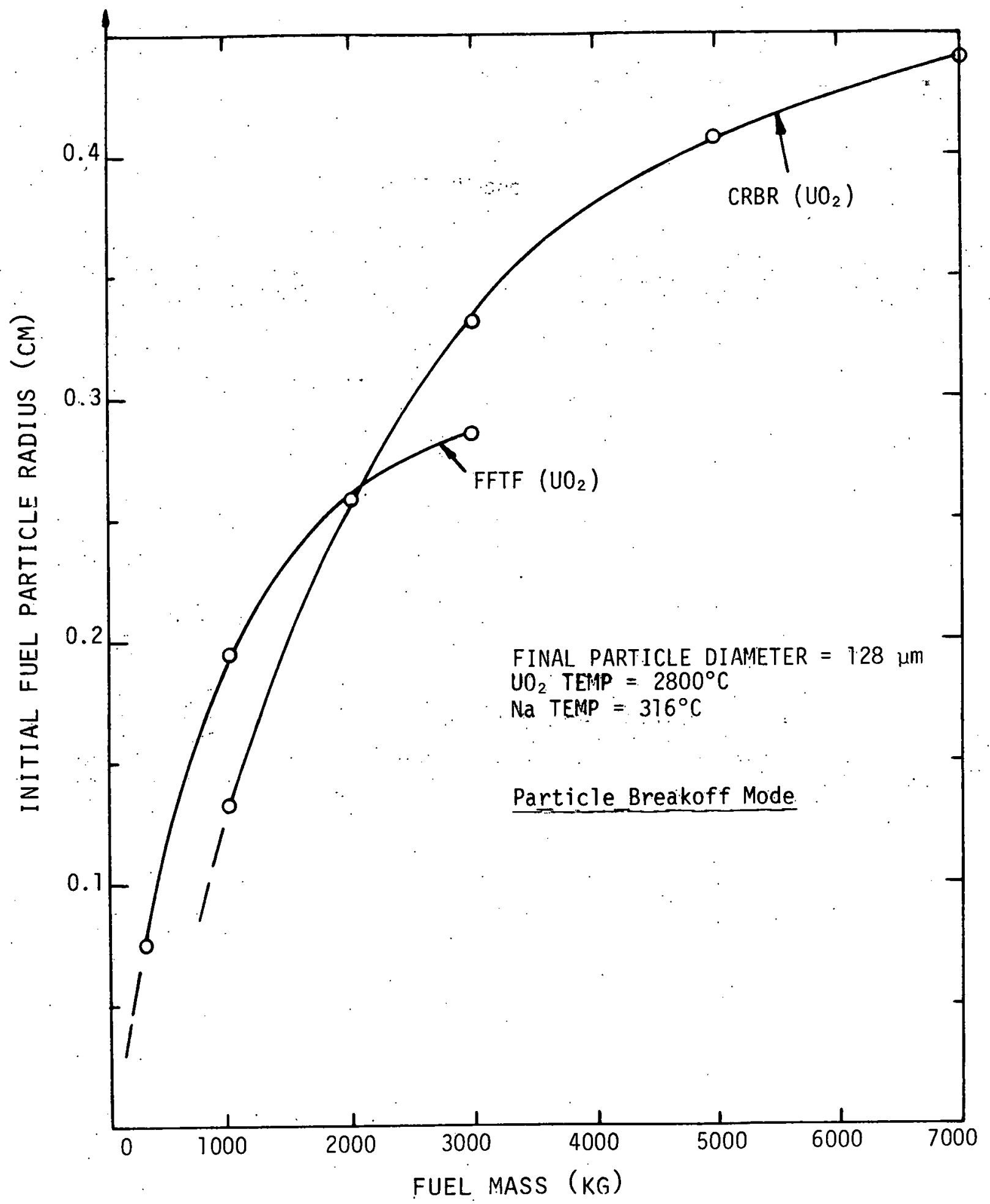

FIGURE 12. Limiting Initial $\mathrm{UO}_{2}$ Particle Radii for FFTF and CRBR 
the limiting,mixing time constants for a given fuel mass from Fig. 3 and then picking the corresponding initial fuel particle radius whose approximate mixing time constant was equal to the limiting value from fig. 9, assuming $T_{I}=1070^{\circ} \mathrm{C}$ with the particle breakoff mode. Particle sizes above the curve in Figure 12 represent initial fuel particles which have larger approximate mixing time constants. Having mixing time constants larger than the limiting values, the expected work potentials will be less than the $40 \mathrm{MW}-\mathrm{sec}$ limit. Small initial particles sizes will, therefore, provide work potentials greater than the limiting criteria. The limiting effects of the solidification of UC were not investigated further in this section because its approximate mixing time constants are much smaller than the limiting mixing time constants. The limiting mixing requirements for the UC fuel in the CRBR range from $100 \mathrm{msec}$ to $700 \mathrm{msec}$ (see Figure 5), whereas the approximate solidification mixing time constant for a $2000 \mu \mathrm{m}$ diameter UC fuel particle is only $18 \mathrm{msec}$. This implies that much larger initial particles would have to be postulated to exist for the UC versus $\mathrm{UO}_{2}$ before this solidification limited fragmentation model could be shown to limit the work potential to $40 \mathrm{MW}-\mathrm{sec}$.

The results of the $\mathrm{UO}_{2}$ solidification and mixing rates are interesting in that they indicate for the proposed mechanism that initial particle radii of $3000 \mu \mathrm{m}$ or greater will limit work potentials to less than the $40 \mathrm{MW}-\mathrm{sec}$ limit for the FFTF. In the same light, $\mathrm{UO}_{2}$ fuel particles initially at values. greater than $4500 \mu \mathrm{m}$ will limit the work potential to values less than the limiting value of $70 \mathrm{MW}-\mathrm{sec}$ for the CRBR. 
Although the proposed mechanism cannot conclusively show that FCIs having work potentials greater than the limiting value for the reactor system are impossible, there are a few salient points. First, that if this proposed model is applicable to the $\mathrm{UO}_{2}-\mathrm{Na}$ system, the results indicate that coarse mixing $\left(R_{\text {initial }}<3000 \mu \mathrm{m}\right.$ for the FFTF and $R_{\text {initial }} \leqslant$ $4500 \mu \mathrm{m}$ for (RBR) of the fuel and coolant must be accomplished before the fragmentation begins to provide the limiting mixing time constants by this proposed model. Secondly, that the results for UC indicate that the initial particle size characterizing coarse mixing does not restrict the fuel particle sizes to values as small as those of $\mathrm{UO}_{2}$ for the limiting maximum time constants to be achieved.

\subsection{Incoherent Fuel Release Effects}

In Section 4.3; approximate mixing time constants were determined for the solidification limited fragmentation model. In effect, this model assumes that the final amount of fuel and coolant that will mix is ini-. tially present in the fuel-coolant mixing zone. This may be true at some point in an accident sequence where sodium re-enters a voided core. Such a situation may be representative of a LOF accident where a fluidized state of two-phase vapor-liquid fuel and steel may form in the core. On the other hand, in a TOP accident in which fuel melting is not expected to be as extensive as in the LOF accident sequence $(7,8)$, the prime concern, then, is the initial release of molten fuel into the coolant channels. In 
this case, fuel release is not instantaneous but is governed by finite fuel release rates.

-To determine the 1 imiting effects of these fuel release rates, a method of determining mixing time constants representing these release rates is described. This method is hopefully general enough to be applied to any particular TOP case. For this analysis, the results of the TOP mechanistic analysis for the FFTF were evaluated (18). The reason for this choice is that the fuel channel failure sequences are clearly defined in the report providing the necessary framework for this model.

The method that was employed translates the fuel channel failure rates as given in the Hanford Engineering Development Laboratory (HEDL). Three base cases were investigated by HEDL; Beginning of Life Core, Beginning of Equilibrium Core Cycle, End of Equilibrium Core Cycle. Although there exists no actual "equilibrium" core in the FFTF, core Cycle 4 was considered to be the best representative of future cores. Figures 13 through 15 show the predicted channel failures with time for the three cases. Assumed in this analysis was a $50 \% / \mathrm{sec}$ initial reactivity insertion rate. Although a parametric variation of reactivity insertion rates included reactivity insertion rates as high as $\$ 3 / \mathrm{sec}$, the $50 \$ / \mathrm{sec}$ rate should be adequate for several reasons. First, the highest conceivable reactivity insertion rate is only a few cents per second based on the withdrawal of the highest worth control rod (18). Second, the fuel channel failure rates were calculated assuming no fuel squirting which would extend the reactivity transient because no credit is taken for the negative 
reactivity feedback effects of fuel ejection and sweepout.

To define the curves in these figures analytically, each channel failure case was fitted by an equation of the form:

$$
\begin{aligned}
& \text { Channel Failures }=\operatorname{Max}\left(1-e^{-t / \tau_{m}}\right) ; \\
& \text { Max }- \text { maximum number of failed channels; } \\
& t=\text { time in msec; } \\
& \tau_{m}-\text { failure constant (msec). }
\end{aligned}
$$

The maximum number of channel failures was chosen by inspection of the channel failure curves. Then, the failure constant was determined by setting the channel failures at $t=300 \mathrm{msec}$ to be $95 \%$ of Max. This somewhat arbitrary technique should conservatively bound the channel failures because slug impact is expected between 30 and $70 \mathrm{msec}$ for our cases. The next step, the translation of channel failures to fuel release, was based on several assumptions:

(1) The maximum amount of molten fuel released on the average from a failed channel is $10 \%$ of the fuel in the fuel pins. (This number is derived from HEDL's more detailed analys is of fuel squirting from the pins.)

(2) Maximum fuel release (10\%) occurs instantaneosly at the time of channel failure.

(3) Fragmentation and mixing of the fuel also occurs simultaneously with channel failure.

With these assumptions, the above channel failure equation is transformed 
into a molten fuel release equation. MAX becomes the maximum amount of fuel released equal to $10 \%$ of the fuel in the maximum number of failed channels. Table 4 summarizes the maximum fuel release and failure constants for each of the three cases.

TABLE 4. Fuel Release Constants

$\begin{array}{lllll} & \text { BOL } & \text { BOEC } & \text { EOEC } \\ \text { Maximum Channel Failures } & 38 & 50 & 70 \\ \text { Maximum Fuel Release }(\mathrm{kg}) & 148.5 & 195.3 & 273.5 \\ \tau_{\mathrm{m}} & 160 & 100 & 130\end{array}$

As before, for the analysis of the solidification limited fragmentation model, the above approximate failure constants can be used to assess the limiting characteristics of the fuel failure rates. In Figure 16, the results for the limiting mixing time constants and the fuel failure constants are compared. As we can see, the failure constants are well above the limiting values, thereby indicating that work potentials are expected to be less than the $40 \mathrm{MW}-\mathrm{sec}$ limit for the FFTF. Furthermore, if a higher percentage of fuel was to be released (> 10\%) at channel failure, the fuel failure rate (i.e., equivalent mixing time constant) is still expected to provide work potential values less than the $40 \mathrm{MW}-\mathrm{sec}$ limit.

This method was employed in a conservative manner to account for any uncertainties involved in translating fuel channel failure rates into fuel release rates. A number of items were not accounted for that would tend to extend the fuel release times providing higher actual failure constants. 
For instance, the actual fuel squirting will take a finite amount of time. Thus, total fuel release does not occur at the point of channel failure. Additionally, the complete fragmentation and mixing of the fuel and sodium will probably require some time, which is also not accounted for.

Much of the conservatism can be removed if the actual fuel release rates can be calculated directly as a result of a TOP accident. In the HEDL report, these release rates are not generally well defined. However, the results of the HEDL report indicate that the actual fuel releases at some point in time are considerably smaller than those calculated by the conservative method used in this section. 


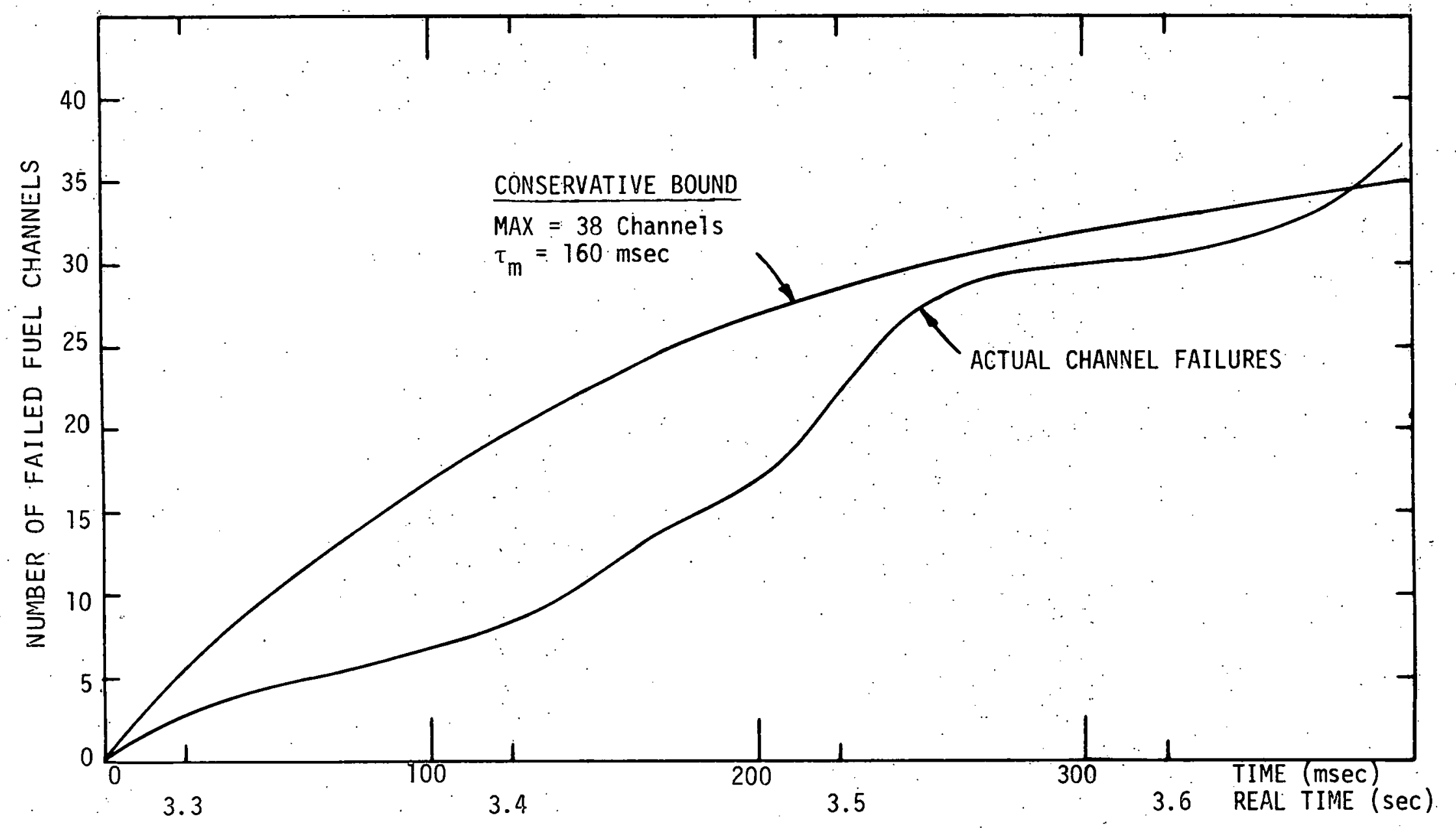

FIGURE 13. Fuel Channel Failure versus Time in the FFTF for Beginning of Life Cycle Transient Overpower Accident 


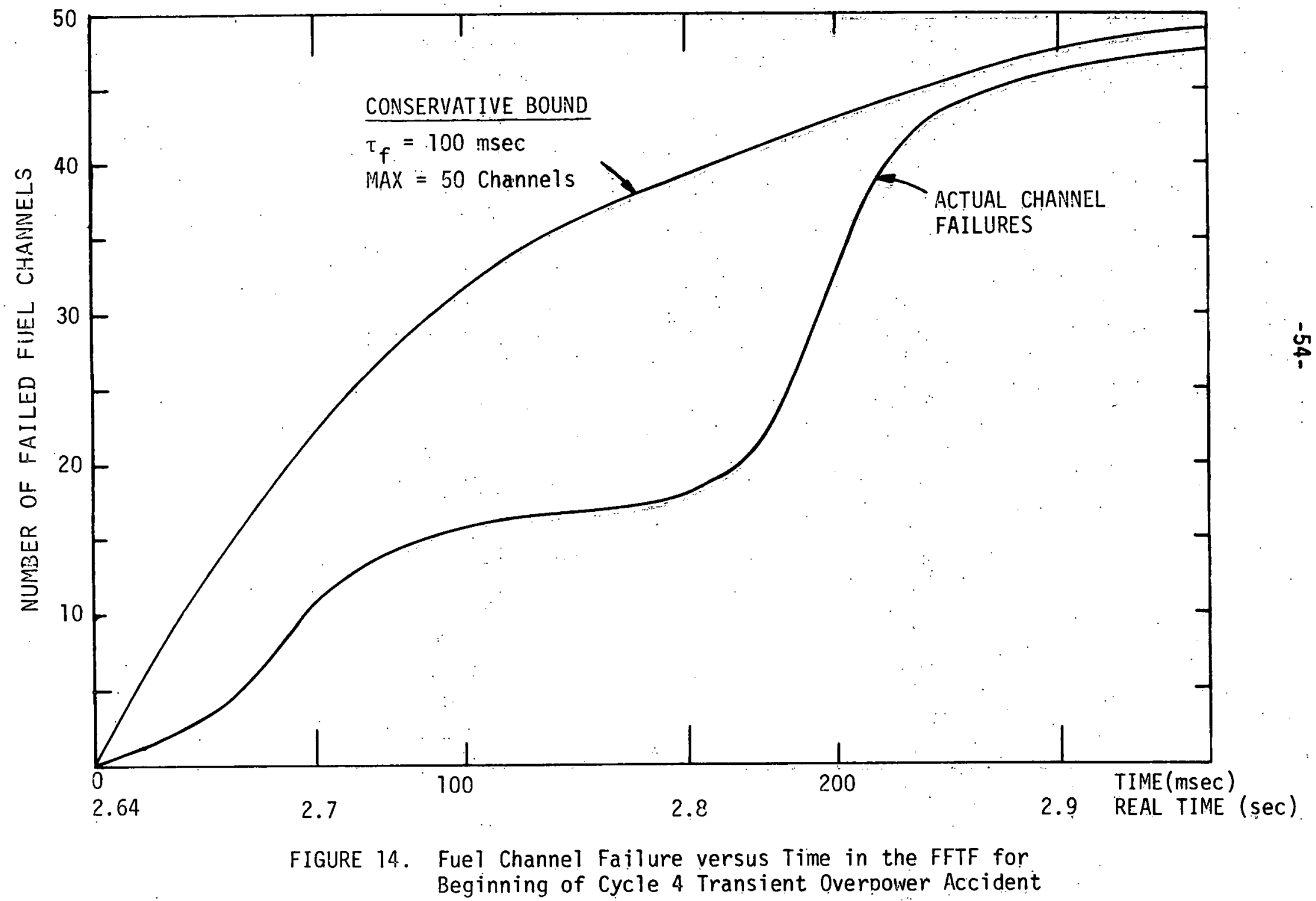




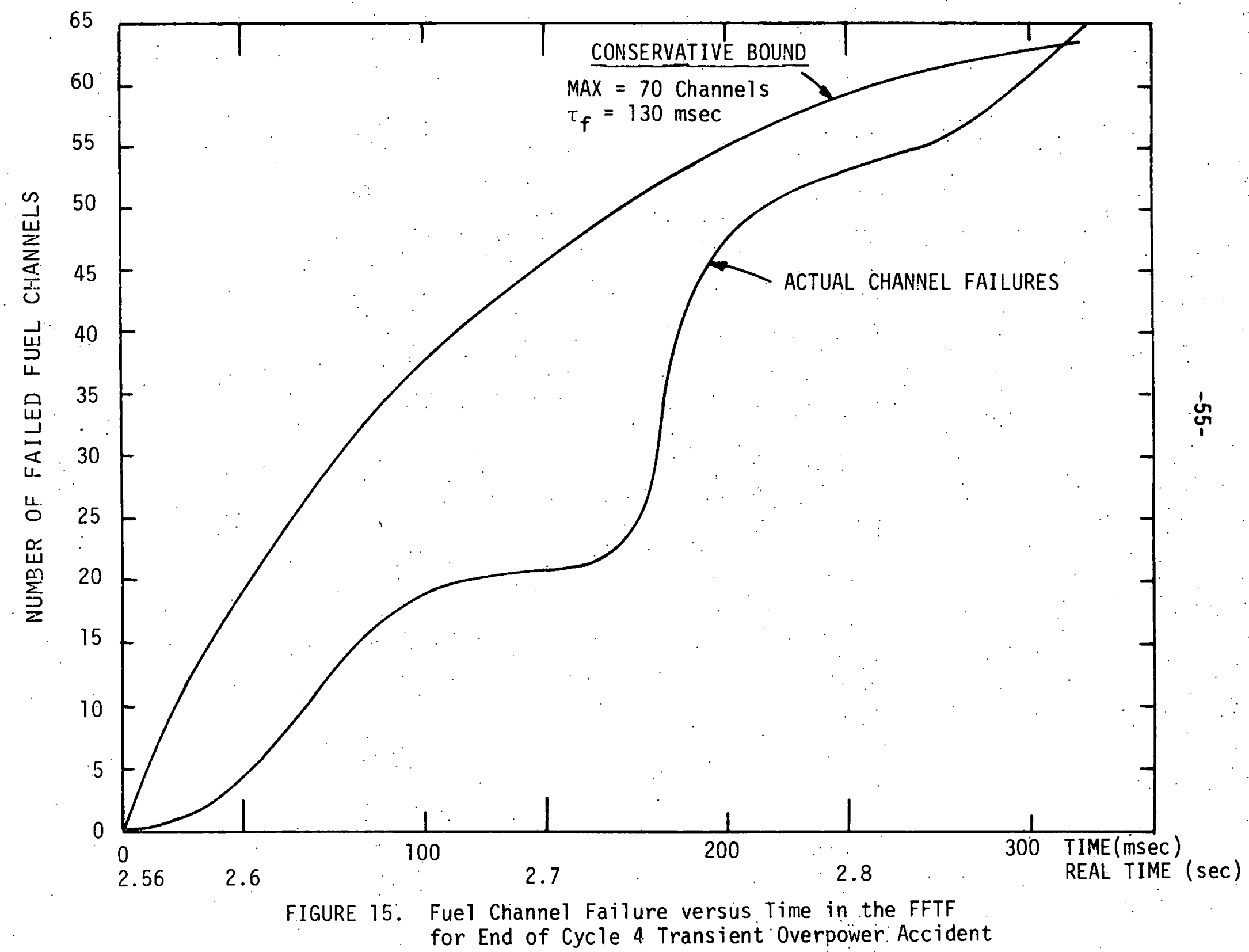




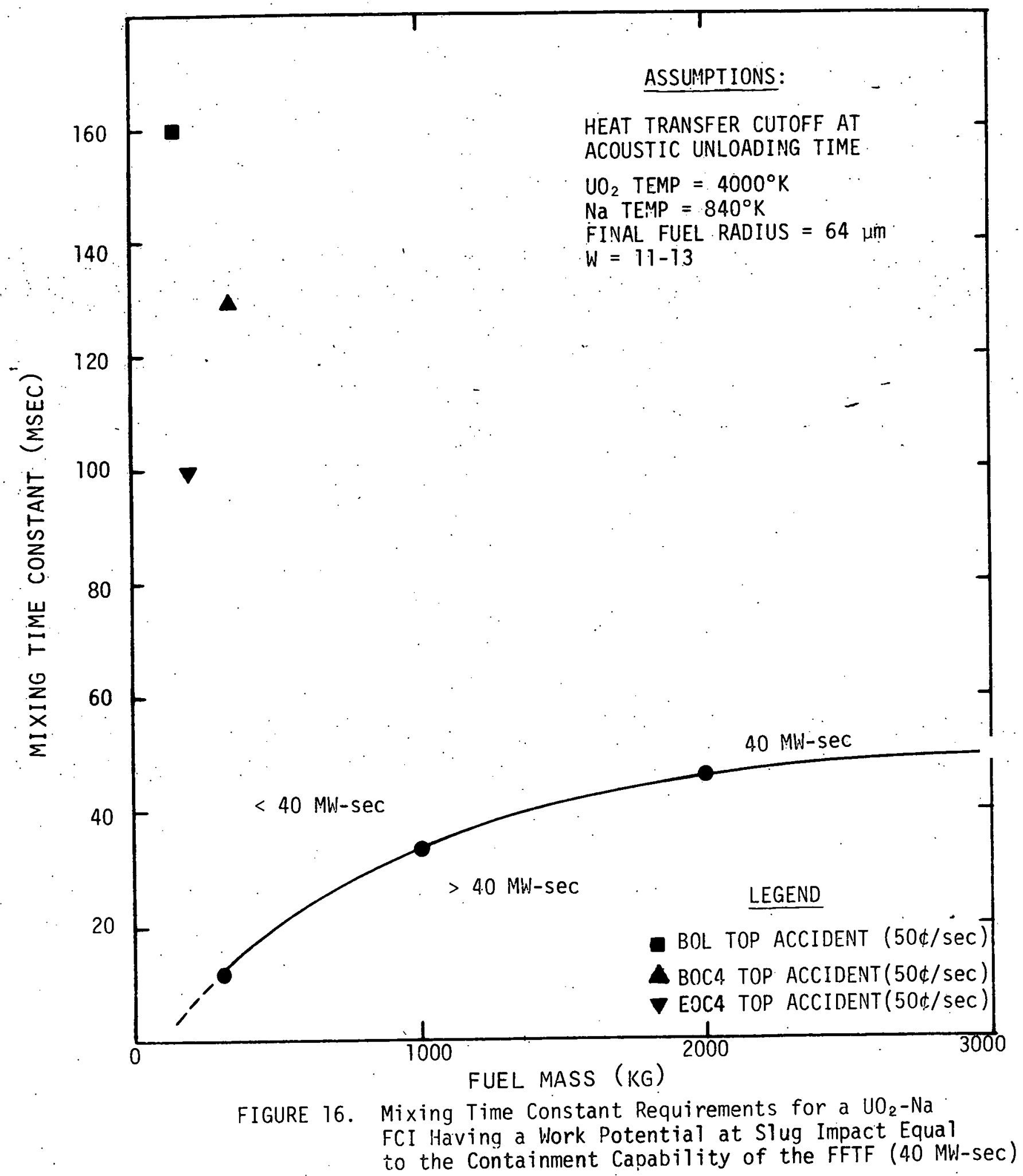




\section{CONCLUSIONS AND RECOMMENDATIONS}

The work that was performed for this report represents a simple estimate of the mixing requirements for a fuel-coolant interaction that will provide expansion work potentials at slug impact that are expected to be limiting (i.e., in terms of containment capability) for the particular reactor system. The limiting mixing time constants were determined for a range of fuel masses thus providing a means of evaluating the mixing requirements for a range of accident severities that lead to various core involvements. It also provides a means of determining whether a particular physical mechanism is limiting in the sense that it will provide work potentials less than the limiting containment value.

Three mechanisms were investigated in this work to determine if they represented limiting mechanisms. The energy requirement calculation for the mixing of fuel and coolant by the stored thermal energy in the fuel was not found to be limiting. The energy required for the mixing of the fuel and coolant based on the limiting mixing time constants was so small that extremely short mixing time constants would have to be postulated to make this a limiting mechanism. The solidification limited fragmentation calculations can be shown to be limiting if and only if one can say what the initial fuel particle sizes will be before the solidification induced fragmentation takes place. Unfortunately, at this time it is not possible to do this. One important conclusion, however, from this work is that the initial fuel particle sizes for UC fuel that are limiting are considerably 
larger than that for $\mathrm{UO}_{2}$ in ei ther the FFTF or the CRBR. In other words, the initial coarse mixing of fuel and coolant accomplished by whatever means must be far more extensive for $\mathrm{UO}_{2}$ cases to provide approximate mixing time constants that will produce work potentials greater than the limiting values.

The third mechanism that was investigated was the fuel release rates as determined from the results of the mechanistic analysis of the TOP accident in the FFTF. This mechanism, unlike the others, was clearly shown to limit the work potential to values less than the limiting criteria. The result, of course, applies to the particular accident sequence that was used. In that regard, it is recommended that similar analyses be carried out for additional accident sequences and ranges of assumed initiating conditions to determine the limiting characteristics of this mechanism for other accidents.

It is also recommended that if this method of comparison between a parametric evaluation of the limiting mixing time constants and the approximate mixing time constants based on physical mechanisms is to be continued, a more accurate description of the limiting constants should be determined. A suggested area of improvement is the use of a more detailed description of the limiting criteria for a fuel-coolant interaction, perhaps, in terms of the actual loads transmitted to the reactor structures. It is believed, however, that the key assumptions made for this analysis provide conservative results for the limiting mixing time constants.

The basic physical model used of an FCI should provide inherently 
conservative results for the work potential of an FCI. The one-dimensional model of constraint with the rigid reactor vessel assumption is expected to overestimate the pressure in the interaction zone and therefore overestimate the work potential at slug impact (Appendix A). The model also assumes no heat transfer to the slug from the FCI zone by either heat conduction or gas-liquid interface mixing. Recent calculations indicate that large reductions in the work energies can be expected if gas-liquid interface mixing is taken into account (Appendix $A$ and reference 24). Another major model assumption used for these calculations was the vapor blanketing/no heat loss to the cold structures option in the AII model. This provides what is felt to be a best-estimate of the actual FCI conditions (Appendix A). For the description of the FCI, a number of input parameters (ANL model) were assumed for these calculations. These were mentioned in Section 3.1 and are listed in Table 2. These are also expected to provide conservative results. However, to determine how sensitive our results are to these input parameter assumptions, a sensitivity analysis of the work potential at slug impact was performed for these parameters. The base case used for this analys is is a full core FCI in the oxide-fueled CRBR. The base case input parameters are listed in Table 5. The effect of varying these parameters is shown in Figure 17. The varied parameters include:- fuel temperature, sodium temperature, fuel/ sodium mass ratio, and the final fuel particle radius. The results indicate that varying the fuel temperature and the final fuel particle radius most strongly influence the work potential at slug impact and thus affect 


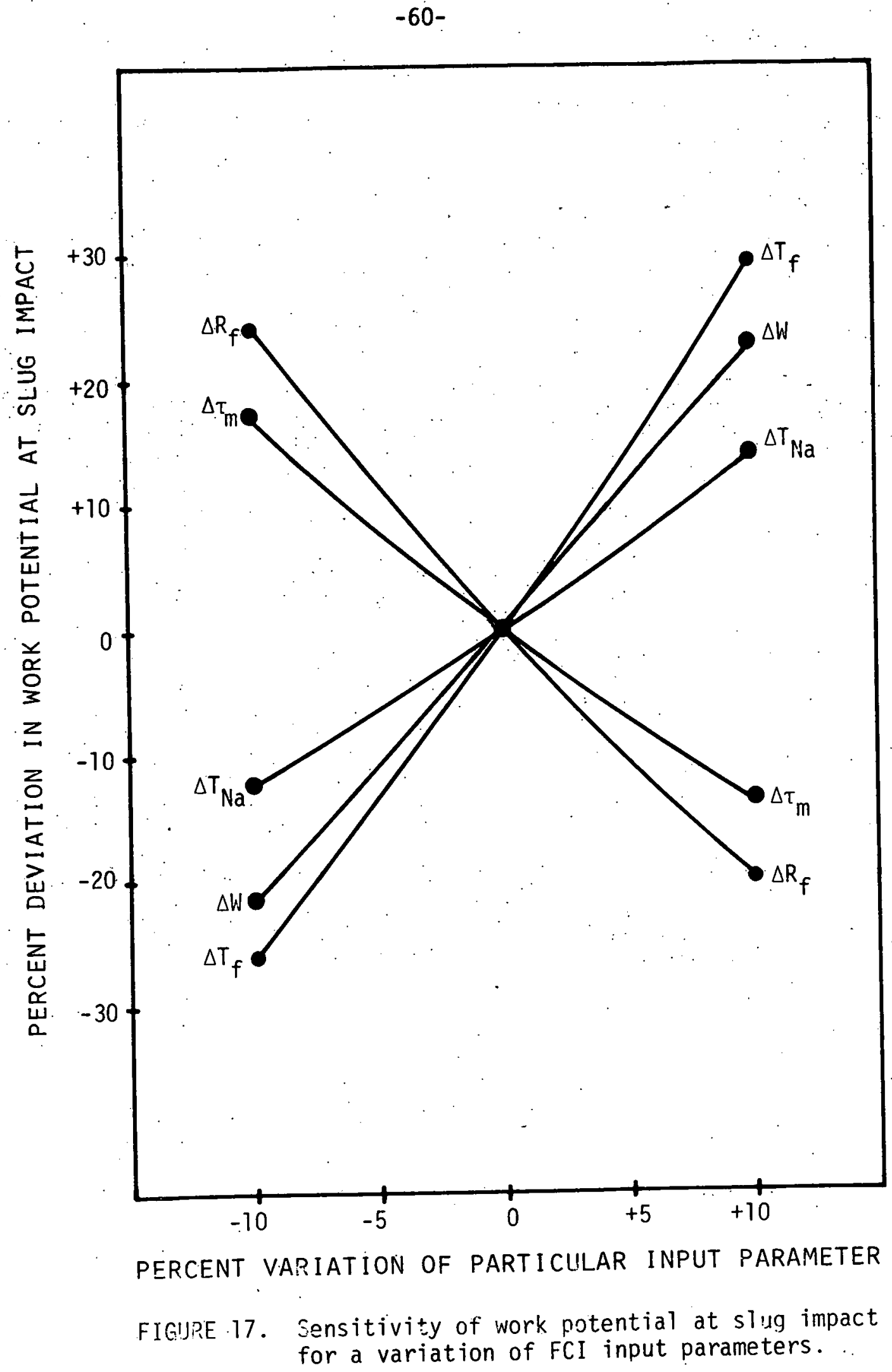




\section{TABLE 5. Base Case Input Parameters \\ for the Sensitivity Analysis.}

$\begin{array}{lr}\text { Fuel } & \mathrm{UO}_{2} \\ \text { Reactor System } & \mathrm{CRBR} \\ \text { Fuel Mass }(\mathrm{kg}) & 7000 \\ \text { Fuel Temperature }\left({ }^{\circ} \mathrm{K}\right) & 4000 \\ \text { W } & 12 \\ \text { Sodium Temperature }\left({ }^{\circ} \mathrm{K}\right) & 808 \\ \text { Final Fuel Particle Radius ( } \mathrm{Km}) & 64 \\ \text { Mixing Time Constant (msec) } & 80\end{array}$

the limiting mixing time constant the most as well.

To assess roughly how these variations in the work potential translate into variations in the mixing time constant, the mixing time constant was also varied from the base case. This particular curve on Figure 17 is particularly useful. If, for instance, a $10 \%$ increase in the fuel temperature provides approximately a $30 \%$ increase in the work potential, this is seen to be equivalent to approximately a $10 \%$ decrease in the mixing time constant. This type of analys is can be performed for any parametric variation.

As can be seen, the work potential is indeed sensitive to the assumed input parameters. However, it is felt that conservative values for each were chosen (depending upon the nature of their effect) such that the limiting mixing requirement analys is with the conservative model assumptions should be, in general, conservative. 


\section{REFERENCES}

1. D.H. Cho, Modelling of Molten Fuel Coolant Interactions, Trans. Amer. Nucl. Soc. 15, Vol. 1 (1972).

2. J.F. Jackșon, M.G. Stevenson, J.F. Marchaterre, R.H. Sevy, R. Avery, Trends in LMFBR Hypothetical-Accident Analysis, paper presented at the Fast Reactor Safety Conference, Beverly Hills, California, 2-4. April 1974.

3. A.W. Cronenberg, M.A. Grolmes, A Review of Fragmentation Models Relative to Molten $\mathrm{UO}_{2}$ Breakup when Quenched in Sodium Coolant, paper presented at Winter Meeting of the ASME, New York, 17-22 November 1974.

4. H.K. Fauske, An Assessment of Thermal Interaction in Oxide Fueled Fast Reactors, ANL/RAS 74-19, August 1974.

5. Y.W. Chang, J. Gvildys, S.H. Fistedis, Analysis of the Primary Containment Response Using a Hydrodynamic-Elastic-Plastic Computer Code, Nucl. Engr. and Design 27, (174), 155-175

6. Y.W. Chang, J. Grildys, S.H. Fistedis, A New Approach for Determining Coolant Slug Impact in a Fast Reactor Accident," Trans. Amer. Nucl. Soc. 14 (1971).

7. Final Safety Analysis Report for the FFTF, Appendix A, Hypothetical Analysis for Test of Containment, December 1975.

8. Preliminary Safety Analysis Report for the CRBR, Appendix D, Evaluation of Hypothetical Core Disruptive Accidents for CRBR, July 1975. 
9. H.K. Fauske, "The Role of Energetic Mixed-Oxide Fuel-Sodium Thermal Interactions in Liquid-Metal Fast Breeder Reactor Safety," paper presented at Chicago Int'1. Mtg. on Fast Reactor Safety, Oct. 5-8, 1976.

10. Personal communication with Michael Grolmes, ANL.

11. D.H. Cho, R.0. Ivins, R.W. Wright, "A Rate Limited Model of Molten Fuel/Coolant Interactions: Model Development and Preliminary Calculations, ANL-7919, March 1972.

12. D.H. Cho, W.L. Chen, R.W. Wright, "A Parametric Study of Pressure Generation and Sodium Slug Energy from Molten Fuel Coolant Interactions, ANL 8105, August 1974.

13. W.L. Chen, D.H. Cho, M.S. Kazimi, "Recent Additions to the Parametric Model of Fuel Coolant'Interactions, ANL 8130, September 1974.

14. Hiroshi Mizuta, "Fragmentation of Uranium Dioxide After Molten Uranium Dioxide-Sodium Interaction," J. Nucl. Sci.\& Tech. 11 (11) 480-487, November (1974).

15. M... Corradini, "Prediction of Minimum $\mathrm{UO}_{2}$ Particle Size Band on Thermal Stress Initiated Fracture Model," CO0-2781-4 TR, MIT, August 1976.

16. D.H. Cho, H.K. Fauske, M.A. Grolmes, "Mixing Requirements for Energetic Fuel/Coolant Interaction and AEROSOLS," Trans. Amer. Nucl. Soc. $23(1976)$.

17. D.H. Cho, H.K. Fauske, M.A. Grolmes, "Some Aspects of Mixing in LargeMass, Energetic Fuel-Coolant Interactions," paper presented at Chicago Int'1. Mtg. on Fast Reactor Safety and Related Physics, October 5-8, 1976. 
18. A.E. Waltar, et al., An Analysis of the Unprotected Transient Overpower Accident in the FTR, HEDL-TME-75-50, Hanford Engineering Development Lab; Richland, Wash., June 1975.

19. A.W. Cronenberg, H.K. Fauske, $\mathrm{UO}_{2}$ Solidification Phenomena Associated with Rapid Cooling in Liquid Sodium, J. Nucl Mat'ls. 00 (1974).

20. A.W. Cronenberg, T.C. Chawla, H.K. Fauske, A Thermal Stress Mechanism for the Fragmentation of Molten $\mathrm{UO}_{2}$ Upon Contact with Sodium Coolant, Nucl. Engr. \& Des. 30, 434-443 (1974).

21. Roland B. Knapp and Neil E. Todreas, Thermal Stress Initiated Fracture as a Fragmentation Mechanism in the $\mathrm{UO}_{2}$-Sodium Fuel-Coolant Interaction, Nucl. Engr. \& Des. 35 (1975).

22. A.W. Cronenberg, Richard L. Coats, A Comparison of Solidification Phenomena for $\mathrm{UO}_{2}, U C$, and UN Relative to Quenching in Sodium Coolant, to be published in Nuclear Engineering and Design.

23. Roland B. Knapp, Thermal Stress Initiated Fracture as a Fragmentation Mechanism in the $\mathrm{UO}_{2}$-Sodium Fuel-Coolant Interaction, 31-10938-2831-5 TR, May 1975.

24. M. Corradini, A. Sonin, N. Todreas, A Proposed Heat Transfer Model to Describe Experimental Results in the Stanford Research Institute Tests, to be published. 
APPENDIX A:

ANL PARAMETRIC FUEL-COOLANT MODEL

\section{A.1 Introduction}

In the earlier models of molten fuel-coolant interactions, a thermodynamic approach was used to estimate the maximum work potential available from an FCI (1). This approach assumed the instantaneous heating of the coolant and as a result did not provide the pressure as a function of time in the interaction zone. Without these pressure-time histories, an assessment of the structural damage could not be made. One of the first analyses that provided the necessary pressure-time histories was a transient analysis by Padilla that accounted for the rate processes (2). Another "second generation" calculational model was the ANL parametric FCI model (3). Both of these models provided the pressure-time histories required for a realistic assessment of the consequences of an FCI. In general, two competing processes are involved in the calculation of pressure in the interaction zone; the heating of the coolant by the fuel causing pressure and the movement of the surrounding constraints relieving the pressure. Due to the uncertainties that exist in the complicated processes of molten fuel-coolant mixing and fragmentation and in the heat transfer mechanisms, these unknown rate limiting processes are incorporated into the ANL model as input parameters. In this way, parametric studies can be made for reasonable ranges of the input parameters to 
determine what effect the assumed input parameters have on the pressure generation.

The ANL model was used in the main text of this report to calculate the work potentials from different FCIs. In particular, it was used to relate the limiting work potentials and the mixing time constants. To understand how these calculations are performed, the FCI-B version of the ANL model is described in detail along with the input parameters used to describe initial conditions and the various rate processes.

\section{A.2 Model Formulation}

\section{A.2.1 Physical Model and General Formulation}

The physical model of an FCI in the FCI-B version of the ANL parametric model can be seen in Figure A.1. A volume of molten fuel-coolant mixture is formed in certain zones of the reactor core. This zone is called the fuel-coolant interaction zone or mixing zone. As the coolant is heated by the fuel, the coolant expands and the pressure in the mixing zone increases. The mixing zone then expands against the constraint of the sodium slug above the core and the sodium slugs accelerates upward. Sodium slug impact occurs when the interaction zone has expanded a volume equal to that of the cover gas region.

Several major assumptions have been made in this model that should be pointed out. First, the volume change in the mixing zone is due only 


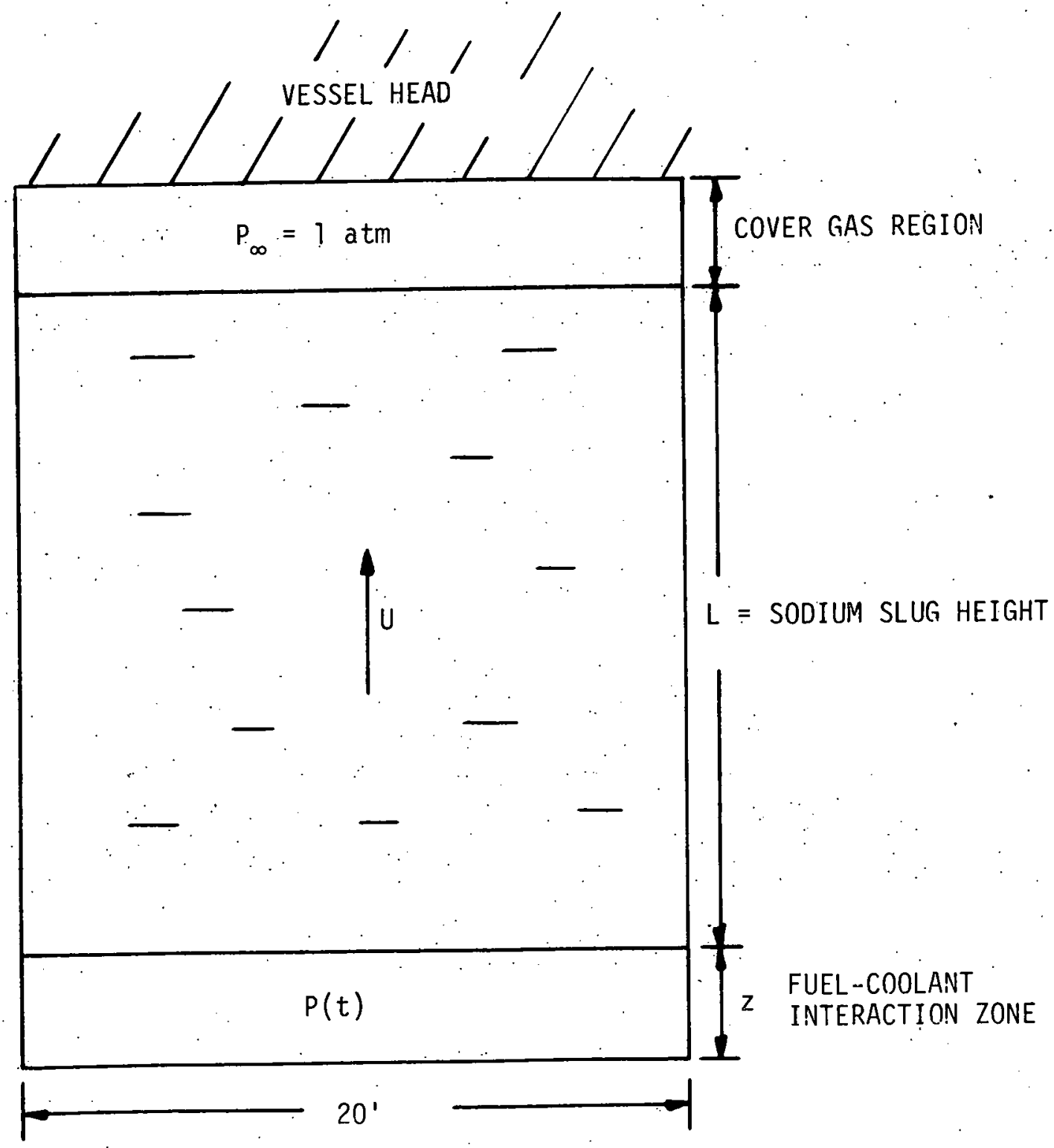

FIGURE A.1 One-Dimensional lodel Used in AivL FCI Parametric Mode 1 
to the volume change of the sodium. The volume change of the molten fuel has been neglected. The effect of this assumption was studied by ANL. It was determined that neglecting the volume change of the fuel would cause a $10 \%$ increase in the pressure levels. Due to the present state of the art in modeling fuel-coolant interactions, correction of this was not felt to be warranted (3). Secondly, it is assumed that the heated coolant is in a state of uniform thermodynamic equilibrium throughout the mixing zone and the mixing zone does not exchange heat or mass with the surroundings. Recent scoping calculations indicate that during an HCDA with sodium present in the core, the mechanical work potential of an FCI could be significantly reduced if the heat losses to the cold fission-gas-plenum cladding were considered (4). A further study by Chen and Cho (5) shows this to be true. In their analysis, they compared the work output for the four different possibilities of vapor blanketing the fuel, thus reducing the heat transfer and/or the heat. losses to fission gas plenum cladding. Their results are presented in Figure A.2. The lines drawn at interaction zone fronts of 50 and $70 \mathrm{~cm}$ correspond to interface positions at slug impact for the FFTF and CRBR and hence cover the range of interest for this analysis. For this range, the two cases of no vapor blanketing with heat loss and vapor blanketing without heat loss are quite similar. Because the FCI-B version of the ANL parametric model does not have the option for including heat losses to the surrounding structures, vapor blanketing was assumed to occur. This phenomena was approximated by using the heat transfer cutoff option in the FCI-B 
- ONSET OF VAPORIZATION OF. INTERACTION ZONE

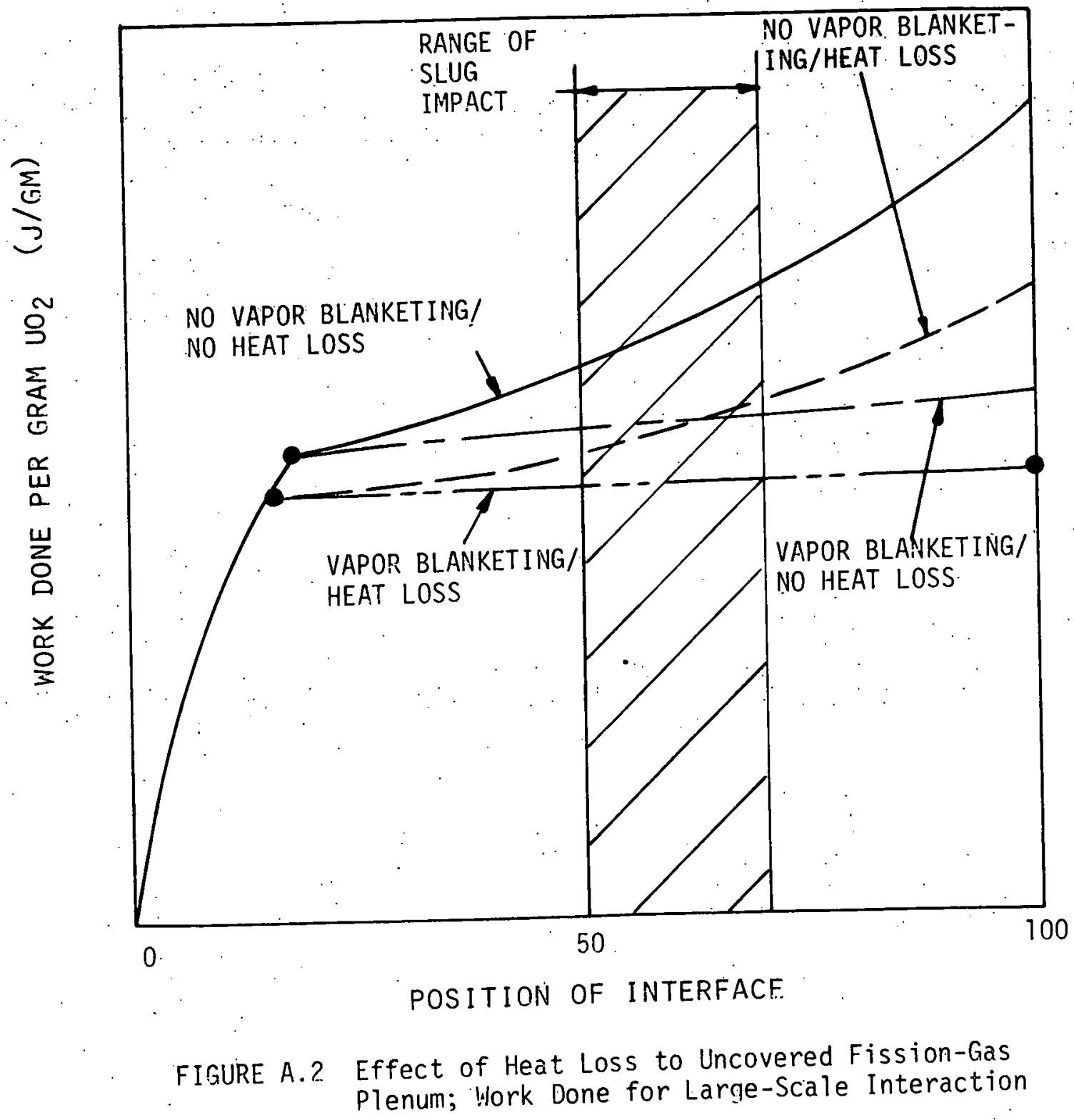


version. Comparisons of these different means of reducing the heat transfer from the fuel to coolant show that the results from each are quite close (6). A further reduction in the work potential could be realized. if the heat losses from the expanding vapor bubble to the surrounding liquid are taken into account correctly.

Analysis of the Stanford Research. Institute tests support this claim and predicts that work reductions of the order of 3 to 9 are possible (7). This result, however, was not used in this analysis and therefore our results are expected to be very conservative. The effect of assuming a thermodynamic equilibrium in the interaction zone has not been investigated.

With the above set of assumptions, the change in the volume of the heated coolant, $V$, is related, in general, to the changes in the enthalpy $H$ and pressure $P$. This is accomplished by using the first law of thermodynamics:

$$
\frac{d H}{d t}=\frac{d Q}{d t}+\frac{V d P}{d t}
$$

where the equation of state for the coolant can be expressed as a function of the pressure and specific volume,

$$
H=H(P, V)
$$

(Note: all quantities refer to a unit mass of the heated coolant and $\mathrm{dQ} / \mathrm{dt}$ represents the overall heating rate of the coolant in the mixing zone.) The above equations have two unknowns, $P$ and $V$, and are independent of Eq. $(A-1)$. An additional relation is required to solve for $P$ 
and $V$. It is provided by the constraint of the surroundings and is called the equation of constraint,

$$
P=f\left(v, \frac{d V}{d t}, \frac{d^{2} v}{d t^{2}}\right)
$$

This represents the constraining effects of the surroundings on the expansion of the mixing zone. In our case, this involves only the unheated coolant above the core. With the above relation and the appropriate expressions for $d Q / d t$ that will describe the processes of fragmentation and mixing and subsequent heat transfer, Eqs. (A-1), (A-2), and (A-3) can be solved to provide the pressure generation, the expansion of the mixing zone, and the acceleration of the sodium slug.

\section{A.2.2 Equation of State for Coolant Mixing Zone}

The exact form of Eq. (A-1) used in the ANL parametric model depends upon the available empirical correlations for the equation of state. For a pure liquid or vapor phase, $\mathrm{P}-\mathrm{V}-\mathrm{T}$ rather than $\mathrm{P}-\mathrm{V}-\mathrm{H}$ relationships are used. Using the thermodynamic relation,

$$
d H=C_{p} d T+\left[V-T\left(\frac{\partial V}{\partial T}\right)_{p}\right] d P \text {, }
$$

Eq. $(A-1)$ can be rewritten as

$$
C_{p} \frac{d T}{d t}=\frac{d Q}{d t}+T V \alpha_{p} \frac{d P}{d t} \text {, }
$$

where $\alpha_{p}$ is the thermal expansion coefficient: 


$$
a_{p}=\frac{1}{V} \cdot\left(\frac{\partial V}{\partial T}\right)_{p},
$$

and Eq. (A-2) is replaced with

$$
V=V(P, T)
$$

Differentiating this equation with respect to time gives

$$
\frac{d V}{d t}=\frac{\partial V}{\partial P}\left(\frac{d P}{d t}\right)+\frac{\partial V}{\partial T}\left(\frac{d T}{d t}\right)
$$

Using the following form for the isothermal compressibility, $\beta_{T}$,

$$
\beta_{T} \equiv-\frac{1}{V}\left(\frac{\partial V}{\partial P}\right)_{T}
$$

and the definition for $q$ in Eq. $(A-6)$, Eq. $(A-8)$ reduces to

$$
\frac{d V}{d t}=-\beta_{T} V \frac{d P}{d t}+\alpha_{p} V \frac{d T}{d t}
$$

For a two-phase mixture, Eq. (A-1) can be used as it is. For the equation of state, the following forms of empirical correlations are used:

$$
P=P(T)
$$

and

$$
H=x H_{v}+(1-x) H_{\ell},
$$

where $H_{v}$ is a function of temperature only and represents the enthalpy of saturated vapor. $H_{\ell}$ is also a function of temperature only and represents the enthalpy of saturated liquid. Differentiating Eq. (A-12) with respect to time yields 


$$
\frac{d H}{d t}=x \frac{d H_{v}}{d t}+(1-x) \frac{d H_{\ell}}{d t}+\Delta H_{\ell v} \frac{d x}{d t}
$$

where $\Delta H_{\ell v}$ is the latent heat of vaporization:

$$
\Delta H_{l v}=H_{v}-H_{\ell} \text {. }
$$

Furthermore,

$$
v=x v_{v}+(1-x) v_{\ell}
$$

and

$$
\frac{d V}{d t}=x \frac{d V_{v}}{d t}+(1-x) \frac{d V_{\ell}}{d t}+\Delta V_{\ell v} \frac{d x}{d t}
$$

where $v_{v}$ is the specific volume of saturated vapor and $V_{\ell}$ is the specific volume of saturated liquid. $\Delta V_{\ell v}$ is defined as

$$
\Delta v_{\ell v}=v_{v}-v_{\ell}
$$

All forms for the equation of state for the sodium coolant are taken from Reference (8).

\section{A.2.3 Heat Transfer Approximations}

Two different approximations were used in the original version of the FCI parametric model. For these approximations, a mixing zone was considered with a uniform dispersion of fuel particles in the coolant as a result of fragmentation of the molten fuel. The fuel particle size was used as a characteristic measure of both the fragmentation and mixing. The first approximation was called the quasi-steady state Heat Transfer Model. 
This method utilized a single heat transfer coefficient based upon the thermal conductivity of fuel (i.e., heat transfer limited only by the thermal conduction resistance of the fuel) and the size of fuel particle. This approximation accounted somewhat for a finite rate of fragmentation and mixing of the molten fuel and coolant. It implied that by the time. the fragmentation of the fuel was completed, a temperature gradient had been established in the fuel particle. The other approximation was called the Transient conduction method. This approximation also, assumed a uniform dispersion of fuel particles to form in the coolant by an instantaneous, fragmentation of the molten fuel. However, this method solved for the transient heat conduction equation with an integral method, giving the fuel temperature as a function, of the radius, as well as of time. A linear temperature profile was assumed in the fuel. The FCI-B version of the FCI parametric model was developed with a third formulation for the heat transfer. This particular formulation is used in the mixing requirement analysis and is described in detail.

The new formulation was developed in order that the fragmentation and mixing time would be independent of the fuel particle size. This new approximation is called the finite rate of fragmentation model. In essence, the instantaneous formation of a uniform dispersion of fuel particles in the mixing zone is no longer assumed. It is assumed to occur over some finite amount of time. The heating rate $d Q / d t$ of the sodium in the fuel-coolant mixing zone is defined by 


$$
\frac{d Q}{d t}=h A\left(T_{f}-T_{N a}\right)
$$

The heat transfer coefficient is assumed to be

$$
h=\frac{k_{f}}{\sqrt{\pi \alpha_{f} t}}+\frac{k_{f}}{R} .
$$

This heat transfer coefficient is a concatenation of two coefficients. At small times, the first term dominates the heat transfer coefficient. It represents a coefficient based upon the temperature profile for the fuel (assumed to be a semi-infinite slab) with a fixed surface temperature. At large times, the first term goes to zero and the second term dominates. The second term is the heat transfer coefficient used in the quasi-steady state heat transfer approximation and represents a heat transfer coefficient based upon a linear temperature profile across the entire fuel particle radius.

The heat transfer a rea available per gram of heated sodium, $A$, is represented by

$$
A=A_{0}\left[1-e\left(-\frac{t}{\tau_{m}}\right)\right],
$$

where $A_{0}$ is the final value for the heat transfer area when the fragmentation and mixing are complete. The term $A_{0}$ equals

$$
A_{0}=\frac{3 W}{\rho_{f} R_{f}}
$$

The variable $\tau_{m}$ is the characteristic measure of the rate of fragmentation and mixing and is called the fragmentation and mixing time constant. 
It is often referred to as simply the mixing time constant. Using the above forms for the heat transfer coefficient $h$ and heat transfer area A. Eq. $(A-18)$ becomes

$$
\frac{d Q}{d t}=(h A)_{0}\left[(\sqrt{3 / \pi})\left(\sqrt{t} h^{/ t}\right)+1\right]\left[1-e\left(-\frac{t}{\tau_{m}}\right)\right]\left(T_{f}-T_{N a}\right)
$$

where

$$
(h A)_{0}=\frac{C_{f} W}{t_{h}}
$$

and

$$
t_{h}=\frac{R^{2}}{3 \alpha_{f}}
$$

It should be noted that Eq. (A-22) does not describe any particular mechanisms of fragmentation and mixing. However, it does present a convenient way of examining the effects of the fuel particle size or the rate of the fragmentation and mixing time constant. The physical meaning, in particular, of the fragmentation and mixing time constant will differ depending on the particular accident sequence in question (6).

\section{A.2.4 One-Dimensional Model of Constraint}

Figure A.l represents a one-dimensional problem in which the mixing zone has been assumed to extend across the entire diameter of the reactor vessel. This, in effect, provides a line pressure source that uniformly accelerates the sodium slug upwards. A rigid boundary condition has been assumed for the constraint of the sodium below the core. Additionally, 
the vessel wall is assumed to be rigid. Calculations performed by the REXCO-HEP computer code have demonstrated that this one-dimensional model of constraint overestimates the sodium slug energy at impact by $30-40 \%$ (9). This conclusion was made by comparing the slug energy at impact to the expansion work of the interaction zone at slug impact in the REXCO calculations. This provided the percent overestimation because the ANL parametric model assumes all the expansion work energy goes into accelerating the sodium slug.

Two formulations were considered for the constraining effects of the coolant slug above the core.

\section{(1) Acoustic Constraint of Infinite Extent}

This formulation assumes that the coolant is of infinite extent and compressible, and does not exchange heat or mass with the mixing zone. The acoustic approximation is

$$
P(t)-P_{0}=\rho_{0} c_{0} \cdot \frac{d Z}{d t},
$$

where $P(t)$ is the pressure in the mixing zone, and $P_{0}, \rho_{0}$ and $c_{0}$ are the initial pressure, density, and sonic velocity of the unheated sodium slug. $Z(t)$ is the position of the mixing zone/sodium slug. The above acoustic constraint is valid for times less than the acoustic relief time, $2 L / c_{0}$, where $L$ is the height of the sodium slug (i.e., distance to the nearest free reflecting surface). The flow velocity $\mathrm{dz} / \mathrm{dt}$ is related to the change in the total mixing volume $V_{T O T}$ by 


$$
\frac{d V_{T O T}}{d t}=s \frac{d z}{d t}
$$

where $S$ is the flow area per gram of heated coolant. Assuming no volume change for the fuel, this becomes

$$
\frac{d V_{\text {TOT }}}{d t}=\frac{d V}{d t}+\frac{d V_{g}}{d t}
$$

where $V$ is the specific volume of the coolant and $V_{g}$ is the volume of any non-condensible gas present per gram of heated coolant. In the limiting mixing requirement analysis, $V_{g}$ is assumed to be zero. Therefore, Eq. (A-27) becomes

$$
\frac{d V}{d t}=s \frac{d z}{d t}
$$

Using this result in Eq. $(A-25)$ gives

$$
\frac{d V}{d t}=\frac{S}{\rho_{0} c_{0}}\left[P(t)-P_{0}\right]
$$

\section{(2) Inertial Constraint}

The second formulation of the coolant constraint assumes the coolant slug to be incompressible. Again, no mass or heat is assumed to be exchanged from the mixing zone to the coolant slug.

A macroscopic momentum balance provides the equation of motion for the coolant slug:

$$
\frac{d U}{d t}=-g+\frac{P(t)-P_{\infty}}{\rho_{0} L},
$$


where $U$ is the velocity of the coolant slug and $P_{\infty}$ is the pressure of the cover gas region (assumed to be 1 atm in our analysis). Again, $L$ is the height of the coolant slug. The slug velocity can be related to the change in $V_{T O T}$ by

$$
\frac{d V_{T O T}}{d t}=S * U \ldots
$$

Again, neglecting the volume change in the fuel, we get for the change in the coolant volume,

$$
\frac{d V}{d t}=S * U .
$$

The computer code provides three options for using these formulations: acoustic constraint for all times, inertial constraint for all times, or an acoustic/inertial constraint where the acoustic constraint is used up to the acoustic unloading time and beyond that the inertial constraint is used. The third option was used in the present analysis.

A summary of the above pertinent equations is found in Table A.1.

\section{A. 3 ANL Parametric Model Input}

\section{A.3.1 Introduction}

The major input parameters and particular input options are listed in Table A.2. The first two columns represent the FFTF and the CRBR fueled with $\mathrm{UO}_{2}$ (representing the mixed-oxide fuel). The third column represents the input parameters for the CRBR fueled with UC. Operating conditions 
TABLE A.1. Summary of Pertinent Equations

Heat

Transfer

Energy

Conservation

for Coolant

$$
\frac{d Q}{d t}=h A\left(T_{f}-T_{N a}\right)
$$

4등 with:

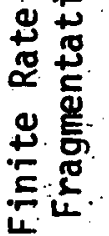

$$
h A=(h A)_{0}\left[\left(\frac{3}{\pi}\right)^{\frac{3}{2}}\left(\frac{t_{h}}{t}\right)^{\frac{1}{2}}+1\right]\left[1-\exp \left(-\frac{t}{\tau_{m}}\right)\right]
$$

and

$$
(h A)_{0}=\frac{c_{f} w}{t_{h}} \text { and } t_{h}=\frac{R^{2}}{3 \alpha_{f}} \text {. }
$$

Liquid

Phase

$$
C_{p} \frac{d T}{d t}=\frac{d Q}{d t}+T V \alpha_{p} \frac{d P}{d t}
$$

Two-

Phase.

$$
\frac{d H}{d t}=\frac{d Q}{d t}+V \cdot \frac{d P}{d t}
$$

Liquid

Phase

$$
\frac{d V}{d t}=-\beta_{T} V \frac{d P}{d t}+\alpha_{p} V \frac{d T}{d t}
$$

\section{Equation}

of

$$
P=P(T) \quad \text { (Vapor pressure equation) }
$$

State

Two-

$$
\frac{d H}{d t}=\left[x \frac{d H_{v}}{d T}+(1-x) \frac{d H_{\ell}}{d T}\right] \frac{d T}{d t}+\left(H_{v}-H_{\ell}\right) \frac{d x}{d t}
$$

$$
\frac{d V}{d t}=\left[x \frac{d V_{v}}{d T}+(1-x) \frac{d V_{\ell}}{d T}\right] \frac{d T}{d t}+\left(V_{v}-V_{\ell}\right) \frac{d x}{d t}
$$

Acoustic $\frac{d V}{d t}=\frac{S}{\rho_{0} C_{0}}\left(P-P_{\infty}\right)$

Constraint

$$
\begin{array}{ll}
\frac{d V}{d t}=S \cdot U \\
\text { Inertial } \\
\frac{d U}{d t}=-g+\frac{P-P_{\infty}}{\rho_{0} L}
\end{array}
$$


of the CRBR, for this case, were assumed to equal that of a mixed oxide fueled CRBR.

For a more complete guide to the computer program including a detailed input guide and a list of the various options, a user's guide can be found in Reference 10. In Table A.2, several input parameters are marked "variable;" the reason is that they will vary depending on the particular case being run. Descriptions of how these parameters are determined follow.

\section{A.3.2 Case Dependent Input Parameters}

\section{A.3.2.1 FCI Mixing Zone Height}

In an earlier study, it was shown that increasing mixing zone height would provide greater work potential (6). However, per gram of sodium, the smaller the mixing zone the greater the work potential (6). Therefore, to provide conservative results, the minimum mixing zone heights are used for each case. This is accomplished by assuming all available sodium in a cross-sectional slice of the core is used. (The actual definition for the mixing zone height, $L_{M}$, assumes all the sodium in the mixing zone to interact with the molten fuel.) The important core geometry parameters were taken from References 11 and 12 .

Figure A. 3 represents a cross-sectional slice of the fuel channels in the FFTF and the CRBR. From the channel dimensions, Table A.3 was constructed to provide the flow areas for sodium in the channel and the entire 
TABLE A.2. Major Input Parameters to the ANL FCI Parametric Model.

\section{Parameter}

Cover Gas Region $(\mathrm{cm})$

Sodium Slug Height $(\mathrm{cm})$

FCI Zone Height $(\mathrm{cm})$

Flow Area $\left(\mathrm{cm}^{2} / \mathrm{gm} \mathrm{Na}\right)$

W-Fuel/Sodium Mass Ratio

Fuel Particle Radius (um)

Mixing Time Constant

Mass of Sodium

Heated Sodium Temperature $\left({ }^{\circ} \mathrm{K}\right)$

FCI Zone Pressure (atm)

Heated Sodium Specific Volume $\left(\mathrm{cm}^{3} / \mathrm{gm}\right)$

Fuel Temperature $\left({ }^{\circ} \mathrm{K}\right)$

Specific Heat of Fuel $\left(\mathrm{cal} / \mathrm{gm}^{\circ} \mathrm{C}\right.$ )

Thermal Conductivity of Fuel (ca.l/ $\mathrm{cm}-\mathrm{sec}^{\circ} \mathrm{C}$ )

Fuel Density $\left(\mathrm{gm} / \mathrm{cm}^{3}\right)$
EFTF CRBR CRBR (UC)

$50 \quad 70.70$

$520 \quad 643 \quad 643$

Var.* Var. Var.

Var. Var. Var.

Var. Var. Var.

$64 \quad 64 \quad 64$

Var. Var. Var.

Var. Var. Var.

$840^{\circ}-808^{\circ} .808^{\circ}$

$1.40-1.51-1.51$

$\begin{array}{lll}1.20 & 1.21 \quad 1.21\end{array}$

$4000^{\circ} \quad 4000^{\circ} \quad 5000^{\circ}$

$\begin{array}{lll}0.12 & 0.12 & 0.08\end{array}$

$\begin{array}{lll}0.005 & 0.005 & 0.053\end{array}$

$9.8 \cdot 9.8 \cdot 12.4$

\section{OTHER ASSUMPTIONS:}

- Acoustic constraint up to acoustic unloading time and inertial constraint for longer times.

- Heat transfer cutoff at acoustic unloading time.

- Rigid vessel wall.

- Sodium slug properties are the same as those of the heated sodium.

*Var. E Variable 


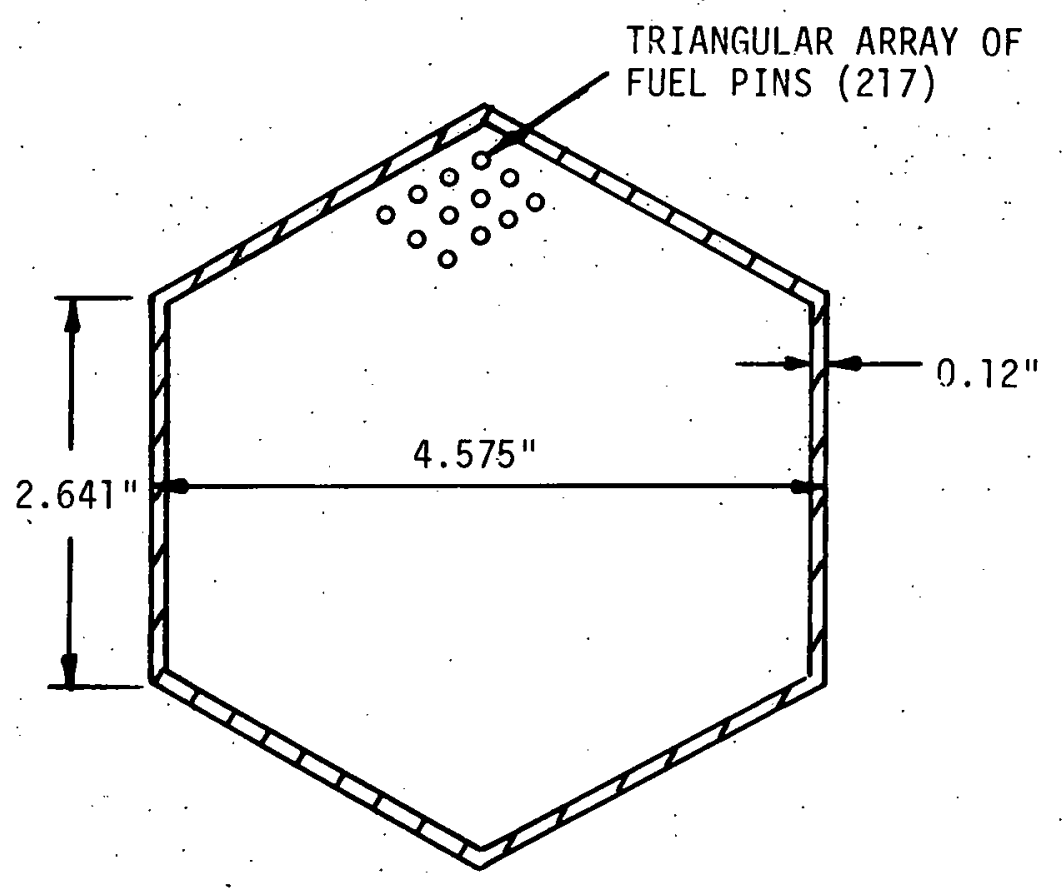

FIGURE A.3 Fuel Channel Dimensions in the FFTF and the CRBR 
TABLE A.3 Core Flow Areas.

$\underline{\text { FFTF } \quad \text { CRBR }}$

1. Channel Area (including SS can)

18.13

18.13 $\left(\right.$ in $^{3} /$ in $)$

2. SS Can Area $\left(\mathrm{in}^{3} / \mathrm{in}\right)$

1.86

1.86

3. Fuel Rod Area* per Channel $\left(\mathrm{in}^{3} / \mathrm{in}\right)$

$9.02 \because 9.02$

4. Resultant Sodium Flow Area** per

7.25

7.25 Channel $\left(\mathrm{in}^{3} / \mathrm{in}\right)$

5. Number of Subassemblies

73

198

(Channe 1s)

6. Total Sodium Flow Area for Core $\left(\mathrm{in}^{3} / \mathrm{in}\right)$

7. Total Sodium Flow Area for Core $\left(\mathrm{cm}^{3} / \mathrm{cm}\right)$

* 217 Fuel Pins (Diameter $=0.23^{\prime \prime}$ )

** Neglects Wire Wrap 
cores of the FFTF and CRBR. In this table, the spacer area is neglected which would reduce the sodium flow area inside the channel. This omission is offset, however, by the omission of the coolant flow between the channels.

With the values in Table. A.3, the minimum mixing zone length can be determined. Given a certain mass of interacting sodium, and corresponding volume, the mixing zone length can be determined by the following equation:

$$
\mathrm{L}_{\mathrm{M}}=\frac{\mathrm{V}_{\mathrm{Na}}}{\text { Flow area }}
$$

where

$$
V_{\mathrm{Na}}=\mathrm{M}_{\mathrm{Na}} / \rho_{\mathrm{Na}}
$$

For the FFTF,

$$
\rho_{\mathrm{Na}}=0.833 \mathrm{gm} / \mathrm{cm}^{3} \quad\left(\text { at } \mathrm{T}=840^{\circ} \mathrm{K}\right)
$$

and from Table A.3,

$$
\text { Flow Area }=3413 \mathrm{~cm}^{3} / \mathrm{cm} \text { : }
$$

Using Eq. (A-33), and the above values, the mixing zone height for the FFTF cases can be calculated using

$$
L_{M}=3.52 \times 10^{-4} \mathrm{MNa}_{\mathrm{Na}}
$$

For the CRBR,

$$
\rho_{\mathrm{Na}}=0.826 \mathrm{gm} / \mathrm{cm}^{3} \quad\left(\text { at } \mathrm{T}=808^{\circ} \mathrm{K}\right) \text {, }
$$


and from Table A. 3,

$$
\text { Flow Area }=9264 \mathrm{~cm}^{3} / \mathrm{cm} \text {. }
$$

For the CRBR cases, the equivalent expression for Eq. (A-35) is

$$
L_{M}=1.30 \times 10^{-4} \mathrm{M}_{\mathrm{Na}}
$$

\section{A.3.2.2 Vesse1. Flow Area}

The vessel flow area, SS, is not to be confused with the previous flow area calculated by inspecting the core geometry. This flow area is calculated by simply dividing the vessel cross-sectional area by the amount of sodium in the mixing zone for the particular FCI.

Assuming the vessel to be $617 \mathrm{~cm}$ in diameter for both FFTF and CRBR, the vessel flow area, SS, is calculated by.

$$
\text { SS }=\frac{\text { Vessel area }}{M_{\mathrm{Na}}}
$$

where

$$
\begin{aligned}
\text { Vesse1 area } & =\pi(617)^{2} / 4 \\
& =2.99 \times 10^{5} \mathrm{~cm}^{3} .
\end{aligned}
$$

Using this in Eq. $(A-37)$, we get

$$
\mathrm{SS}=299.2 \times 10^{3} / \mathrm{M}_{\mathrm{Na}}
$$

Because the vessel diameters are the same for both the FFTF and CRBR, this equation holds for both reactor systems. 


\section{A.3.2.3 Fuel/Sodium Mass Ratios}

In the earlier computer runs, it was assumed that for a given amount of fuel, an optimum fuel/sodium mass ratio existed that would provide the maximum work potential. This original assumption was based upon the previous results (6) that indicated that optimum fuel/sodium mass ratio depended upon the final pressure of the vapor expansion. For instance, a fuel/sodium ratio of 10 was thought to be the optimum for an expansion down to one atmosphere. On the other hand, a ratio of 13 would be the optimum for an expansion down to approximately 30 atmospheres. With these numbers in hand, guesses were made as to the final pressure at slug impact and appropriate fuel/sodium mass ratios were chosen. In general, the initial choices were close enough to avoid additional runs. However, it was determined by a parametric variation of the fuel/sodium ratios for a fixed amount of fuel that an optimum does not really exist at a point between the ratios of 10 and 13. In fact, the relation is approximately linear (Figure A.4). This figure presents the work potential as a function of fuel/sodium mass ratios for a fixed fuel mass in the FFTF. This, of course, affects the results obtained earlier.

The overall effect of this oversight is not large. By reviewing Appendix G, most runs used mass ratios between 11 and 12 . If mass ratio of 13 had been used, an increase of from approximately 6 to 14 percent would be realized. Nevertheless, a correction is not felt to be warranted at this point because the overall change in the mixing time constants would not be significant due to the uncertainties that exist in the FCI heat transfer and mixing mechanisms. 


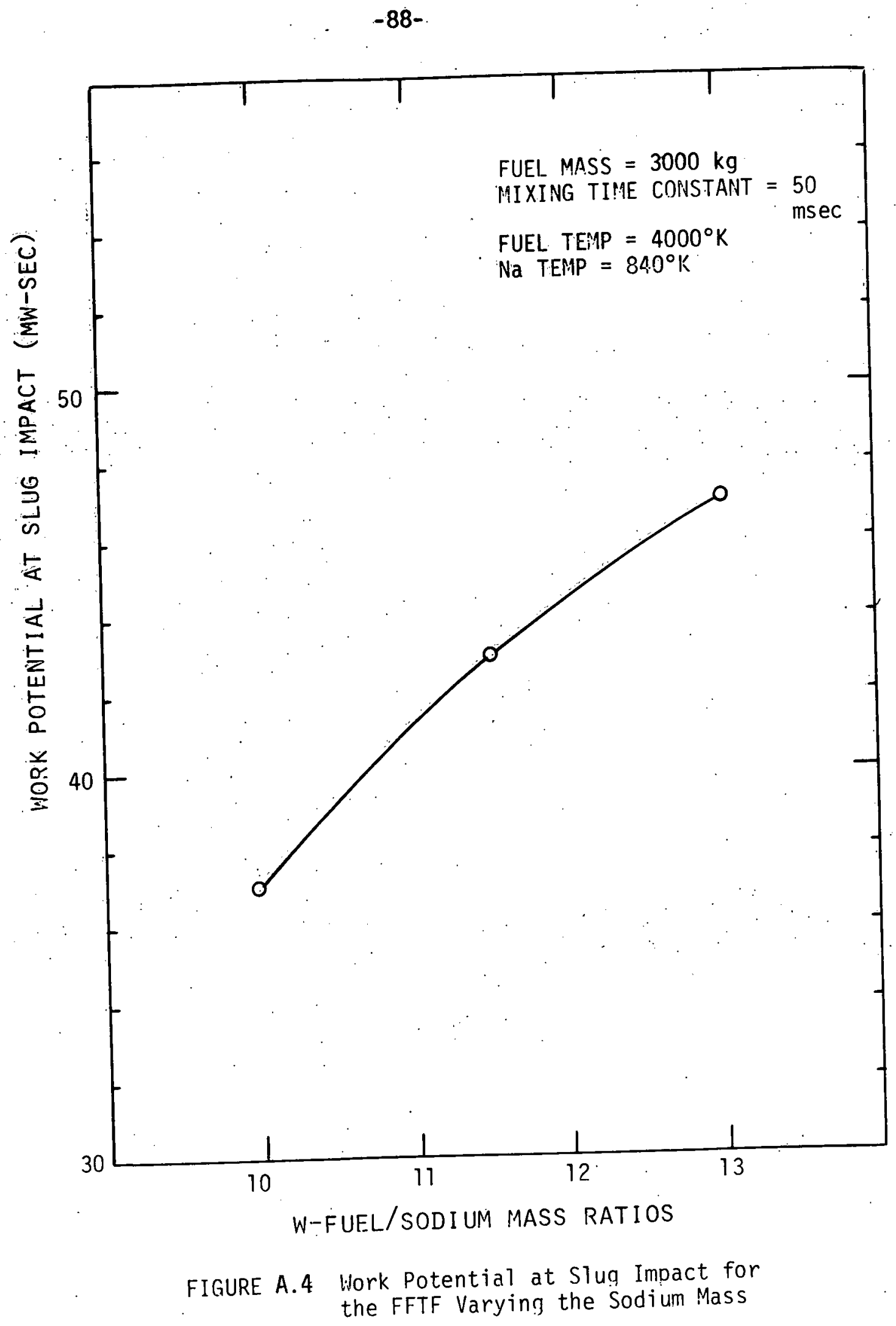


Furthermore, a fuel-to-sodium mass ratio of approximately 10.5 region exists in the core under normal operating procedures. If the fuel were to meet and interact with the sodium, this ratio would probably decrease to less than 10.5 due to the fact that the amount of fuel that would interact with the coolant would only be a fraction of the initial molten fuel.

Furthermore, equal volumes of mass and fuel provide approximately a 13 to 1 mass ratio:

\section{A.3.2.4 Mixing Time Constants}

The mixing time constants were chosen such that the work potential at slug impact would bound the limiting work potential of the particular reactor system. This iterative scheme usually involved only two runs if judicious choices were used. Fortunately, in most cases, this is all that was necessary. Determining the mixing time constant that represents the limiting work potential was done by a linear interpolation or extrapolation of the mixing time constants and the resultant work potentials.

\section{A. 4 Code Output}

The major output of the code includes ten FCI parameters. These are printed out for each time step including the initial conditions at time $=0.0$. A list of these parameters follows: 
(1) Fuel Temperature $\left({ }^{\circ} \mathrm{K}\right)$

(2) - Sodium Temperature (heated) $\cdot\left({ }^{\circ} \mathrm{K}\right.$ )

(3) Pressure in the Mixing Zone (atm)

(4) The velocity of the unheated sodium slug $(\mathrm{cm} / \mathrm{sec})$

(5) The expansion work $\int P d V$ (atm-cc/g)

(6) The impulse $\int P d t$ (atm-sec)

(7) Position of mixing zone/Slug interface $(\mathrm{cm})$

(8) Sodium specific volume $(\mathrm{cc} / \mathrm{g})$

(9) Mass fraction of sodium vapor

(10) Sodium vapor volume (cc/g)

Included with these parameters are estimates of the error involved. The code will stop executing when the error magnitudes equal that of the parameter values.

For this analysis, the expansion work value was used when the movement of the interface value was equal to the cover gas region height. This would imply slug impact. To provide the correct value for the expansion work in terms of $M W-s e c$, the code output was multiplied by a conversion factor of $(0.1013 \mathrm{MW}-\mathrm{sec} / \mathrm{atm}-\mathrm{cc} / \mathrm{g})$ and then by the mass of interacting sodium for the particular case.

\section{A.5 Code Listing}

A complete listing of the FCI-B version of the. ANL parametric model is not available with all the subroutines. Therefore, a complete listing is in this appendix. 
PARAMETRIC MODEL OF PUEL-COOLANT INTERACTIONS

ACOUSTIC OR INERTIAL CONSTRAINT

THE HEATED SODIUM IS IN A UNIPORM STATE THROUGHOOT THE HIXING ZONE

IMPIICIT REAL*8 (A-H,O-Z)

REAL*8 LM,KF,KB, MASS, MGMAX,NEWERR

DIMENSION Y (20),DY (20),S(20),R(20), YE(20),YU(20), YP(20),NERERR(20)

$1, \operatorname{ERR}(20)$

COMMON /R1/RG,KB,DTE, NOPNS, NNS /R2/VLO,TLO/R3/AI,HT,CPH,AO,

1 DEFORM, PO, PINF, SCD, RPC, VGO, TH, TCUT, SS, SCL, HGMAX, NNP (6)

DATA HMIN $/ 0.1 \mathrm{D}-16 / . \mathrm{HMAX} / 0.1 \mathrm{D}-04 \%$. H0 $0.1 \mathrm{D}-06 / . \mathrm{EPS} / 0.1 \mathrm{D}-05 /$

$1 \mathrm{BB} / 12767.8 / . \mathrm{DD} / 0.61344 /, N Y, K K K, J B I, K K, N E$ KRR, BRR, HP/2*0,2*1,41*0.1 2.JM, N;E/12,10,.20408D 07/. PCONST/1.01325D 06/.AA.EMAX/15.3838.0.1\% 3. $\mathrm{PI} / 3.1416 /$

$N I N=5$

NOUT $=6$

$\mathrm{NZ}=0$

$\mathrm{TCUT}=1 . \mathrm{D} 2$

DEFORM $=0$.

$N N S=0$

NOPN $S=0$

C********* READ INPUT PARABETERS AND INITIAL CONDITIONS **************

READ (NIN, 1001$) \quad(N N P(I), I=1,6), K D, N P U N C H, X I, X P$

READ (NIN, 1002$)$ W, RR,D,DELT,VGO,TH, SCL, LH, MGMAX,MASS,SS

READ (NIN, 1002) (Y (I), I=1,N), VLO,TLO, PGAX,THAX

5 IF (TLO.GT.1.) NNS=1

10 IF (NNP(6) EQ.0) GO TO 30

20 READ (NIN, 1002) TO,PO,PINF, SCD GO TO 40

30 $\mathrm{TO}=\mathrm{Y}(1)$

$\mathrm{P} 0=\mathrm{Y}(2)$

$P I N F=1$.

$S C D=1 . / Y(3)$

SONIC VELOCITY OF SODIUM

MAINOOO

MAI NOOO2

MAIN0003

MAI NOOO4

MAINOOOS

MAIN0006

MAIN0007

MAINO0OB

MAINO009

MAIN0010

MAINOO11

AINOO 12

MAIN 0013

MAINOO14

MAINO015

MAINOO 16

MAI NO017

MAINOO18

HAINOO19

AINOO20

MAINO021

HAINO022

MAINOO23

HAI NO024

BAIN0025

HAIN0026

MAIN 0027

MAINO028

MAINOO29

GAINOO 30

MAINO031

MAIN0032

MAIN0033

MAINOO34

MAINOO35

MAI N0036 
$40 \mathrm{TFF}=\mathrm{TO} * 1.8-460$.

MAIN0037

VSONIC $=2.525268 D \quad 05-29.10907 *(T P P-210$.

$\mathrm{C}$

*** UO2 AND BLANKET GAS PROPERTIRS *******READ-IN INPOTS ******

MAIN0038

MAIN0039 READ (NIN, 1002) CP,KF, EHOF,KB,RG $\mathrm{PC}=1.67$

$R P C=0.6$

C

C******** CALCULATED PARAMETERS *

\section{$* * * * * * * * * * * * * * * * * * * * * * * * * * * * * * * * * * * *$}

$\mathrm{HT}=\mathrm{CF} * \mathrm{RHOF} * \mathrm{R} R * 2 /(3 . * \mathrm{KF})$

$\mathrm{AO}=3 . * \mathrm{~W} /(\mathrm{RH} O \mathrm{~F} * \mathrm{RR})$

$A I=S C D * V S O N I C /(S S * P C O N S T)$

$C F W=C F *$

IF (NNP (1). $\mathrm{EQ} \cdot 0)$ T COT $=2 . * \mathrm{SCL} / \mathrm{VSONIC}$

IF (NNP (4) .EQ.0) GO TO 50

$D \leftarrow F O R M=I M * P I * D * * 3 /(4 . * E * D E L T * M A S S)$

C********* PRINT OUT INITIAL CONDITIONS, PARAMETERS AND OPTIONS *****

50 WRITE (NOUT, 1003 )

WRITE (NOUT, 1004)

WRITE (NOUT, 1005) N,XI,XF,EPS,HO

WRITE (NOUT, 1006) (Y (I), I=1,10)

WRITE (NOOT,1007) W, RR,SS,LM, MASS,D,DELT,SCL,PO,PINF,SCD,PC

WRITE (NOUT, 1009) AI,CFW, HT, AO

IF (VGO.NE.0.) WRITE (NOOT,1008) VGO

IF (NNP(1).EQ.0) WRITE (NOUT, 1010) TCUT

IF (NNP (1) EQ.1) WRITE (NOUT, 1011)

IF (NNP (1).EQ.2) WHITE (NOUT.1012)

IF (NNP (2).NE.1) WRITE (NOUT, 1013) TH

IP (NAP (2).EQ.1) WRITE (NOUT,1014)

IP (NNP (3) . NE.0) WBITE (NOUT, 1015) MGMAX

WRITE (NOUT, 1017) VSONIC

WRITE (NOUT, 1018) CP,KF, RHOF

WRITE (NOUT,1019) KB, RG

IF (NNP (4).NE.0) WRITE (NOUT, 1020) DEFORM

MAINOO40

MAI NOO41

DAIN0042

MAIN0043

AINOO A 4

MaIN 0045

MAIN0046

MAINO047

MAIN0048

MAIN0049

MAINO050

$\triangle A I N 0051$

MAIN0052

MAINO053

MAI N 0054

AAIN0055

HAIN0056

MAIN0057

MAIN0058

MAI.NO059.

HAIN0060

MAIN0061

MaIN0062

MaIN0063

MAINO064

MAIN0065

MAIN0066

MAIN0067

A AIN0068

MAIN0069

MAINO070

MAIN0071

DO $60 \quad I=1, N$

MAI N0072 
$60 S(I)=D A B S(Y(I))$

WRITE (NOUT, 1003)

MAIN0073

NNF NS $=$ NOFNS

MAI N0074

$\mathrm{X}=\mathrm{XI}$

$\mathrm{XP}=\mathrm{X}$

$\mathrm{TTL}=X F-X I$

80 IF (X.GE.XP) GO TO 81

GO TO 84

81 WITE (NOUT, 1021) X, HP, NNFNS, ( $Y(I), N E$ NERR (I), I=1, 10)

IF(Y (6) . GT.70.0) GO TO 279

$X P=X P+0.1 D-04 * D F L O A T(K D)$

C********* PERFORM A STEP IN SOLUTION OP DIPEERENTIAL RQOATIONS

84 IF $((X F-X) / T T L . L E . O)$ GOTO 79
IF (DABS(HO).LT.HMIN) HO=DSIGN (HAIN,HO)

IF (DABS (HO) . GT. HMAX) HO=DSIGN (HUAX,HO)

IF $((X F-X-H O) / T T L . L T .0)$ H O X XF - X

IF $(X . G E . X P)$ GO TO 86

IF $((X P-X-H O) \cdot L T \cdot 0.) \cdot H O=X P-X$

86 IF $(X . E Q \cdot 0$.$) GO TO 85$

IF (NNP (3) . EQ..0) GO TO 85

CALL DIFFUN $(X, Y, D Y)$

DT $P=D Y(4) / D Y(1)$

GO TO 88

85 DTF $=1$.

$88 \times \mathrm{T}=\mathrm{X}$

$\mathrm{JMAX}=\mathrm{JM}+4$

DO $87 \quad I=1, N$

$Y P(I)=Y(I)$

87. $Y . E(I)=Y(I)+F R R(I)$ $\mathrm{HS}=\mathrm{HO}$

CALL DIFI (N, X,Y,DY, HO, HAIN, EPS,JH, S, R, KK, YU, JP, JMAX, JBL, PC)

CALL DPBND $(N, X, Y, D Y, H O, E P S, E R R, J M, H M I N, J P, Y B, O\}$

DO $89 I=1, N$

89 NEHERR(I) = ERR (I)

PSAT $=D E X P(A A-B B / Y(1)) / Y(1) * * D D$

IP (NNP(1).NE.0) GO TO 201

MAINO075

MAIN0076

MAIN0077

HAIN0078

MAIN0079

MAIN0080

MAIN0081

MAIN0082

MAIN0083

MAIN0084

MAIN0085

MAIN0086

MAIN0087

HAIN 0088

GAINOO 89

MAINO090

MAIN0091

MAI NOO92

MAIN0093

MAIN0094

MAINO095

MaIN0096

DAINO097

MAIN0.098

GAINO099

MAI MO 100

MAIN0101

MAINO102

MaIN010.3

MAINO 104

GAIN0105

MAIN0 106

MAIN0107

SAINO 108 


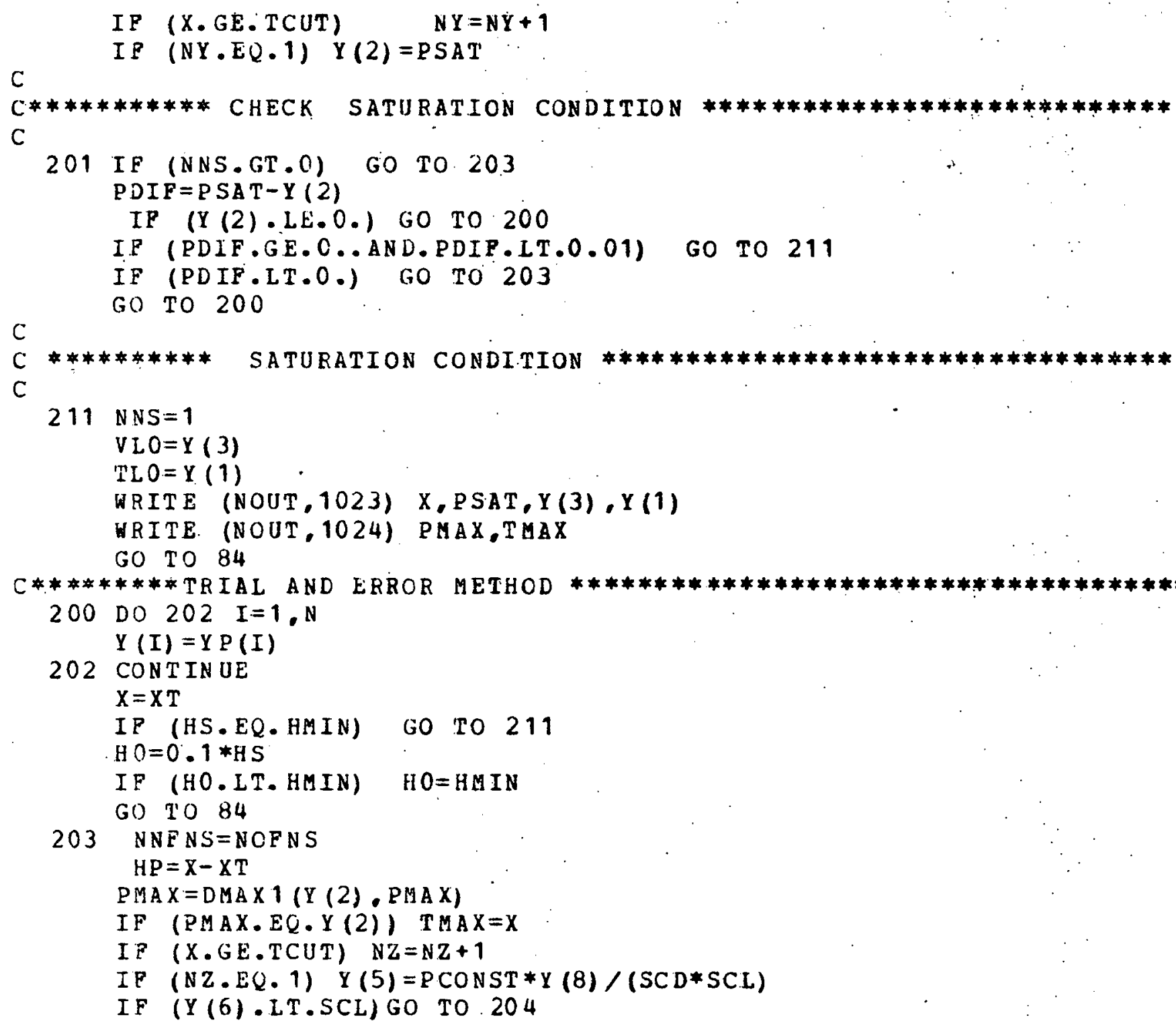

MAIN0.109 MAI NO110 MAINO111 MAINO112 MAIN0113 MAIN0114 MAINO 115 MAI N0116 MAINO 117 MAIN0118 MAIN 0119 MAINO120 MAINO121 MAINO 122 MAIN0123 MAINO 124 MAINO125 MAI N0126 MAINO $127 \stackrel{\circ}{\rightleftarrows}$ MAIN0128 MAINO 129 MAI N0130 MAINO131 MAINO 132 MAIN 0133 MAIN0134 MAIN0135 MAINO136 MAINO137 MAINO 138 MAINO 139 MAINO140 GAINO141 MAIN 0142 MAINO143 MAINO 144 
WRITE (NOUT, 1025) SCL

GO TO 79

204 IF (KK.GE.0) GO TO 80

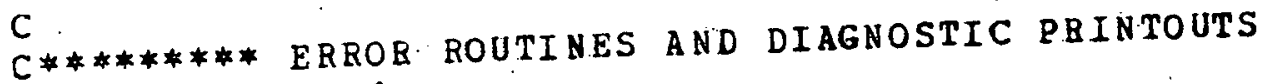

$120 \mathrm{KKK}=\mathrm{KKK}+1$

$K R=+1$

$E A=0$

DO $121 I=1, \mathrm{~N}$

$I F(E A . G T . R(I) / S(I))$ GOTO 121

$E A=R(I) / S(I)$

$\mathrm{NA}=\mathrm{I}$

121 CONTINUE

WRITE (NOUT, 1021) $X, H P, N O F N S$ ( $(I(I), E R R(I), I=1,10)$

HRITE (NOUT, 1026) X,HP,EA, NA

IF (EMAX.GE.EA) GOTO 127

ARITE (NOUT, 1027)

GO TO 79

127 EPS $=$ EA

$\mathrm{HO}=\mathrm{HP}$

WRITE (NOUT, 1028) EPS

GO TO 80

c.

C

79 STOP

279 WRITE (NOUT, 1024) PMAX,THAX

WRITE (NOUT, 1031)

IP (NPUNCH.EQ.0) GO TO 280

NNP $(6)=1$

$X I=X$

PIJNCH 1001, (NNP (I), I=1,6),KD,NPONCH, NOCUT, XI, XP

PUNCH 1002, W,RR,D,DELT; VGO,TM, SCL, LM, MGMAX,MASS, SS

PUNCH 1002, (Y(I), I=1,N), VLO, TLO, PMAX, TMAX

PUNCH 1002 , TO,PO, PINF, SCD

PONCH 1002, CF, KF, RHOF, KB, RG
$\operatorname{MaINO} 14.5$

MAINO146

MAINO147

MAINO148.

MAIN0.149

MAINO 150

MAIN0151

MAINO 152

HAIN0153

MAINO 154

MAI NO 155

MAIN0156

MAINO 157

HAINO158

MAINO 159

MAI NO160

MAINO 161

HAIN0162

MAINO163

MAINO 164

MAIN0165

HAINO 166

MAINO 167

MAIN0168

MAIN0169

MAI NO170

MAINO171

MAINO 172

BAINO173

MAINO 174

AAI NO175

MAINO 176

MAIN0177

MAIN0178

MAINO179

AAINO 180 

C

MAIN0184

1001 FORMAT (8I5./.2D30.5)

1002 PORMAT (6D12.5)

1003 FORMAT (1H1)
1004 PORMAT (/.' PARAMETBIC MODEL OF FOEL-COOLANT INTERACTIONS')

1005 FORMAT (1H0.9X,'SOLVE $N=\circ$.I2; EQUATIONS FAOM XI $1=, \mathrm{E} 12.5, \mathrm{WTH} \cdot$ 2SIZE HO= , E12.5)

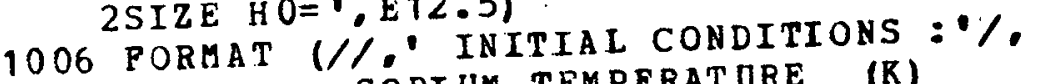

$\begin{array}{ll}1 . \mathrm{T} & =\text { SODIUM TEMPERATDRE (R) } \\ 2^{\prime} \mathrm{P} & =\text { FRESSURE (ATH) }\end{array}$

$2^{\prime} \mathrm{P} \quad=$ FRESSURE (ATH)

3. $V$ SODIUM SPECIFIC VOLUAE (CC/G)

4. TE = FUEI TEMPERATURE (K)

5. $U$ = SODI UM COLUMN VELOCITY (CH/SEC)

6. DS

7. HORK

=BOUNDARY POSITION (CH)

WORK = PDV HORK (ATH-CC/G)

8. PDT =SUM OF PDT. IMPOLSE (ATH-SEC)

9. QUAL = MASS FHACTION OP SODIUM VAPOB

* $\nabla \mathrm{G}$

= SODIUA VAPOR VOLUHE

(CC/G)

1007 PORMAT (// BASIC PARAMETERS: $\% /(\dot{G} / \mathrm{G})$

$\begin{array}{lllll}1 \cdot & \text { (FUEL/SODIUM MASS RATIC) } \\ 2 & \text { RR } & \text { (FUEL PARTICLE RADIUS) (CM) }\end{array}$

3. ${ }^{2}$ SS (FLOW AREA) (SQ CM/G)

4. (INITIAL MIXING ZONB LENGTH) (CM)

5. MASS(TOTAL SODIUM MASS) (G)

5. MASS (TOTAL SODIUM MASS) (G)

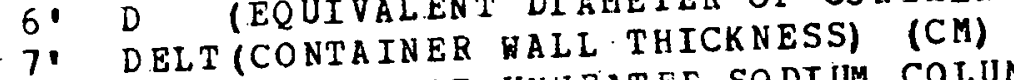

8. SCL (LENGTH OF UNHEATEL SODI

PRESSURE IN THE UNDISTURBED SODIUH D $12.5 .10 \mathrm{X}$

5. PINF

$7 \cdot S C D$

PRESSURE IN THE UNDIST
PLENUM PBESSURE (ATM)

DENSITY OF UNHEATED SODIOM

8. $\mathrm{PC}$

1008 FORMAT
POLYTROPIC EXPON ENT ('
CUSHION GAS EPFECT
D12.5.\%.

- $12.5 . \%$.

D12.5,10X.

012.5 .1$.

- D12.5.10x.

- D12.5./.

- D12.5.10x.

D 12.5)

- $D 12.5,10 \mathrm{X}$,

- D12.5.1/.

D12.5.10X.

- D $12.5 .1 /$.

- $12.5,10 \mathrm{X}$.

- D12.5.1.72X' (CA) \%

- $012.5,10 x$.

D $12.5 .1 .20 x^{\prime}$ (ATA) $\%$ $(G / C C)$

D12.5.10x.

$V G O=\cdot D 12.5, "(C C / G N A) \cdot / /)$
D $12.5 .10 x$.

D $12.5,10 \mathrm{x}$.
MAINO 185

MAIN0186

MAIN0187

MAINO188

MAINO189

MAINO 190

MAINO191

MAINO 192

MAIN 0193

MAIN0194

MAINO 195

MAIN0196

MAINO 197

MAIN0198

MAINO 199

MAIN0200

MAINO201

MAIN0202

MAINO203

MAINO 204

MAINO 205

MAINO206

HAINO207

MAIN0208

AINO 209

HAINO210

MAINO211

MAIN0212

MAINO 213

MAINO214

MAINO215

MAINO216 
1009 FORMAT. $\left(/ / 0^{\circ}\right.$ CalCULATED PARALETERS : $\%$

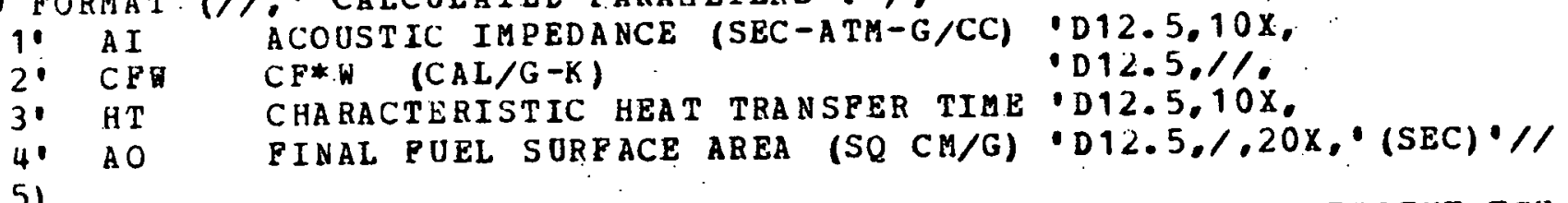

1010 FORMAT (' CONSTRAINT MODEL: ACOUSTIC - INERTIAL CONSTRAINT TCU $1 \mathrm{~T}=\cdot \mathrm{D} 12.5 . / / 1)$

1011 FORMAT (" CONSTRAINT MODEL: ACOUSTIC CONSTRAINT POB ALL TIMES" $)$ 1012 FORMAT (" CONSTRAINT MODEL: INERTIAL CONSTRAINT PJB ALL TIMES'/)

1013 FORMAT ${ }^{\circ}$ HEAT TRANSFER MODEL: HEAT TRANSPER WITH A FINITE RATE 1OP PRAGMENTATION.

$$
\text { H.20X, TH= D } 12.5, / / 1
$$

1014 FORMAT (' HEAT TRANSFER MODEL:QUASI-STEADY STATE HEAT TRANSFER//)

1015 FORMAT (" EPFECT OF GAS/VAPOR BLANKETING OP FUEL PARTICLES, $/ .10 X$, 1 TOTAL MASS OF BLANKET GAS, MGMAX= D12.5)

1017 FORMAT (" SONIC VELOCITY OF SODIUM:

1018 FORMAT (' DO2 PROPERTIES: $C P=\cdot D 12.50^{\circ} K F=\cdot D 12.50^{\circ}$ AND RHOP='D 12.5)

1019 FORMAT (" BLANKET GAS PROERRTIES : KB='D12.5, AND RG='D12.5)

1020 FORMAT (' EFPECT OF ELASTIC WALL DEFORMATION ***** DEFORM=1 D 12.5)

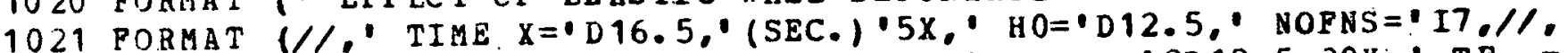
$1 . \mathrm{T}=12 \mathrm{D} 12.5,30 \mathrm{X}, \mathrm{P}=12 \mathrm{D} 12.5 . / \mathrm{V}=12 \mathrm{D} 12.5,30 \mathrm{X}, \mathrm{TF}$

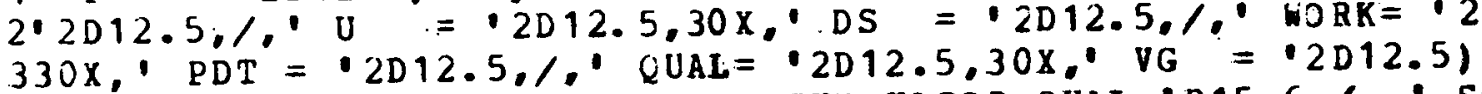

1022 PORMAT (" MASS FRACTION OF SODIUM VAPOR QUAL='D15.6./." SODIUM VA IPOR VOLUME VG $=$ 'D15.6)

1023 FORMAT $(/ / .22 \mathrm{~B}$ SATURATION CONDITION $/ / .20 \mathrm{X}, 9 \mathrm{~B} \times(\mathrm{SEC})=012.5 . / /$.

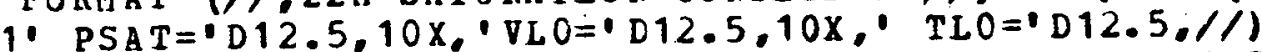

1024 FORMAT (" MAXIAUM PRESSURB 'D 12.5.' (ATM) OCCURS. AT TIME=' 1D 12.5, (SEC)'

1025 PORMAT ( 1 H0,7X,' END OF CASB **** Y $(6) . G T . L=1012.50^{\circ} \mathrm{CH}$ ')

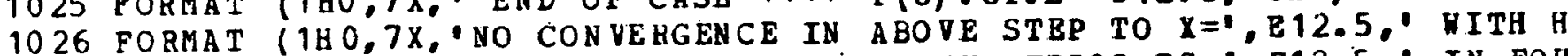
$10=0$, E 12.5, $, / 8 X, 0^{\circ}$ THE LIMITING RELATIVE ERROR IS $, E 12.5,{ }^{\circ}$ IN EQU 2ATION ', I $2, \cdot, ")$

1027 FORMAT (1H0.7X, 'CASE ABANDONED, OUTSIDE LIMITS OF HAIN AND BHAX.")

1028 PORMAT (1HO, $7 \mathrm{X},{ }^{\circ}$ CASE CONTINUES UITH EPS=',E12.5)

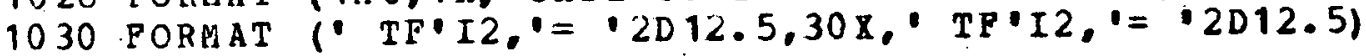

MAINO217

MAIN0218

MAINO219

MAINO220

MAINO221

MAINO222

MAIN 0223

HAINO 224

MAINO225

MAINO 226

MAIN 0227

MAINO228

MAIN0229

MAINO230

MAINO231

MAIN0232

MAIN 0233

MAINO 234

MAINO235

MAIN0236

MAINO237

MAIN0238

MAINO239

MaIN0240

GAIN 0241

MAIN0242

GAIN 0243

MAINO244

MAINO245

MAINO 246

MAIN 0247

MAIN0248

MAINO249

MAINO 250

MAINO251

GA.INO 252 

END 
SUBRODTINE DIFPUN $(X, Y, D Y)$

DIPFOOO 1

IMPLICIT REAL*8 (A-H,O-Z)

REAL * 8 KB, MG, MGMAX

DIMENSION Y $(20), D Y(20)$

COMMON/R1/ RG,KB,DTF, NOPNS, NNS/R2/VLO,TLO/R3/AI,HT,CFW, AO,

1 DEPORM, PO, PINF, SCD, RPC, VGO,TM, TCUT, SS, SCL, NGMAX, NNP (6)

DATA A $0 / 0.21968 \mathrm{D}-03 / . \mathrm{A} 1 / 0.81226 \mathrm{D}-07 / . \mathrm{A} 2 / 0.97135 \mathrm{D}-11 / . \mathrm{A} 3 / 0.68998$ $1 \mathrm{D}-15 / . \mathrm{B} 0 / 0.69651 \mathrm{D}-05 / . \mathrm{B} 1 / 0.26741 \mathrm{D}-07 / . \mathrm{B} 2 /-0.14891 \mathrm{D}-10 / . \mathrm{B} 3 / 0.82082 \mathrm{D}$ $2-14 / . \mathrm{C} 0 / 0.389352 / . \mathrm{C} 1 /-0.199078 \mathrm{D}-03 / . \mathrm{C} 2 / 0.110542 \mathrm{D}-06 / . \mathrm{HGO} /$

$30.186050 \mathrm{D} 04 \%$ HG1/-0.14691D $01 /$, BG $2 / 0.10 .381 \mathrm{D}-02 /$, BG3/-0.23238D-06/ 4. HLO/-0.92130DO3\% HL 1/0.19434 D 01/. HL $2 /-0.10510 \mathrm{D}-02 /$, HL3/0.22418D$506 / .220 /-0.97258 / .2 Z 1 / 0.42417 \mathrm{D}-02 / .222 /-0.28996 \mathrm{D}-05 / .223 / 0.55424 \mathrm{D}-$ $609 / . A A / 15.3838 / . B B / 12767.8 / . C C / 41.29 / . D D / 0.61344 / . G C / 980.665 /$. 7 PCONST $/ 1.013250$ 06/

8 PORMAT (// $* * * * * * * * * *$ RE-ENTRY INTO LICUID PHASE ********')

9 FORMAT ("EQUATION OP STATE IS INCORRECT NEAR THE CRITICAL POINT. $1 \mathrm{HGL}$ IS LESS THAN $0.1 / 0^{\prime}$ THE TEMPERATURE = D 12.5.' DEG.. HG = $2 \mathrm{D} 12.5, \mathrm{AND} H \mathrm{HL}=\mathrm{D} 12.5)$

$\mathrm{QCR}=-0.0001$

NOUT $=6$

$D U D T=0$.

$\mathrm{DDDT}=0$.

$D Q U A L=0$.

$D \vee \nabla G=0$.

$G \vee P=0$.

$V G=0$.

$M G=0$.

$N X=0$

$C P G=0$.

DO $5 . I=11,20$

5 DY $(I)=0$.

IF (NNP(1),EQ.0) GO TO 10

GO T'O 20

10 IP (X.GT.TCUT) NX=1

20 IP (NNP(1) EQ.2) NX=1 $\mathrm{T}=\mathrm{Y}(1)$

DIFF0002

DIF P0003

DIFPO004

DIFP0005

DIF P0006

DIFP0007

DIP P0008

DİFP0009

DIPPOO10

DIPP0011

DIP P0012

DIPF 0.013

DIPF0014

DIPF0015

DIF F00 16

DIF F0017

DIP F0018

DIP FO019

DIFP0020

D IP P0021

DIPP0022

DIPPO023

DIFFO024

DIF P0025

DIP F0026

DIFF0027

DIP P0028

DIF P0029

DIF P0030

DIF P0031

DIFF0032

DIFF0033

DIF P0034

DIP POO 35

DIPF0036 
$\mathrm{P}=\mathrm{Y}(2)$

$V=Y(3)$

$T F=T(4)$

$\mathrm{U}=\mathrm{Y}(5)$.

QUA L $=Y(9)$

IF $(P . G T \cdot 0) \quad G V P=.P O * * R P C * V G O * R P C / P * *(1 .+R P C)$

$\mathrm{T} 2=\mathrm{T} * \mathrm{~T}$

$\mathrm{T} 3=\mathrm{T} 2 * \mathrm{~T}$

$T 4=T 3 * T$

$\mathrm{AP}=\mathrm{A} O+\mathrm{A} 1 * \mathrm{~T}+\mathrm{A} 2 * \mathrm{~T} 2+\mathrm{A} 3 * \mathrm{~T} 3$

$\mathrm{Z}=\mathrm{ZZO}+\mathrm{ZZ} 1 * \mathrm{~T}+\mathrm{ZZ} 2 * \mathrm{~T} 2+\mathrm{ZZ} 3 * \mathrm{~T} 3$

$\mathrm{TB}=\mathrm{T}$

$\operatorname{PSAT}=\mathrm{DEXP}(A A-B B / T) / T * D D$

C

C********* HEAT TRANSFER CALCULATIONS

$\mathrm{C}$

$D Q D T=0$.

IF (NNP (5) EEQ.0) GO TO 21

IP (X.GT.TCOT) GO TO 110

21 IP $(X . B Q .0$.$) GO TO 110$

PRAGM $=1$.

IF (NNP (2) . EQ.1) GO TO 101

IF (TM.NE.0.) PRAGM $=1$. -DEXP $(-X / T M)$

$\mathrm{HA}=\mathrm{CPW}(0.9772 * \mathrm{DSQRT}(\mathrm{HT} / \mathrm{X})+1). * \mathrm{PRAGM} / \mathrm{HT}$

GO TO 103

C

$101 \mathrm{HA}=\mathrm{CFW} / \mathrm{HT}$

C

103 IF (NNP(3) E EQ.0) GO TO 104

IF (MGMAX.EQ.0.AAN.QUAL.LE.0.) GO TO 104

$M G=M G M A X * F R A G M$

$A R E A=A O * F B A G M$

$C P G=0.6$

$T B=(T+T F) / 2$.

$V G=R G * T B / P$

DIPF0037

DIFP0038

DIF P0O39

DIF POO40

DIFFOO41

DIP POO 42

DIP P 0043

DIPPO044

DIPP0045

DIPF0046

DIPF0047

DIP P0048

DIPFO049

DIF P0050

DIF P0051

D.IFP0052

DIFP0053

DIPPO054

DIPE0055 \%

DIFF0056

DIPF0057

DIF P0058

DIFP0059

DIF $0060^{\circ}$

DIF P0061

DIPF0062

DIPP0063

DIF 0064

DIP P0065

DIFP0066

DIPF0067

DIFF0068

DIFF0.069

DIPF0070

DIPF 0071

DIPF0072 
$V V=Q U A L * 3.565 * Z * T B / P$

$H G=K B * A R E A * A R E A /(V G * M G+V V)$

$H A=H A * H G /(H A+H G)$

$104 \mathrm{DQDT}=\mathrm{HA} *(\mathrm{TF}-\mathrm{T})$

110 IF (NX.EQ.1) GO TO 30

DVTDT $=(P-P O) / A . I$ GO TO 40

$30 \quad \mathrm{DVTDT}=S S^{*} \mathrm{U}$

40 IF (QUAL.GE.1.) GO TO 314

IF (QOAL.LE.QCR.AND.P.IE.PSAT) GO TO 114

IP (NNS.GT.O) GO TO 113

C

C******* SINGLE PHASE CALCULATIONS

C

$109 Y(9)=0$.

$Y(10)=0$.

$B S=B 0+B 1 * T+B 2 * T 2+B 3 * T 3$

$C P=C O+C 1 * T+C 2 * T 2$

$B T=B S+T * V * A P * * 2 /(C C * C P)$

GO TO 111

314 A $=1 . / \mathrm{T}$

$B T=1 . / P$

$Y(9)=1$.

$\mathrm{CP}=0.6$

$111 \mathrm{Z} 1=B T * V+\triangle G M A X * V G / P+G \nabla P+D E F O R D$

$\mathrm{Z} 2=\mathrm{T} * \mathrm{~V} * \mathrm{AP} / \mathrm{CC}$

$\mathrm{Z} 3=\mathrm{A} P * V+M G M A X * R G /(2 . * \mathrm{P})-\mathrm{Z} 1 * \mathrm{C} / \mathrm{Z} 2$

$\mathrm{Z} 4=\mathrm{RG} * M G M A X /(2, * \mathrm{P} * \mathrm{CF}$ 的) $-21 / 22$

$123 \mathrm{DTDT}=(24 * \mathrm{DQDT}+\mathrm{DVTDT}) / 23$

$D P D T=(C P * D T D T-D Q D T) / Z 2$

$D V D T=\nabla *(-B T * D P D T+A P * D T D T)$

GO TO 121

C

C********* TWO-PHASE CALCULATIONS

$* * * * * * * * * * * * * * * * * * * * * * * * * * * * * * * * * * * *$

$113 \mathrm{HG}=\mathrm{HGO}+\mathrm{HG} 1 * \mathrm{~T}+\mathrm{HG} 2 * \mathrm{~T} 2+\mathrm{HG} 3 * \mathrm{~T} 3$

DIPF0073

DIF F0074

DIFF0075

DIFP0076

DIPF 0077

DIFF0078

DIFP0079

DIPF0080

DIFP0081

DIFF0082

DIPF0083

DIF.F0084

DIFF0085

DIFF0086

D IF P0087

DIFF0088

DIFF0089

DIFP0090

DIPFO091

DIPFO 092

DIPP0093

DIE P0094

DIFF0095

DIF P0096

DIFF0097

DIP P0098

DIFF0099

DIFP0100

DIPE0101

DIPF.0102

DIF P0 103

DIPPO104

DIPPO 105

DIP P0 106

DIPPO107

DIP P0 108 
$H \mathrm{~L}=\mathrm{HLO}+\mathrm{HL} 1 * \mathrm{~T}+\mathrm{HL} 2 * \mathrm{~T} 2+\mathrm{HL} 3 * \mathrm{~T} 3$

$H G L=H G-H L$

DIFE0109

IP (HGL.LE.0.) GO TO 215

DIF FO 110

DIFF0111

$H G L=H G L+C P G *(T B-T)$

DIPFO 112

APINT=AO*(T-TLO) A $1 *(T 2-T L O * * 2) / 2 * A 2 *(T 3-T L O * * 3) / 3 * A 3 *(T 4-$ $1 \mathrm{TLO} 0 * 4) / 4$.

$V L=V L O * D E X P(A P I N T)$

$V G L=V V-V I$

$\mathrm{DHG}=\mathrm{HG} 1+2 . H G 2 * \mathrm{~T}+3 . * \mathrm{HG} * \mathrm{~T} 2-\mathrm{CPG} *(0.5-\mathrm{DTP})$

$\mathrm{DHL}=\mathrm{HL} 1+2 * * \mathrm{HL}$ 2*T+3.*HI $3 * \mathrm{~T} 2$

$\mathrm{DP}=\mathrm{PSAT} *(\mathrm{BB} / \mathrm{T} 2-\mathrm{DD} / \mathrm{T})$

$\mathrm{DZ}=\mathrm{ZZ} 1+2 \cdot \mathrm{ZZ2} * \mathrm{~T}+3 . * \mathrm{ZZ} 3 * \mathrm{~T} 2$

$D V G=3.565 / P *(D Z * T B+(1 .+D T F) * Z / 2 .-Z * T B * D P / P)$

$D V L=A P * V L$

$F D H=Q U A L * D H G+(1.0-Q U A L) * D H L$

$F D V=Q U A L * D V G+(1.0-Q O A L) * D V L$

$\mathrm{HV}=\mathrm{HGL} / \mathrm{VGL}$

$\mathrm{G} 1=\mathrm{GMAX} * \mathrm{VG} / \mathrm{P}+\mathrm{GVP}+\mathrm{DEFORM}$

$\mathrm{G} 4=\mathrm{MGMAX} * \mathrm{RG} /(2 \cdot * \mathrm{P})$

$G 2=F D H-H V *(F D V+G 4)+D P *(H V * G 1-V / C C)$

$\mathrm{G} 3=-\mathrm{H} \nabla * \mathrm{G} 4 / \mathrm{CF}$

$\mathrm{DTDT}=((1 .+\mathrm{G} 3) * \mathrm{DQDT}-\mathrm{HV} * \mathrm{DVTDT}) / \mathrm{G} 2$

$\mathrm{DVDT}=\mathrm{DVTDT}+(\mathrm{G} * \mathrm{DP}-\mathrm{G} 4) * \mathrm{DT} \mathrm{DT}+\mathrm{G} 4 * \mathrm{DQDT} / \mathrm{CP}$

$\mathrm{DPDT}=\mathrm{DP} * \mathrm{DTDT}$

DQUAL $=(D V D T-F D V * D T D T) / V G L$

$D V V G=D Q U A L * V V+O U A L * D V G * D T D T$

121 DTFDT $=-D Q D T / C F H$

IF $(\mathrm{NX} \cdot \mathrm{EQ} \cdot \mathrm{O})$ GO TO 127

$126 \mathrm{DUDT}=-\mathrm{GC}+\mathrm{PCONST} *(\mathrm{P}-\mathrm{PINF}) /(\mathrm{SCD} * \mathrm{SCL})$ $\mathrm{DDDT}=\mathrm{U}$

127 NOPN S=NOEN S + 1
DY $(1)=D T D T$
$D Y(2)=D P D T$
DY (3) =DVDT
DY $(4)=D T F D T$

DIPF0113

DIRFO114

DIFPO115

DIPF0116

DIPEO117

DIPF0118

DIFFO 119

DIEF0120

DIFF0121

DIF F 0122

DIFF012.3

DIP FO 124

DIFE0125

DIFFO126

DIPF0 127 용

DIF PO 128

DIFF0129

DIPFO 130

DIF F0131

DIFPO 132

DIPFO133

DIFFO134

DIFP0135

DIFF0136

DIFP0137

DIFP0138

DIFPO 139

DIPPO 140

DIPFO141

DIFFO 142

DIFFO143

DIFPO 144 
$D Y(5)=D \cup D T$

- DY $(6)=D D D T$

$\operatorname{DY}(7)=\mathrm{P} * \mathrm{DV} D T$

DY $(8)=$ P

DY $(9)=D Q U A L$

$D Y(10)=D V V G$

RETU RN

215 GRITE (NOUT,9) T,HG,HL STOP

114 IF (NNS.EQ.0) GO TO 214 HRITE (NOUT, 8)

214 NNS $=0$ GO TO 109

END

DIPE0148

DIFFO 149

DIF P 0150

DIFP0151

DIFFO 152

DIFF0 153

DIR FO 154

DIF F0 155

DIPEO 156

DIFFO 157

DIFFO 158 
SUBROUTINE DFBND (N, X, Y,DY, H, EPS, ERR, JM, HHIN,JP, YE, ISUIT)

IMPLICIT REAL*8 (A-H,O-Z)

$R E A L * 8 \quad X, Y, D Y, H, E P S, E R R, H M I N$

DIMENSION Y (20), YE (20), ERE (20), Y $1(20), D Y(20), S(20), R(20)$

$J B L=-1$

$\mathrm{JMAX}=\mathrm{JP}$

IF (ISHIT . GT. O) GO TO 10

CALL DIPI (N,X,YE,DY ,H,HMIN,EPS,JM,S,R,KK,Y 1,JP,JMAX,JBL,FC) GO TO 15

10 CALL DDIF (N, X, YE, DY, H, HMIN, EPS, JM, S, R, KK, Y 1. JP, JMAX,JBL, PC)

15 DO $20 \quad I=1, N$ $A=Y E(I)-Y(I)$

$B=Y 1(I)-Y(I)$

IF (DABS (A) -DABS (B)) 30.30 .40

$30 \operatorname{ERR}(I)=B$

GO TO 20

$40 \operatorname{ERR}(I)=A$

20 CONTINUE

$\mathrm{X}=\mathrm{X}+\mathrm{H}$

$\mathrm{H}=\mathrm{PC} * \mathrm{H}$

RETURN

END

DFBN0001

DFB N 0002

DFBN0003

DPB N 0004

DPBNO005

DPBNO006

DPBN 0007

DFB N0008

DFBNO009

DPBNOO 10

DPBNO011.

DFBNOO12

DFB N 0013

DFBNOO 14

DFBNO015

DFBN 0016

DFBNO017

DPBNO018

DPBNOO19:

DFB N 0020

DFBNO0 2.1

DPB N 0022 
$D(10)=576 . D 0$

3 DIPIO004 DIF I0005 DIPI0006

5 DIFI0007

6 DIPI0008 DIFI0009

D IP I0010

7 DIFI0011

8 DIPI0012

9 DIPI0013

10 DIPIO0 14

11 DIFI0015.

12 DIPI0016.

13 DIF I0017

14 DIPI0018

15 DIPIO019

16 DIFI0020

17 DIPI0021

DIFI0022

18 DIPI0023

19 DIPIO024

21 DIFI0025

22 DIPI0026

23 DIFI0027

24 DIFI0028

25 DIP I0029

26 DIPI0030

27 DIPIO031

28 DIFI0032

29 DIPI0033

30 DIPIO0 34

31 DIPI0035

32 DIPI0036 
8

$$
D(12)=2304 . D O
$$

$K O N V=+1$

$\operatorname{IF}(J \cdot L E \cdot(J M / 2))$ KONV $=-1$

IF $(J: L E \cdot(J M+1))$ GOTO 10 $I=J M+1$

$D(L)=4 \cdot D O * D(L-2)$

$\mathrm{PC}=.7071068 * \mathrm{PC}$

GOTO 12

$$
\mathrm{L}=\mathrm{J}
$$

$D(L)=D F L O A T(M * M)$

$P C=1.0+D$ FLOAT $(J M+1-J) / 6.0$

12

$$
M=M+M
$$

$G=H / D F L O A T(M)$

$B=G+G$

$\mathrm{J} P=\mathrm{J}$

IF ((JBH.LT.0) .OR $\cdot(J \cdot G E \cdot(J A A X-1)))$ GOTO 16

DO $14 I=1, \mathrm{~N}$

$Y M(I)=Y H(I, J)$

$Y L(I)=Y G(I, J)$

$S(I)=S G(I, J)$

14 CONTINUE

$$
\text { GOTO } 25
$$

16 DO $18 \quad I=1, N$

$Y L(I)=Y A(I)$

$Y M(I)=Y A(I)+G * D Z(I)$

$S(I)=S A(I)$

18

CONTINUE

$\mathrm{KH}=\mathrm{M} / 2$

$\mathrm{XU}=\mathrm{X}$

DO $24 \quad K=2, M$

$\mathrm{X} D=\mathrm{XU}+\mathrm{G}$

CALL DIFFUN (XU,YM;DY)

DO $20 \quad I=1, N$

$U=Y L(I)+B \star D Y(I)$

$Y L(I)=Y M(I)$

$Y M(I)=U$
33 DIPI0037
34 DIPI0038
35 DIP I0039
37 DIPI0040
39 DIP I0041
40 DIFI0042
DIPI0043
42 DIPI0044
43 DIPI0045
DIP I0046
DIPI0047
46 DIFI0048
DIFI0049
48 DIPI0050
DIFI0051
49 DIPI0052
51 DIPI0053
52 DIPI0054
53 DIF I0055
54 DIPI0056 i
55 DIP I0057
56 DIFI0058
57 DIPI0059
58 DIF I0060
59 DIPI0061
60 DIP I0062
61 DIFI0063
62 DIPI0064
63 DIPIO065
64 DIF I0066
65 DIPI0067
66 DIPI0068
67 DIP I0069
68 DIFI0070
69 DIF I0071
70 DIFI0072 


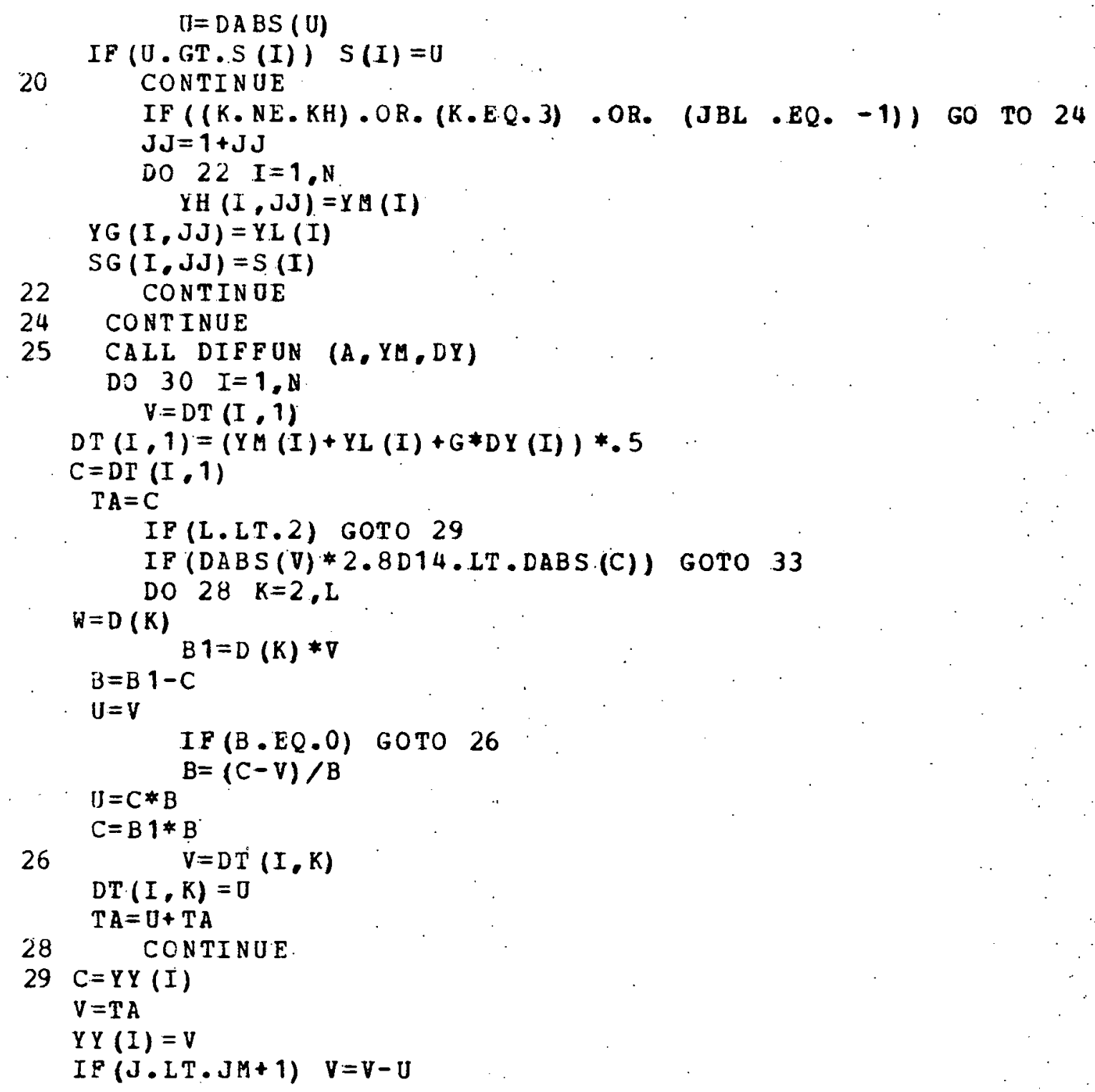

71 DIPI0073

72 DIPI0074

74 DIPI0075 DIPI0076

77 DIFI0077

78 DIF I0078

79 DIFI0079

80 DIP I0080

81 DIFI0081

82 DIFI0082

83 DIFI0083

84 DIFI008.4

85 DIFI0085

86 DIPI0086

87 DIE I0087

88 DIPI0088

89 DIFI0089

90 DIFI0.090 DIPI0091

96 DIPI0092 DIFI0093

9.7 DIF I0094

98 DIFI0095

99 DIP I0096

100 DIFI0097

102 DIFI0098

103 DIFI0099

104 DIP I0 100

105 DIPI0101

106 DIFI0 102

107 DIP.I0 103

108 DIPI0104 D IF I0 105 DIPI0 10.6 DIPI0107 DIPI0108 
$V=V+V-C$
$R(I)=D A B S(I(I)-T A)$

$I P(J B L \cdot E Q \cdot 1) Y(I)=T A$

IF (J BL,$E Q \cdot-1) \quad Y(I)=C$

$Y U(I)=V$

IF (DABS $(V-C) \quad$ GT. W *EPS*S (I) ) KONV=-1

30

CONTINUE

IF (KONV.GE.O AAND. (JBL •EQ. 1)) GO TO 34

$D(3)=4 . D O$

$D(5)=16 \cdot D 0$

$\mathrm{JBO}=-\mathrm{JBO}$

$M=J R$

$\mathrm{J} R=\mathrm{JS}$

$J S=M+M$

$D(7)=64 . D 0$

$D(9)=256 . D 0$

$D(11)=1024 . D O$

32 CONTIN UE

IP (JBL $\cdot E Q \cdot-1)$. GO TO 34

$\mathrm{JBH}=-\mathrm{JBH}$

33 IF (DABS (H) . LE.HMIN) GOTO 35

$\mathrm{H}=\mathrm{H} / 2$.

IF (DABS (H) . GE.HMIN) GOTO 4

$H=D S I G N(H M I N, H)$

GOTO 3

34 RETURN

$.35 \mathrm{KK}=-1$

GOTO 34

ENTRY DDIF (N,X,Y, DY, H,HMIN, EPS,JM, S,R,KK,YO,JP,JMAX,JBL; PC)

DO $36 I=1, N$

$Y(I)=Y A(I)$

36 CONTINUE

GOTO 3

END
DIPIO 109

112 D IP IO 110

DIPI0111

DIPIO 112

DIPI0113

DIPIO 114

116 DIPI01.15

DIPIO 116

119 DIPIO117

120 DIFI0118

121 DIPIO119

122 DIFI0120

123 DIFIO 121

124 DIPIO122

125 DIFI0123

126 DIF IO 124

127 DIPI0125

128 DIFIO 126

DIPI0127

129 DIPIO128

130 DIPIO 129

132 DIFIO 130

133 DIFIO131

DIPI0132

136 DIPI0 133

139 DIPI0134

140 DIFI0135

141 DIFI0136

DIEI 0137

143 DIF I0 138

144 DIPI0139

145 D IF IO 140

146 DIFI0141

154 DIPIO 142 
REFERENCES (APPENDIX A)

1. E.P. Hicks, D.C. Menzies, "Theoretical Studies on the Fast Reactor Maximum Accident," Proc. Conf. on Safety, Fuels, and Core Design in Large Fast Power Reactors, Oct. 11-14, 1965, ANL-7120, 654-670.

2. A. Padilla, Jr., "Transient Analysis of Fuel Sodium Interactions," Trans. Amer. Nucl. Soc. 13 (1), 375 (1970).

3. D.H. Cho, R.O. Ivins, R.W. Wright, "A Rate Limited Model of Molten Fuel-Coolant Interactions: Model Development and Preliminary Calculations," ANL 7919, March 1972.

4. T.G. Theofanous and H.K. Fauske, "An Energy Dissipation Mechanism Due to the Cladding of the Fission-Gas Plenum During an HCDA," Trans. Amer. Nucl. Soc. 16, 195 (1973).

5. W.L. Chen, D.H. Cho, "Heat Loss to Cold Structure During a FuelCoolant Interaction," ANL 8129, September 1974.

6. D.H. Cho, W.L. Chen, R.W. Wright, "A Parametric Study of Pressure Generation and Sodium Slug Energy from Molten Fuel Coolant Interactions, ANL 8105, August 1974.

7. M. Corradini, A. Sonin, N. Todreas, "A Proposed Heat Transfer Model to Describe Experimental Results in the Stanford Research Institute Tests," to be published.

8. G.H. Golden, et al., "Thermophysical Properties of Sodium," ANL 7323.

9. Y.W. Chang, J. Gvildys, S.H. Fistedis, "Analysis of Primary Containment Response Using a Hydrodynamic-Elastic-Plastic Computer Code," Nucl. Engr. and Design 27(174), 155-175 
10. W.L. Chen, D.H. Cho, M.S. Kazimi, "Recent Additions to the Parametric Model of Fue1 Coolant Interactions", ANL 8130, September 1974.

11. Final Safety Analysis Report for the FFTF, December 1975.

12. Preliminary Safety Analys is Report for the CRBR, July 1975. 


\section{APPENDIX B: \\ SOLIDIFICATION CALCULATIONS \\ (APPROXIMATE MIXING TIME CONSTANTS)}

A number of different cases were run for the solidification rates of $\mathrm{UO}_{2}, U C$, and $U N$. From these calculations, approximate mixing time constants were determined for the two solidification modes as mentioned in the text of this report. Of these calculations, only a limited number were used in the text. Therefore, to document the results for all cases, Tables B.1, B.2, and B. 3 are provided.

A listing of the computer code used to make these calculations is included following Table B.3

TABLE B. 1 Approximate Mixing Time Constants for $\mathrm{UO}_{2}\left(T_{f}=2800^{\circ} \mathrm{C}\right)$.

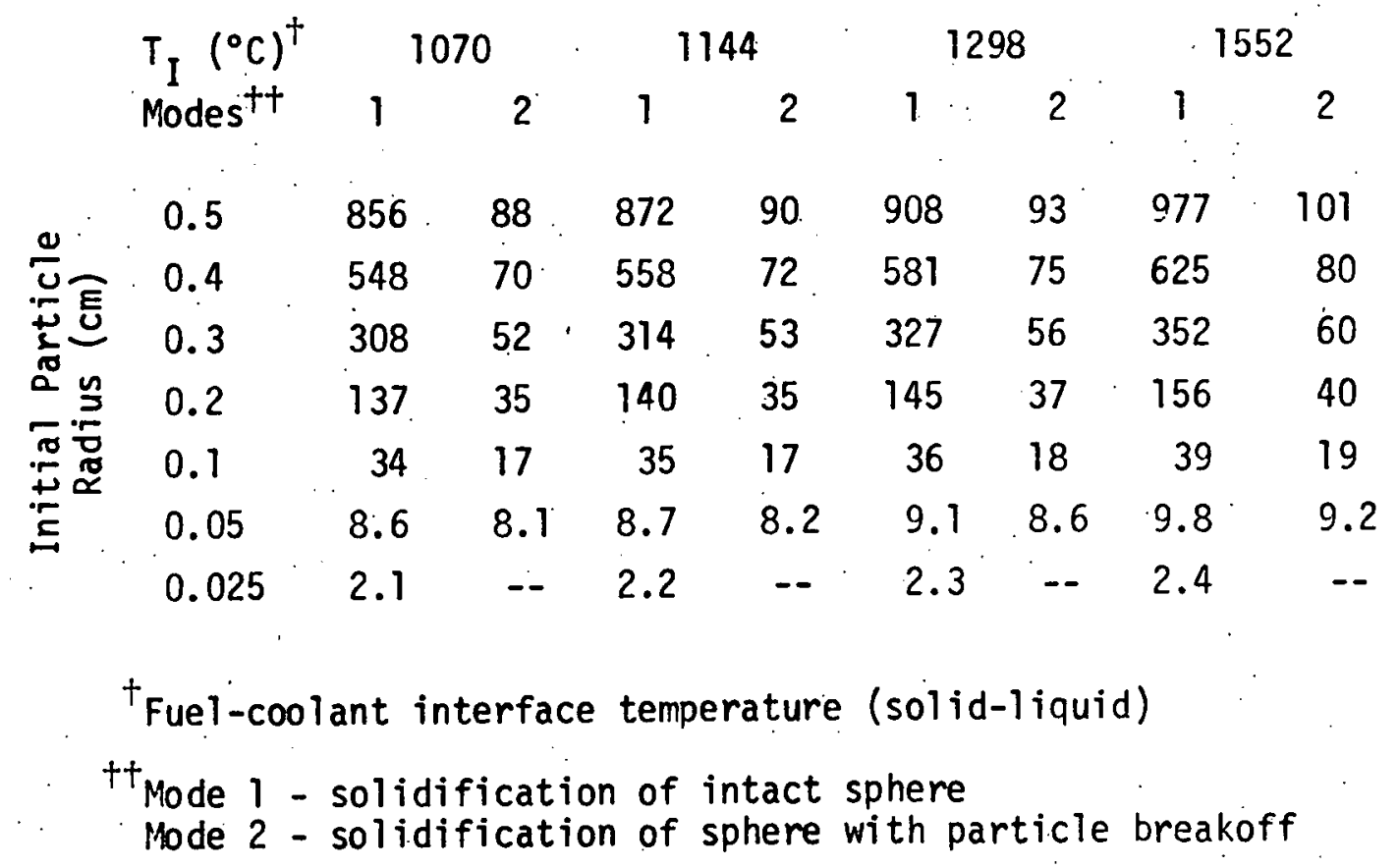


TABLE B.2. Approximate Mixing Time

$$
\text { constants for } U C\left(T_{f}=2530^{\circ}\right)
$$

$T^{1}\left({ }^{\circ} \mathrm{C}\right)$

1569

1715

1831

Mode 1 Intact Breakoff. Intact Breakoff Intact Breakoff

\begin{tabular}{|c|c|c|c|c|c|c|}
\hline 0.5 & 149 & 16 & 169 & 18 & 191 & 20 \\
\hline 0.4 & 95 & 12 & 108 & 14 & 122 & 16 \\
\hline 0.3 & 54 & 9. & 67 & 11 & 69 & 12 \\
\hline$\cong 0.2$ & 24 & 6 & 27 & 7.0 & 30 & 7.9 \\
\hline $\begin{array}{lll}\pi & 0.1\end{array}$ & 6.0 & 3.0 & 6.8 & 3.4 & 7.6 & 3.8 \\
\hline 0.05 & 1.5 & 1.4 & 1.7 & 1.6 & 1.9 & 1.8 \\
\hline 0.025 & 0.4 & -- & 0.4 & -- & 0.5 & -- \\
\hline
\end{tabular}

TABLE B.3. Approximate Mixing Time Constants for $\operatorname{UN}\left(T_{f}=2860^{\circ} \mathrm{C}, R_{f}=0.0064 \mathrm{~cm}\right)$

$T\left({ }^{\circ} \cdot \mathrm{C}\right)$ Mode
1884 Intact Breakoff
2028 Intact Breakoff Intact Breakoff

\begin{tabular}{|c|c|c|c|c|c|c|}
\hline 0.5 & 140 & 15 & 158 & 17 & 178 & 19 \\
\hline$E^{0.4}$ & 90 & 12 & 101 & 13 & 114 & 15 \\
\hline 0.3 & 50 & 8.7 & 57 & 9.9 & 64 & 11 \\
\hline$\cong 0.2$ & 22 & 5.7 & 25 & 6.5 & 28 & 7.3 \\
\hline 0.1 & $6^{\circ}$ & 2.8 & 6.3 & 3.2 & 7.1 & 3.6 \\
\hline 0.05 & 1.4 & 1.3 & 1.6 & 1.5 & 1.8 & 1.7 \\
\hline 0.025 & 0.4 & -- & 0.4 & -- & 0.4 & -- \\
\hline
\end{tabular}


THIS RROGRAM CALCULATES THE RATE OP SOLIDIFICATION IN A SPHERE BY THE ADAM'S APPROXIMATION. THERE IS A CHOICE OP THO SOLIDIFICATION MODES; SOLIDIFICATION OP AN INTACT SPHERE OR A SPHERE HITH A PIXED PARIICLE BREAKOPF. MIXING TIME CONSTANTS THAT RELATE TO THE

CHO-WRIGUT MODEL ARE ALSO GIVEN.

INPUT VARIABLES

FIRST CARD (FORMAT-6F 10.4.2I5)

SPHT $=$ SPECIPIC HEAT (CAL/GH-C)

$S L=L A T E N T$ HEAT OP PUSION(CAL/GM)

$T M=M E L T I N G$ POINT OP SPHERE'S MATERIAL $(C)$

$T I=I N T E R F A C E$ TEMPERATURE (C)

TS $=$ THERMAL DIFFUSIVITY $(\mathrm{CM} * \mathrm{CM} / \mathrm{SEC})$

A $1=$ STARTING POINT POR CALCULATIONS $(0.00001)$

ISUB=NUMBER OF SUBDIVISIONS FJR NUMERICAL INTEGRATION.(5)

NN = NUMBER OF RADIAL SECTIONS (PRINTOUT PURPOSES=30)

SECOND CARD (FORMAT-7F10.4)

RI (I) = INITIAL RADIUS OF MOLTEN SPHERE ( UP OO 7 RADII IN CH.)

THIRD CARD

ICHK=SOLIDIPICATION MODE ( 0 =INTACT SPHERE, 1=PARTICLE BREAKUFF) RP=RADIUS OF FINAL PARTICLE IN CM. (NEEDED FOR BOTH MODES)

NOTE: THERE CAN BE AS MANY SECOND AND THIRD CARDS AS NEEDED. LAST TWO CARDS MUST BE BLANK.

EXTERNAL DTDAF

DIMENSION TIME $(100)$, RATIO $(100)$, RI (7)

COMMON R,S PHT,TM;TI, SL,TS,A 1

500 FORMAT $(6$ F10.5.2I5)

510 FORMAT $(7 P 10.4)$

520 PORMAT (I. $10, \mathrm{~F} 10.4)$

FORMAT (1' 9X, SURFACE AREA GENERATION WITH TIME'./10X,'INITIAL PA
MAINO001

MAIN0002

MAIN0.003

MAINOOOL

MAINOOO5

MAIN0006

MAINO007

MAIN0008

MAIN0009

MAINOO 10

MAINO011

MAINO0 12

MAIN0013

MAINO014

MAI N0015

MAINO016

MAIN0017

MAIN00.18

MAI N0019

MAINO020

MAINO021

MAINO022

MAINO023

MAIN0024

MAINO025

MAIN0026

MAIN0027

MAINO028

MAIN0029

MAINOO 30

MAIN0.031

MAINO032

MAINO033

MAINO034

MAINOO35

MAINOO36 
1RTICLE RIDIUS ',F6:3/10X,'PINAL PARTICLE RADIUS ',P6.4)

MAI N 0037

540 PORMAT (//16X,'TIME'.4X,'RADIUS',6X.'AREa',5X,'RATIO')

550 FORMAT $(10 X, 3$ F $10.4, F 10.2)$

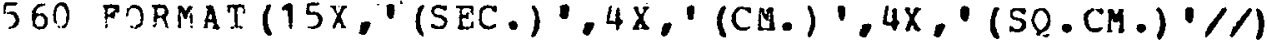

570 EORMAT ( $10 \mathrm{X}$, 'ASSUMING PARTICLE BREAKOFF')

580 PORMAT ( $10 \mathrm{X}$, 'ASSOMING NO PARTICLE BREAKOPP')

READ (5,500) SPHT, SI, TM, TI, TS, A 1, IS UB, NN

10 READ $(5,510)$ (RI (I), I = 1,7)

READ $(5,520)$ ICHK, RF

DO $100 \cdot I=1,7$

IF (PII I ) . EQ.0.0) GO TO 12

GO TO 14

12 IF (I.EQ.1) GO TO 9.99

GO TO 10

14 WRTTE $(6,530)$ RI (I), BF

IF (ICHK. EQ. O) GO TO 20

15 XRITE $(6,570)$

GO TO 25

20 WRITE $(6,580)$

25 WPITE $(6,540)$

WRITE $(6.560)$

$R=R I(I)$

$T=0.0$

$A R E A=0.0$

$\mathrm{J}=0$

I S TOP $=0$

VOL $1=4 *(3.14159) * R * 3 / 3$.

.EN D $=R$

AREAP $=3 *$ VOI $1 / \mathrm{RF}$

30 START $=$ END

$\mathrm{J}=\mathrm{J}+1$

IF (ICHK.EO.O) GO TO 40

$\mathrm{R}=\mathrm{EN} \mathrm{D}$

$E N D=S T A R T-2 * R F$

IF (END.EQ.0.0) END $=0.00001$

IF (END.LT.O.C) GO TO 55

MAINO038

MAINO039

MAINOO 40

MAIN0041

MAIN0042

MAINO043

MAINOO44

MAIN0045

MAI N0046

MAINO047

MAINOO48

MAINO049

MAINO050

MAINO051

MAIN0.052

MaINO053

MAIN0054

MAIN0055

MAIN0056

MAINO057

MAINO0 58

MAI N0059

MAINO060

MAIN0061

MAIN0062

MAIN0063

MAIN0064

MAIN0065

MAIN0066

MAI N0067

MAIN0068

MAIN0069

MAIN0070

MAIN0071

MAINO072 
DV OL $=4 * 3.14159 *(\mathrm{START} * * 3-\mathrm{END} * 3) / 3$

MAI N0073

GO TO 50

$40 \cdot X=$ FLOAT (J)

DVOL $=$ VOL $1 /$ FLOAT (NN)

$S V O L=X * D V O L$

IF (SVOL.GT.VOL1) GO TO 55

$E N D=(($ VOL $1-X * D V O L) /(4 . *(3.14159)) * 3) * *$.

I $P(E N D . E 0.0 .0) \quad E N D=0.00001$

$50 D T=S I M P S$ (START, END, ISHB, DTDAP)

$\mathrm{T}=\mathrm{T}+\mathrm{DT}$

$\operatorname{TIME}(\mathrm{J})=\mathrm{T}$

$A R E A=A R E A+D V O L * 3 / R F$

RATIO $(J)=A R E A / A R E A F$

WRITE $(6,550) T, E N D, A R E A, R A T I O(J)$

IP(ISTOP.EQ.O) GO TO 30

55 DO $70 \mathrm{~J}=1,8.0$

IE(RATIO(J).GT.0.632) GO TO 60

GO TO 70

60 FRACT $=(0.632-\operatorname{RATIO}(J-1)) /(\operatorname{RATIO}(J)-\operatorname{RATIO}(J-1))$

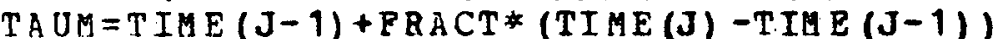

GO TO 80

70 CONTINUE

80 TAUM $=$ TAUM $* 1000$ ตRITE $(6,590)$ TAUM

590 FORMAT $(/ / 10 X$, THE VALUE OF TAO SUB $M=1, F 9.3, \circ$. MSEC')

100 CONTINUE

G) To 10

999 STOP

END

AIN 0074

MAIN 0075

MAIN0076

MAIN0077

MAIN0078

MAIN0079

MAIN0080

MAIN0081

MAIN0082

MAIN0083

MAIN0084

MAIN0085

MAIN0086

MAIN0087

MAIN0088

MAINOO 89

MAINOO90

MAIN009.1

MAIN0092

MAINO093

MAIN0094

MAINO095

MAIN0096

MAIN0097

MAIN0098

MAIN0099

MAIN0100

MAINO101 
FUNCTION DTDAF(X)

COMMON R,SPHT,TM,TI,SL,TS,A 1

DTDAO001

$D E L=R-X$

IF (DEL.LT.A1) GO TO 10

$\mathrm{Y}=\mathrm{X}$

GO TO 15

$10 \quad \mathrm{Y}=\mathrm{R}-\mathrm{A} 1$

$15 \mathrm{DENOM}=2$. * TS*SPHT* $(\mathrm{TM}-\mathrm{TI})$

$\mathrm{Z}=1.0+((4 . * \mathrm{R} * \mathrm{SPHT}) /(3 . * \mathrm{Y} * \mathrm{SL})) *(\mathrm{TM}-\mathrm{TI})$

$D E N U M=(S L * Y-(S L * Y * * 2) / R) *.(1.0+S Q R T(Z))$

DTDAF = DENDM $/$ DENOH* $(-1.0)$

R.TURN

END

DTDA000.2

DTDAO003

DTDA0004

DTDA0005

DTDA0006

DTDA 0007

DTDA0008

DTDA0009

DTDA0010

DTDADO 11

DTDA0012

DTDA0013 
FUNこTION $\operatorname{SIMPS}(D, E, N, F)$

SIMP0001

SIMP0002

SIMP 0003

$\mathrm{H}=\mathrm{T} W \mathrm{OH} / 2$.

SIJMED $=0.0$

SUMI $D=0.0$

D. $10 \quad K=1, N$

$X=D+F L O A T(K-1)$ * TWOH

SIMP0004

SIM P0005

SIMP0006

$S U M E D=S U M E D+F(X)$

SUM I $D=S U M I D+F(X+H)$

S.IMP000.7

SIMP0008

SIMPO009

SIM P0.010

SIMPO011

SIIPO012

RETURN

SIMP0013

END 
APPENDIX C:

LOWER BOUND ON FINAL FUEL PARTICLE SIZE

\section{C.1 Introduction}

In the analysis of the mixing requirements in an FCI for the limiting expansion work potential at slug impact, it is necessary to input a single final fuel particle radius into the FCI-B version of the ANL parametric code (see Appendix A). This input parameter is one of the most important inputs to the model given the initial conditions of the fuel and sodium. It is used to determine the final heat transfer area of the fuel. Consequently, the fuel particle size will have a direct impact on the overall heat transfer rate and the resulting energetics. For a given mixing time constant, the smaller the fuel particle radius, the greater the work potential at slug impact as a result of an FCI. For a fixed work potential, the relationship between the fuel particle radius and mixing time constants can be seen in Figure C.l. Given smaller fuel radii, mixing time constants need not be as small or the overall mixing of fuel and sodium need not be as rapid to produce equivalent work potential. Essentially, if no lower bound is established for the fuel particle size, any mixing time constant, given an extremely small fuel radius, could produce the limiting work potential at slug impact. Therefore, to provide a conservative (highest) estimate of the mixing requirements for the limiting case, without using unrealistic values for the fuel particle size, a lower bound for the final fuel particle radius must be established. 
In actual FCI conditions, fuel fragmentation results in a fuel particle. size distribution rather than a single particle size. Therefore, the finest particle size distribution must first be determined from which a single equivalent fuel particle size can then be determined.

At this time, no analytical method can accurately predict the smallest distribution of fuel particles. Various methods exist that predict fuel particle sizes $(1,2)$ but none can be expected to provide the entire distribution. However, a review of the experimental fuel fragmentation data has resulted in a mathematical formulation for the finest fuel particle size distribution.

In a Japanese paper by Hiroshi Mizuta (3), a summary of the TREAT S-series in-pile data, the Armstrong out-of-pile data and the SPERT CDC in-pile data with the results of 30 additional experimental runs by the PNC was compiled (Figure C.2). From this data, Mizuta fitted by a least square method a log-normal distribution to the finest (worst case) fuel particle distribution in the range of $20-90 \%$ mass of particles smaller than the indicated diameter. This is shown as the darker straight line in Figure C.2. The equation for this density function is

$$
f_{M}(R)=58.1 \exp \left[-\frac{(\log 2 R-2.27)^{2}}{0.944}\right]
$$

Where $R$ is the radius of fuel particle in microns. A graphical representation of this density function can be seen in Figure C.3. 


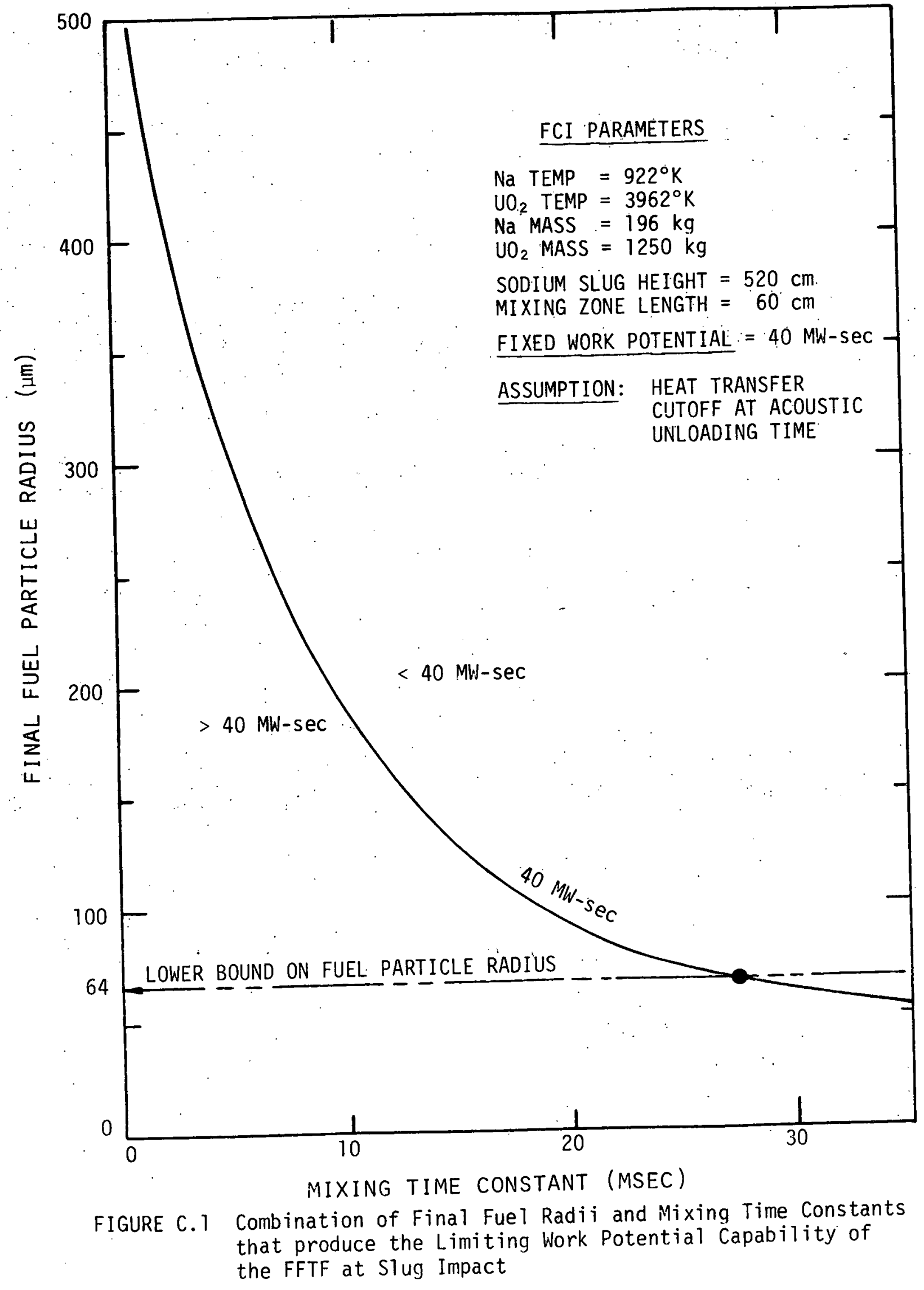




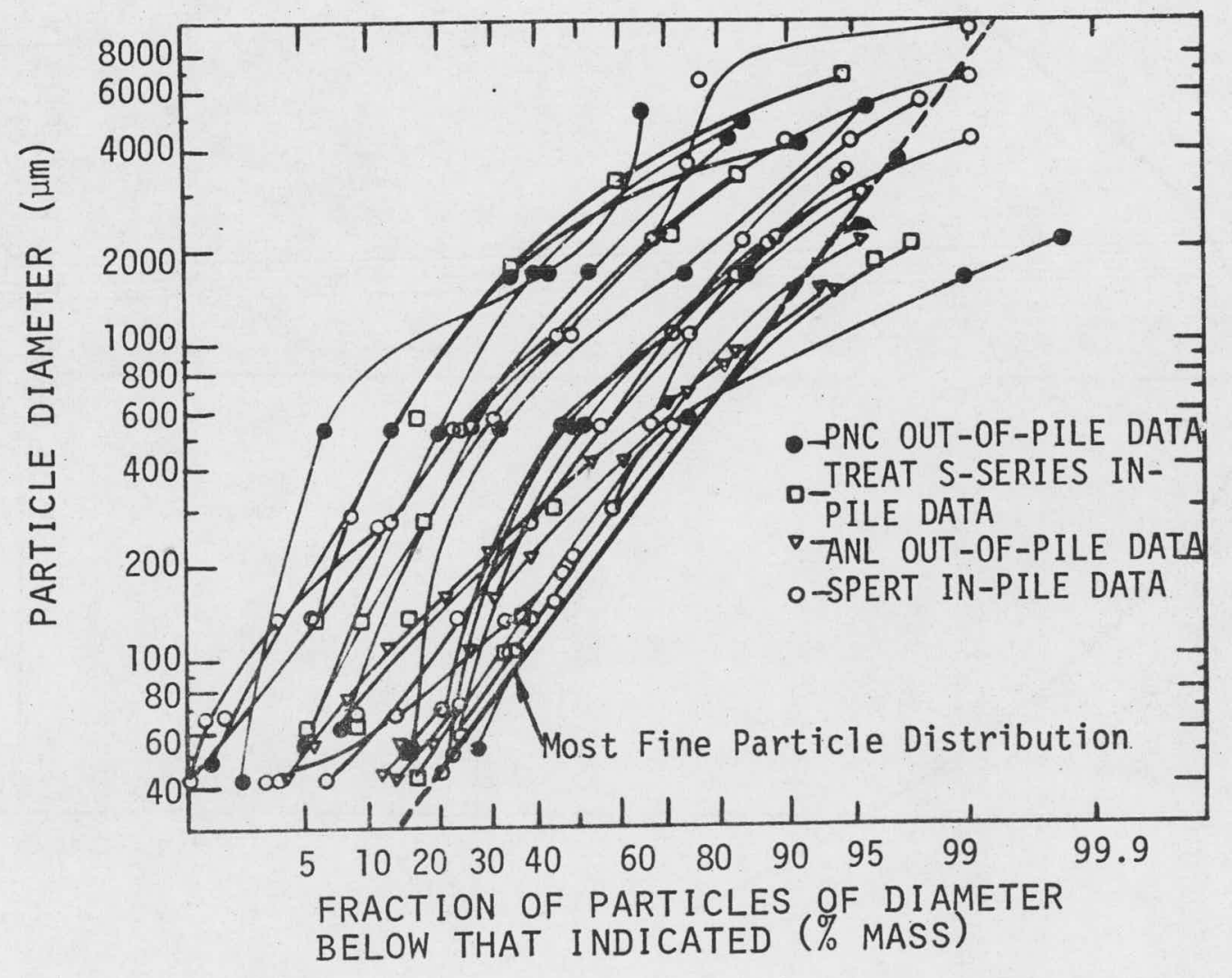

FIGURE C.2 Finest Particle Size Distribution 
FIGURE C. 3 Mizuta's Finest Fuel Particle Distribution

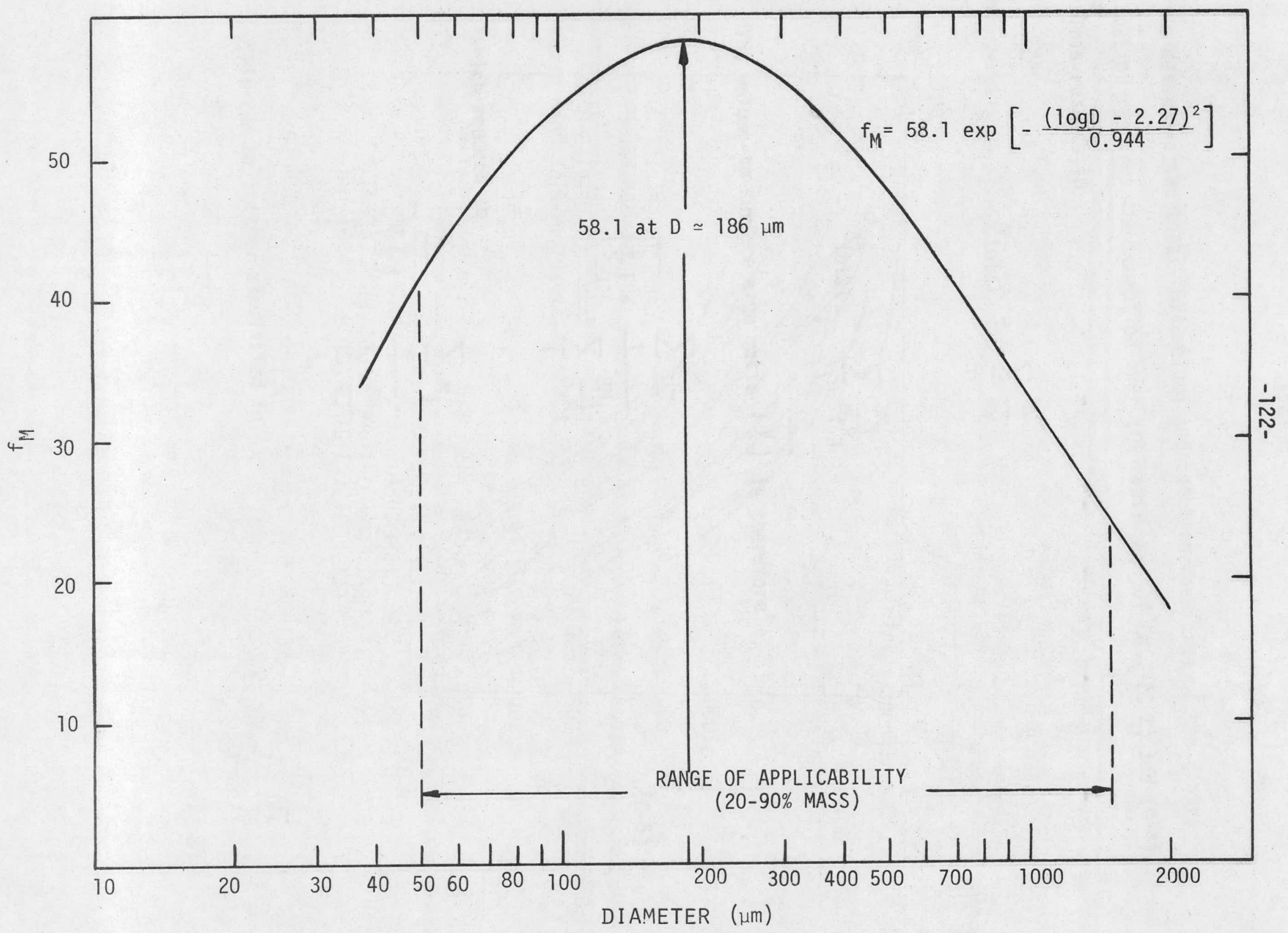




\section{C.2. Translating the Finest Particle Size Distribution to a Single Particle Size}

Having an equation that represents the finest fuel particle distribution observed following an FCI, the next step involves the translation of this distribution to an effective single particle size. To be consistent with the parametric model, the single fuel particle should match the heat transfer characteristics of the particle distribution, namely, the surface area per gram of fuel.

One means of doing this is to establish from the distribution the surface area of all the fuel particles. This value can then be divided by the mass of fuel to provide the average surface area per gram of fuel. Mathematically, this can be described by the following method.

Assume that $M_{i}$ represents the mass of particles having a radius $R_{i}$. The volume of these particles can then be described by

$$
v_{i}=M_{i} / \rho_{f}
$$

The surface area can also be described by

$$
S_{i}=\frac{3 M_{i}}{4 \rho_{f} \pi R_{i}^{3}} 4 \pi R_{i}{ }^{2} \text {, }
$$

where the first term in Eq. (C-3) represents the number of particles and the second term represents the surface area per particle of radius $R_{\mathbf{j}}$. This equation can be reduced to

$$
s_{i}=\frac{3 M_{i}}{\rho_{f}^{R}}
$$


To determine the total fuel volume and total surface area of the distribution requires the summation over all radii $R_{j}$ of Eqs. $(C-2)$ and $(C-4)$. This results in

$$
v_{\text {total }}=\sum_{i} \frac{M_{i}}{\rho_{f}}
$$

and

$$
S_{\text {total }}=\sum_{i} \frac{3 M_{i}}{\rho_{f} R_{i}} \ldots
$$

The volume-to-surface area ratio $\overline{\left(\frac{v}{S}\right)}$ is therefore

$$
\overline{\left(\frac{v}{s}\right)}=\frac{\sum_{i} \frac{M_{j}}{\rho_{f}}}{\sum_{i} \frac{3 M_{i}}{\rho_{f} R_{i}}}
$$

which reduces to

$$
\overline{\left(\frac{v}{S}\right)}=\frac{\sum_{i} M_{i}}{\sum_{i} \frac{3 M_{i}}{R_{i}}}
$$

This can be further simplified to

$$
\overline{\left(\frac{v}{s}\right)}=\frac{1}{3 \sum_{i} \frac{y_{i}}{R_{i}}},
$$


where $y_{\mathfrak{i}}$, the mass fraction, is defined as

$$
y_{i}=\frac{M_{i}}{\sum_{i} M_{i}} \equiv \frac{\dot{M}_{i}}{M_{T}}
$$

Transforming the volume-surface area mean, $\overline{\left(\frac{V}{s}\right)}$, into an equivalent radius particle, $R_{v s}$, requires the additional relation

$$
\begin{aligned}
\overline{\left(\frac{v}{s}\right)} & =\frac{4 \pi R_{v s}{ }^{3} / 3}{4 \pi R_{v s}{ }^{2}} \\
& =\frac{R_{v s}}{3}
\end{aligned}
$$

Equating Eqs. (C-6) and (C-8) yields

$$
R_{v s}=\frac{1}{\sum_{i} \frac{y_{i}}{R_{j}}} .
$$

This method of averaging is known as the Sauter mean or volume-surface mean. It is often used in such surface area determinations (4). For the continuous case where $y$, the mass fraction, is a continuous function of $R$, Eq. (C-9) can be described as

$$
R_{v s}=\frac{1}{\int_{R_{1}}^{R_{2}} \frac{y}{R} d R}
$$

(Precaution should be taken in applying the above formulation to make sure 
that $y$ represents the correct mass fraction for the range of radii $R_{1}$ and $R_{2}$. )

Equation $(C-10)$ is used to determine the equivalent fuel particle. size for Mizuta's final fuel particle distribution. 25 and 750 microns are used as the limits of integration because they represent the range of particle radij through which Mizuta fitted the log-normal distribution. Normalizing Mizuta's function was first necessary so that the correct mass fractions would be-used. This was accomplished by dividing $f_{M}(R)$ by the integral of $f_{M}(R)$ over the function's range of fuel radii,

$$
f_{M}^{N}(R)=\frac{58.1 \exp \left[-(\log 2 R-2.27)^{2} / 0.944\right]}{\int^{750} 58.1 \exp \left[-(\log 2 R-2.27)^{2} / 0.944\right] d R} \text {, }
$$

where $f_{M}^{N}(R)$. represents the normalized function. Performing the integration by a numerical integration technique, the resulting form for $f_{M}^{N}(R)$ is:

$$
f_{M}^{N}(R)=0.001 \exp \left[-(\log 2 R-2.27)^{2} / 0.944\right] .
$$

Using this form for $f_{M}^{N}(R)$ in Eq. $(C-10)$ produces the following form for the volume-surface area mean radius:

$$
R_{v s}=\left\{\int_{25}^{750} \frac{0.001}{R} \exp \left[-(\log 2 R-2.27)^{2} / 0.944\right] d R\right\}^{-1} .
$$


The result for the equivalent Sauter mean particle radius for Mizuta's distribution is $180 \mu \mathrm{m}$.

This, however, represents only $70 \%$ of the total distribution. To account for the $20 \%$ of the fuel particles below a radius of $25 . \mu \mathrm{m}$ and the $10 \%$ above $750 \mu \mathrm{m}$, the discrete formulation for the Sauter mean in Eq. $(C-6)$ is used. First, the remaining particle sizes (above and below Mizuta's distribution) was chosen. The particle size distribution below the $25 \mu \mathrm{m}$ is a very important number and can drastically affect the overall volume-surface mean. This is due to the fact that the surface area per gram of fuel goes up inversely to the radius of the particle. Therefore, an extremely small particle would tend to shift the final overall mean down considerably. To be conservative, but in a realistic fashion, a single radius of $17.3 \mu \mathrm{m}$ was chosen to represent this lower particle size distribution. This is approximately the smallest particle size used by Armstrong to describe the fragmentation results of his $\mathrm{UO}_{2}-\mathrm{Na}$ dropping experiments $(4,5)$. As it turns out, his particle size distribution is very close to Mizuta's finest particle size distribution and should provide an adequate estimate of this lower particle size. On the other end of the spectrum, a value of $1000 \mu \mathrm{m}$ was chosen as the highest particle radius. Again, from Mizuta's compilation of the fragmentation data, this value represents the lowest upper bound to all the data (see Figure C.2). It appears to have been produced in the Japanese experiments.

Table C.I indicates the choice of particle sizes for the calculation of a single fuel particle size to represent the entire spectrum. "Using 
TABLE C.1. Finest Fuel Particle Sizes

$y_{i}$, Mass Fraction

Particle Radius ( $\mu m$ ) : Range (\% Mass)

$$
\begin{array}{lcc}
0.2 & 17.3 & <20 \\
0.7 & 180 & 20-90 \\
0.1 & 1000 & 790 \\
R_{v s} & =\frac{1}{\sum_{i} \frac{y_{i}}{R_{i}}}=\frac{1}{\frac{0.2}{17.3}+\frac{0.7}{180}+\frac{0.1}{1000}} \cong 64 \mu \mathrm{m}
\end{array}
$$


these values for the specified mass ratios, the equivalent volume-surface mean radius is calculated to be $64 \mu \mathrm{m}$.

\section{3 Discussion}

The effect of establishing this lower bound of the fuel particle size can be seen in Figure C.1. With this lower bound, mixing time constants greater than at the point of intersection no longer must be considered. The area above the lower bound beyond this point represents work potentials less than the limiting value of $40 \mathrm{MW}-\mathrm{sec}$ for the FFTF. This methodology can be applied to the CRBR as well for the work potential curve of $70 \mathrm{MW}$-sec.

For the specific case presented in Figure C.1,mixing time constants, if shown to be greater than $27.5 \mathrm{msec}$ in a particular accident situation, will provide calculated work potentials of less than the limiting value of $40 \mathrm{MW}-\mathrm{sec}$. In all further calculations, $64 \mu \mathrm{m}$ is used as the final fuel particle radius. Determining the mixing time constant that produces the limiting work potential criteria at this radius will establish the point of intersection directly between the curve of constant work potential and the lower bound radius of $64 \mu \mathrm{m}$. This point represents the 1 imiting mixing time constant, below which the calculated work potentials exceed the value of the limiting work potential for the particular reactor system. Above this mixing time constant, calculated work potentials will be less than the limiting criteria. 
REFERENCES (APPENDIX C)

1. A.W. Cronenberg, M.A. Grolmes, "A Review of Fragmentation Models Relative to Molten $\mathrm{UO}_{2}$ Breakup when Quenched in Sodium Coolant;" paper presented at 1974 ASME Winter Meeting, New York, Nov. 17-21, 1974.

2. Michael Corradini,. "Prediction of Minimum $\mathrm{UO}_{2}$ Particle Size Based on Thermal Stress Initiated Fracture Model," C00-2781-4 TR, August 1976.

3. Hiroshi Mizuta, "Fragmentation of Uranium Dioxide after Molten Uranium Dioxide-Sodium Interaction," J. Nuclear Science \& Engr., 11(11), 480-487 (1974).

4. W.L. Chen, D.H. Cho, M.S. Kazimi, "Recent Additions to the Parametric Model of Fuel Coolant Interactions," ANL-8130, Sept. 1974.

5. D.R. Armstrong, F.J. Testa, D. Rariden, "Molten $\mathrm{UO}_{2}-\mathrm{Na}$ Dropping Experiments," Trans. Amer. Nucl. Soc. 13, 660 (1970). 
APPENDIX D:

HIGH TEMPERATURE THERMOPHYSICAL FUEL PROPERTIES

\begin{tabular}{|c|c|c|c|}
\hline \multirow[t]{2}{*}{ 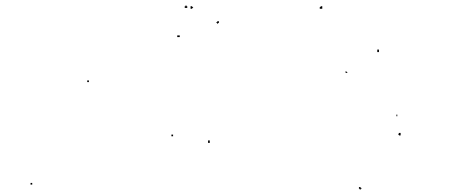 } & \multicolumn{3}{|c|}{ Fuels } \\
\hline & $\mathrm{UO}_{2}$ & $U C$ & UN \\
\hline $\begin{array}{l}\text { Melting Temperature } \\
\left({ }^{\circ} \mathrm{C}\right)\end{array}$ & $2800^{\circ}$ & $2530^{\circ}$ & $2860^{\circ}$ \\
\hline $\begin{array}{l}\text { Boiling Temperature } \\
\left({ }^{\circ} \mathrm{C}\right)\end{array}$ & $\sim 3400^{\circ}$ & $3250^{\circ}$ & $4540^{\circ}$ \\
\hline $\begin{array}{l}\text { Molten Density } \\
\left(\mathrm{gm} / \mathrm{cm}^{3}\right)\end{array}$ & 8.74 & 11.2 & 11.0 \\
\hline $\begin{array}{l}\text { Solid Density } \\
\left(\mathrm{gm} / \mathrm{cm}^{3}\right)\end{array}$ & 11.0 & 13.6 & 14.3 \\
\hline $\begin{array}{l}\text { Thermal Conductivity } \\
\left(\mathrm{cal} / \mathrm{cm}-\sec ^{\circ} \mathrm{C}\right)\end{array}$ & $0: 005$ & 0.053 & 0.066 \\
\hline $\begin{array}{l}\text { Liquid Viscosity } \\
\text { (poises) }\end{array}$ & 0.08 & -- & -- \\
\hline $\begin{array}{l}\text { Specific Heat } \\
\left(\text { cal } / \mathrm{gm}^{\circ} \mathrm{C}\right)\end{array}$ & 0.11 & 0.08 & 0.09 \\
\hline $\begin{array}{l}\text { Heat of Fusion } \\
\text { (cal/gm) }\end{array}$ & 67.0 & 47.2 & 52.4 \\
\hline $\begin{array}{l}\text { Thermal Diffusivity } \\
\left(\mathrm{cm}^{2} / \mathrm{sec}\right)\end{array}$ & 0.0041 & 0.049 & 0.051 \\
\hline
\end{tabular}

The above table of fuel properties were taken mostiy from references 1 and 2. They in general represent the thermophysical properties at atmospheric pressure. A more complete guide to the properties of the advanced fuels can be found in Ref. 3. The boiling point values were calculated from the equations of state for UC and UN in Ref. 3. 


\section{REFERENCES (APPENDIX D)}

1. August W. Cronenberg, Richard L. Coats, "A Comparison of Solidification Phenomena for $\mathrm{UO}_{2}, U \mathrm{C}$, and UN Relative to Quenching in Sodium Coolant," to be published in Nuclear Engineering and Design.

2. M.G. Chasanov, L. Leibowitz, S.D. Gabelnick, "High Temperature Physical Properties of Fast Reactor Materials," J. Nucl. Mat']s 49, 129-135 (1973/1974).

3. C.E. Johnson, "Thermophysical and Mechanical Properties of Advanced Carbide and Nitride Fue1s," ANL-AFP-27, June 1976. 
APPENDIX E:

HYDRODYNAMIC BREAKUP OF A MOLTEN FUEL JET

\section{E.1 Introduction}

Various fuel fragmentation models have been proposed to explain the observed fuel fragmentation following a fuel-coolant interaction (1). One group of these models assumes that the initial fragmentation of the hot molten materials can be caused by hydrodynamic forces. The measure of merit for these models is known as the Weber number, and is defined as:

$$
\text { We }=\frac{\rho_{\text {Na }} V^{2} R_{\text {fuel }}}{\sigma_{\text {fuel }}} \text {, }
$$

where $V$ is the relative velocity between the fuel and the coolant. This dimensionless number represents the ratio of the sodium velocity pressure, $\rho_{\mathrm{Na}} V^{2}$, to the surface tension pressure, $\sigma_{\text {fuel }} / R_{\text {fuel }}$, of the spherical globule (2). The splitting of a liquid globule is assumed to occur when $W e$ is greater than a critical value, We crit. A similar formulation for the Weber number has been used for investigating impact fragmentation in $\mathrm{FCI}$ dropping experiments. In these cases, the Weber number was alternatively defined as $(1,3)$ :

$$
W e=\frac{\rho_{\text {fuel }} D_{\text {fuel }} v^{2}}{\sigma_{\text {fuel }}} \text {, }
$$

where all properties are those of the fuel. This formulation represents a ratio of the inertial forces to the surface tension forces. In the 
latter analys is, the range of critical Weber numbers as observed by Hinze were used. The results of Hinze's experimental work coupled with Eq. $(E-1)$ are also used in this appendix to evaluate the hydrodynamic fragmentation of a molten fuel jet. Such a fuel jet can be postulated to be a result of an overpower situation in a reactor system where fuel melting occurs with the subsequent rupture of the pin cladding. A picture of the idealized fuel jet model used for this analysis is shown in Figure E.1 : Fuel squirting velocities were calculated for a range of pressure differentials; the range of the pressure differentials assumed for these scoping calculations is from 0 to 200 atmospheres. This range should represent adequately the pressure differences that exist during a major part of the fuel squirting.

\section{E.2 Fuel Squirting Velocities}

The fuel squirting velocities are determined by the following equation (4):

$$
G=0.61\left(2 g_{c} \rho_{\text {fuel }} \Delta P . \times 1034.4 \frac{\mathrm{gm} / \mathrm{cm}^{2}}{\mathrm{~atm}}\right)^{\frac{1}{2}}
$$

where $G$ represents the mass flux of liquid fuel $\left(\mathrm{gm} / \mathrm{cm}^{2} \mathrm{sec}\right)$ and $\Delta P$ represents the difference (atmospheres) between the internal pin pressure and the pressure in the FCI mixing zone of the reactor core. This equation is valid for the flow of saturated or subcooled liquids from an orifice assuming the length-to-diameter ratio, $L / D$, is equal to zero. 


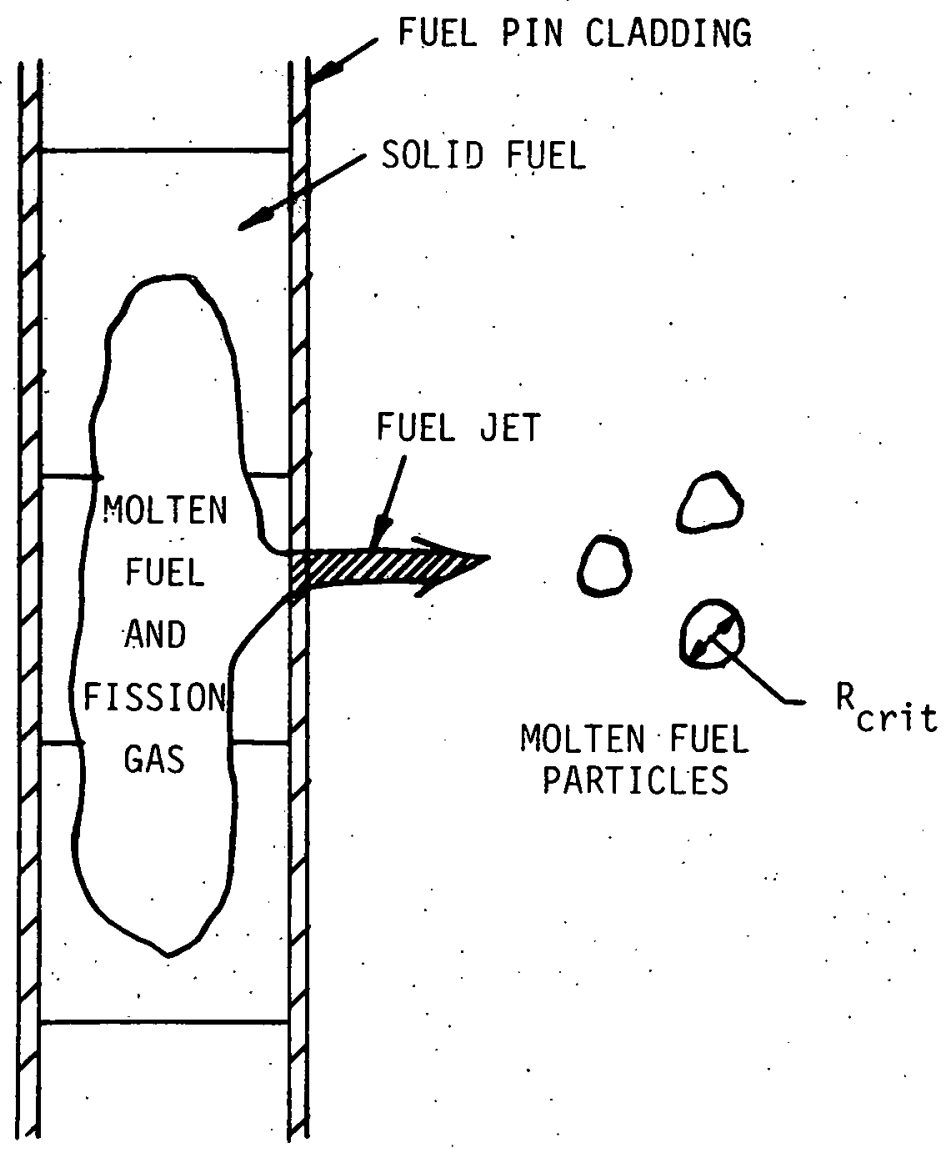

FIGURE E.1. Hydrodynamic Breakup Model of Idealized Fuel Jet. 
This is a conservative representation of cladding rupture because it yields a higher mass flux, a higher we, and smaller resulting particles than if a critical flow were established for a length-to-diameter ratio greater than zero. To determine the velocity of the fuel jet, Eq. (E-3) is divided by the fuel density to give

$$
v_{\text {fuel }}=19.6\left(2 g_{c} \Delta P / \rho_{\text {fuel }}\right)^{\frac{1}{2}},
$$

where $V_{\text {fuel }}$ is expressed in $\mathrm{cm} / \mathrm{sec}$. For this analysis, the properties of $\mathrm{UO}_{2}$ are used. The results for the fuel velocities as a function of $\Delta P$ are presented in Figure E.2.

\section{E.3 Critical Fuel Particle Sizes}

Based on his experimental studies of several different liquids in free-fall experiments, Hinze determined that a majority of the materials tested had critical Weber numbers of around 10 with only one exceptional value of 20. Translating these values to critical Weber numbers that apply to the disintegration of liquid jets, Hinze suggested that the critical Weber number of 10 corresponded to a lower value of 6 for liquid jets. Using his method, a We crit of 11 was determined to be equivalent to the original value of 20 . Using this range of critical Weber numbers for liquid jets in Eq. (E-1) with the results of Section E.2, the largest stable (critical) fuel particle size was determined as a 


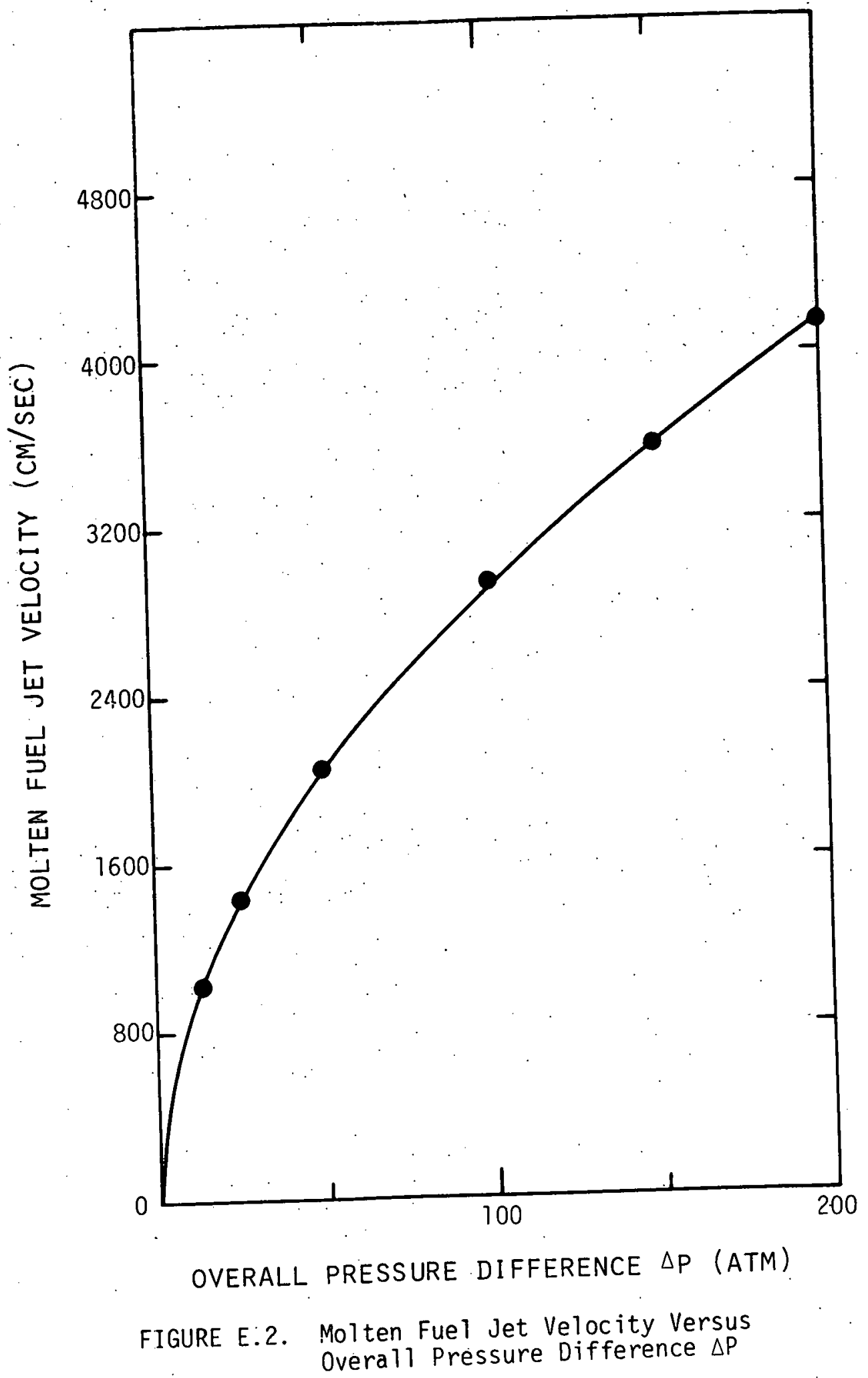


function of the pressure difference: To accomplish this, Eq. (E-1) is first solved for $R_{\text {crit }}$ :

$$
R_{\text {crit }}=\frac{{ }_{\text {crit }} \sigma_{\mathrm{UO}_{2}}}{\rho_{\mathrm{Na}} V_{\mathrm{UO}_{2}}{ }^{2}} \text {, }
$$

where $V^{2}$. was replaced by $V_{\mathrm{UO}_{2}}{ }^{2}$ and $R_{\text {crit }}$ represents the critical fuel particle radius in $\mathrm{cm}$. Using the definition of $V_{\text {fuel }}$ in Eq. (E-4) with $\mathrm{UO}_{2}$ fuel properties, $R_{\text {crit }}$ can be expressed as a function of the pressure differential,

$$
R_{\text {crit }}=\frac{W_{\text {crit }} \sigma_{U_{2} O_{2}} \rho_{U_{2}}}{768 \rho_{\mathrm{Na}} g_{C} \Delta P}
$$

The results for $R_{\text {crit }}$ are presented in Figure E.3.

During an actual pin failure, the overall pressure difference will be initially high but will quickly decrease. This is due to two competing processes: the relieving of the internal pin pressure by the fuel and fission gas ejection, and the pressurization in the FCI zone due to sodium expansion and vaporization. Figure E.4 shows such a pressure-time history of the overall pressure difference by showing both the pin pressure and FCI zone pressure with time. This figure represents a calculation performed for an HCDA in the CRBR (5). Because the overall pressure difference $\Delta P$ changes with time for a failed fuel $p$ in, fuel squirting velocities will also change with time, producing a range of critical fuel particle sizes. Based on Figure E.3, the critical fuel particles will 
FIGURE E.3 Stable Fuel Particle Radii. Following HydroDynamic Breakup of a Molten Fuel Jet

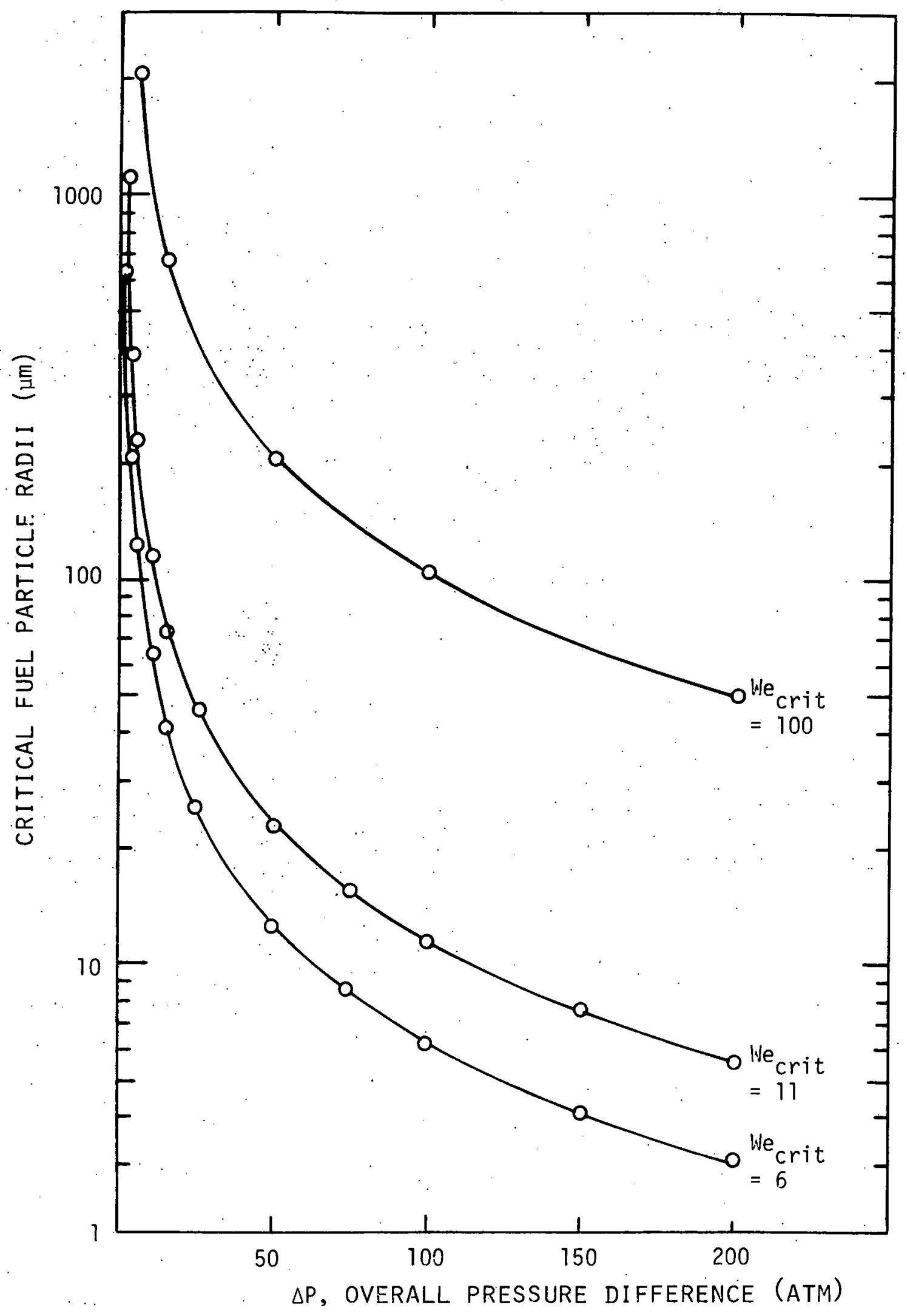


FIGURE E.4 Pin and FCI-Zone Pressure History

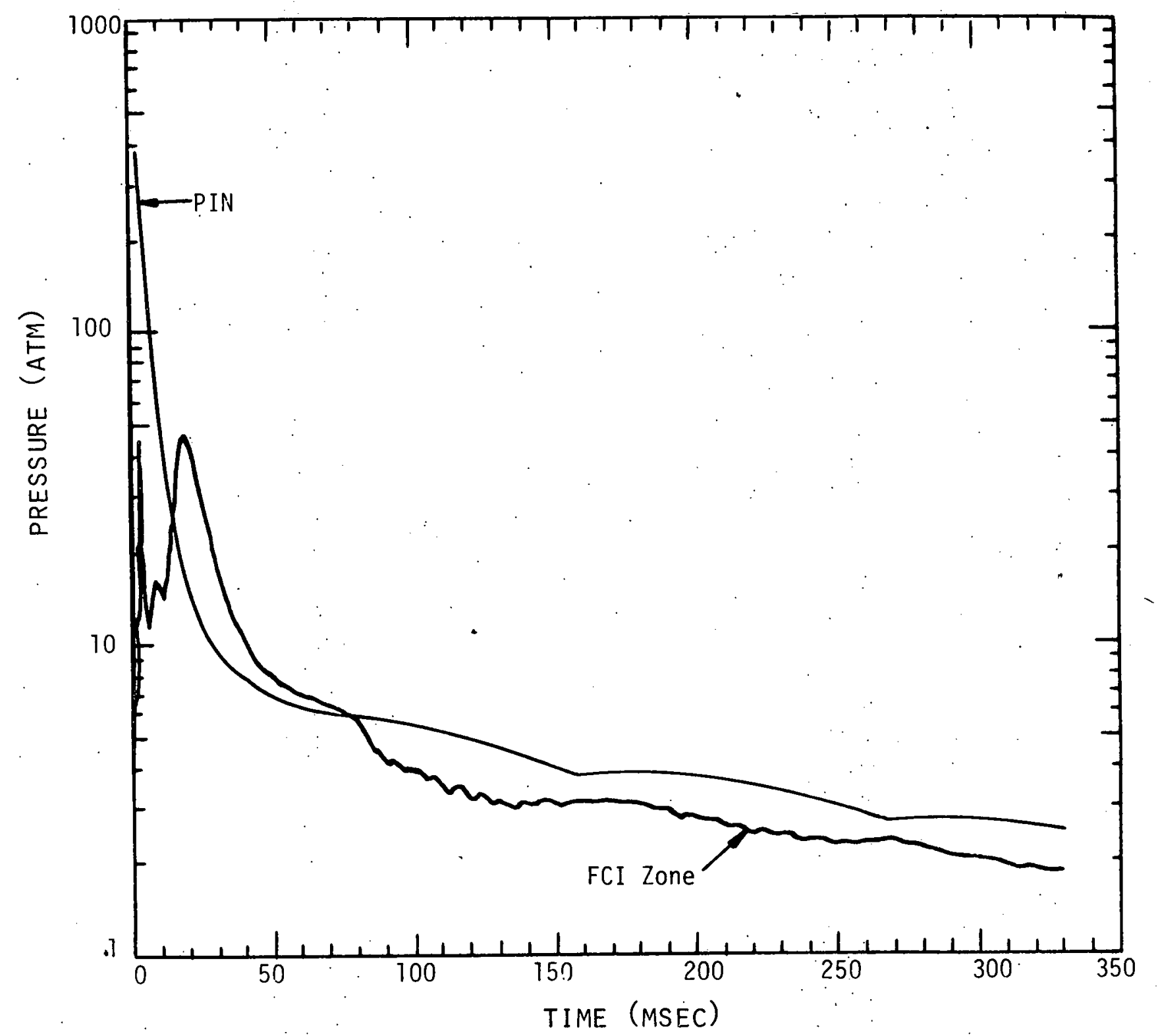


range from a few microns to several thousand microns.

This range of calculated critical fuel particle sizes is well within the distribution of fuel particle sizes that has been observed in molten fuel-jet type experiments (6). To determine the actual distribution of critical fuel particles produced by this fragmentation model, however, would require incorporating a $\Delta P$ versus time history into the analysis.

\section{E.4 Discussion}

The question arises in the above analysis if the hydrodynamic breakup of the fuel jet can occur before the fuel jet impacts the surrounding fuel pins. Hinze provides a means for calculating the splitting-up time for liquid globules initially at Weber numbers in excess of their critical values. His equation for the splitting-up time in seconds is

$$
t \approx \frac{R_{\text {crit }}}{V_{\text {fuel }}}\left[\frac{1}{0.75} \frac{\rho_{\mathrm{UO}_{2}}}{\rho_{\mathrm{Na}}}\left(\frac{\delta}{R}\right)_{\text {crit }}\right]^{\frac{1}{2}}
$$

where $(\delta / R)_{\text {crit }}=0.17 \mathrm{We}_{\text {crit }}$.

The value of 11 for the critical Weber number was used because it will provide not only the largest value for $(\delta / R)$ crit but also the largest stable fuel particle. These factors combined will provide the longest possible splitting-up time. On the other hand, the shortest time for the fuel jet to impact the surrounding fuel pins can be calculated by 
assuming the fuel pin rupture takes place at a point closest to any of the surrounding pins (Figure E.5) and that the fuel jet does not slow down. The time for this impact (assuming the jet velocity is constant) can therefore be calculated by simply dividing the gap width $(0.055$ in $\equiv$ $0.140 \mathrm{~cm})$ by the jet velocity. Figure E.6 presents a comparison of these two times; the splitting-up time and the impact time over the range of $\Delta P$ used before. From these results, the jiquid jet is expected, in general, to split up before it impacts the surrounding fuel pins.

The only comment that perhaps should be made at this time is that the results presented in Figure E.3 for the stable fuel particles will most likely be the smallest due to hydrodynamic breakup. It is possible (2) that during the disintegration of a liquid jet, viscous forces will not only break up the jet but will also slow it down. If, in this case, the slowing down is accomplished before significant particle breakup, the final stable particle sizes will be characteristic of velocities slower than initial fuel ejection velocity. This will have the effect of producing larger stable fuel droplets than is calculated using the initial ejection velocities. 


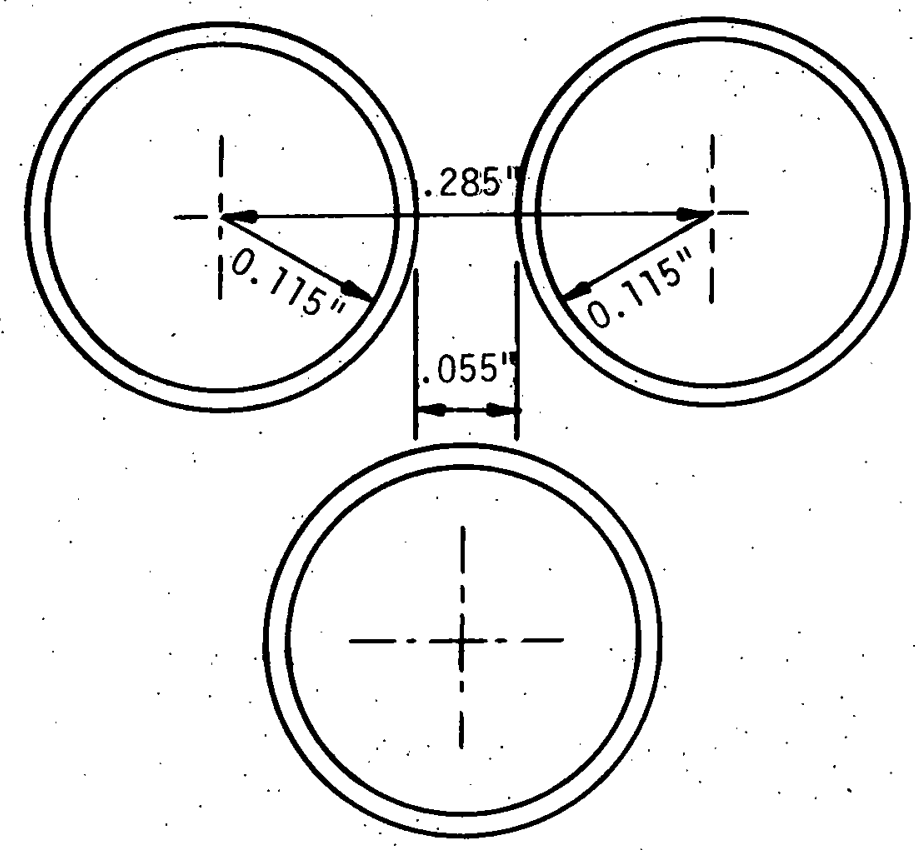

FIGURE E.5. FFTF and CRBR Fuel Pin Geometry. 


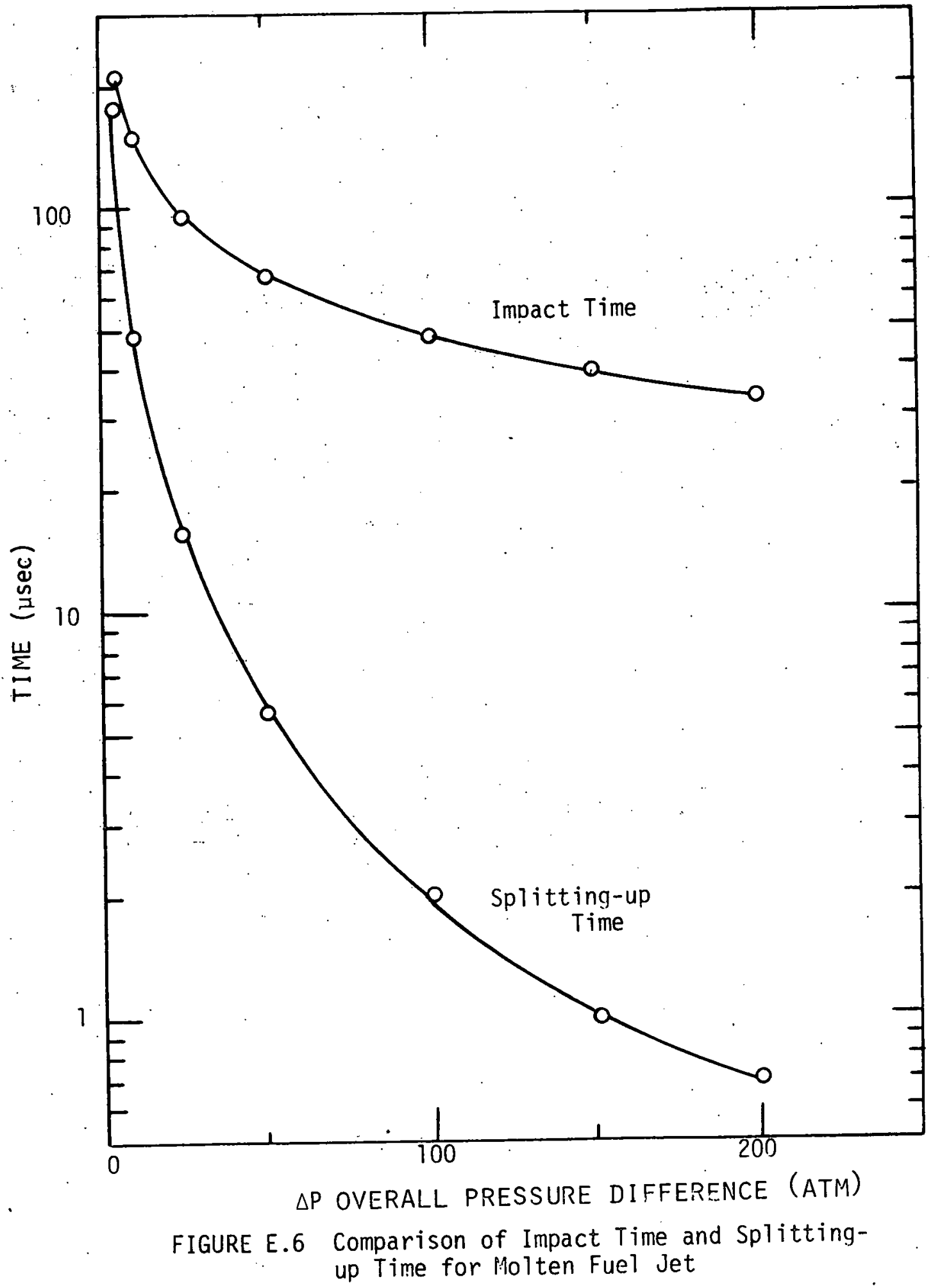


1. August W. Cronenberg, Michael A. Grolmes, "A Review of Fragmentation Models Relative to Molten $\mathrm{UO}_{2}$ Breakup when Quenched in Sodium Coolant," presented at 1974 ASME Winter Meeting, New York, Nov. 17-21, 1974.

2. J.0. Hinze, "Forced Deformations of Viscous Liquid Globules," Appl. Scientific Research, Al, 263-288 (1949).

3. D.R. Armstrong, F.J. Testa, D.C. Rardin, "Interaction of Na with Molten $\mathrm{UO}_{2}$ and Stainless Steel Using a Dropping Mode of Contact," ANL-7890, 1971.

4. Class notes from Course 22.36J, MIT, Spring 1976.

5. W.R. Bohl, et al., "An Analysis of Transient Undercooling and Transient Overpower Accidents without Scram in the Clinch River Breeder Reactor," ANL/RAS 75-29, July 1975.

6. J.J. Barghusen, R.W. Wright, et al., "In-Pile Tests,". LMFBR Nuclear Safety Program Annual Report ANL-7800, p. 321, 1971 : 
APPENDIX F:

FUEL-COOLANT INTERFACE TEMPERATURES

\section{F.1. Introduction}

To evaluate the solidification rate in Appendix $B$ of the molten fuel quenched in the liquid sodium, the fuel-coolant interface temperatures had to be determined. For a pure liquid-liquid system assuming perfect wetting (1), the contact temperature at the liquid-1iquid fuelcoolant temperature is (2):

$$
T_{I}=\frac{T_{H}\left(k_{H} / \sqrt{\alpha_{H}}\right)+T_{C}\left(k_{C} / \sqrt{\alpha_{C}}\right)}{\left(k_{H} / \sqrt{\alpha_{H}}\right)+\left(k_{C} / \sqrt{\alpha_{C}}\right)} \text {, }
$$

where the subscripts $H$ and $C$ refer to the fuel and sodium coolant, respectively. The above equation for the interface temperature is derived for two semi-infinite slabs initially at $\mathrm{T}_{H}$ and $\mathrm{T}_{C}$. For both $\mathrm{NO}_{2}$ and the advanced fuel, $U C$ and $U N$, solidification is expected to commence immediately upon contact with the liquid sodium $(3,4)$. For this case, where the hot substance is solidifying, the interface temperature is (4):

$$
T_{I}=\frac{T_{M}\left(k_{H} / \sqrt{\alpha_{H}}\right)+T_{C}\left(k_{C} / \sqrt{\alpha_{C}}\right) \text { erf } \lambda}{\left(k_{H} / \sqrt{\alpha_{H}}\right)+\left(k_{C} / \sqrt{\alpha_{C}}\right) \operatorname{erf} \lambda} .
$$

where the subscript $M$ refers to the melting point of the fuel. (The complete derivation of the temperature distribution in this geometry can be found in the last section of this appendix.) The erf $\lambda$ terms in 
Eq. (F-2) account for the liberation of the heat of fusion as the fuel solidifies. The $\lambda$ is determined from the following equation when the fuel is assumed to be at its melting temperature (i.e., $T_{H}=T_{M}$ ):

$$
\frac{C_{p} T_{E}}{L \sqrt{\pi}}=\lambda e^{\lambda^{2}}\left(\frac{k_{H} \sqrt{\alpha_{C}}}{k_{c} \sqrt{\alpha_{H}}}+\operatorname{erf} \lambda\right),
$$

where the temperature $T_{E}$ represents a relative temperature (5):

$$
T_{E}=T_{M}-T_{C}
$$

This fact that $T_{E}$ represents a relative temperature has apparently been ignored in previous calculations $(3,4)$ but should be accounted for. If not, errors become noticeable as higher coolant temperatures are used in determining the interface temperature.

\section{F.2 Results}

The fuel-coolant interface temperature was calculated for three different fuels: $U O_{2}, U C$, and $U N$. All the fuels were assumed to be at their melting temperatures. The temperature of the liquid sodium was varied in all cases from $200^{\circ} \mathrm{C}$ to $900^{\circ} \mathrm{C}$. Table F.l presents the results of these calculations for both liquid-liquidinterface temperature and the solid-liquid interface temperature. A compilation of the sodium properties that were used (6) is found in Table F.2. Fuel melting temperatures 
TABLE F.1. Fuel-Coolant Interface Temperatures

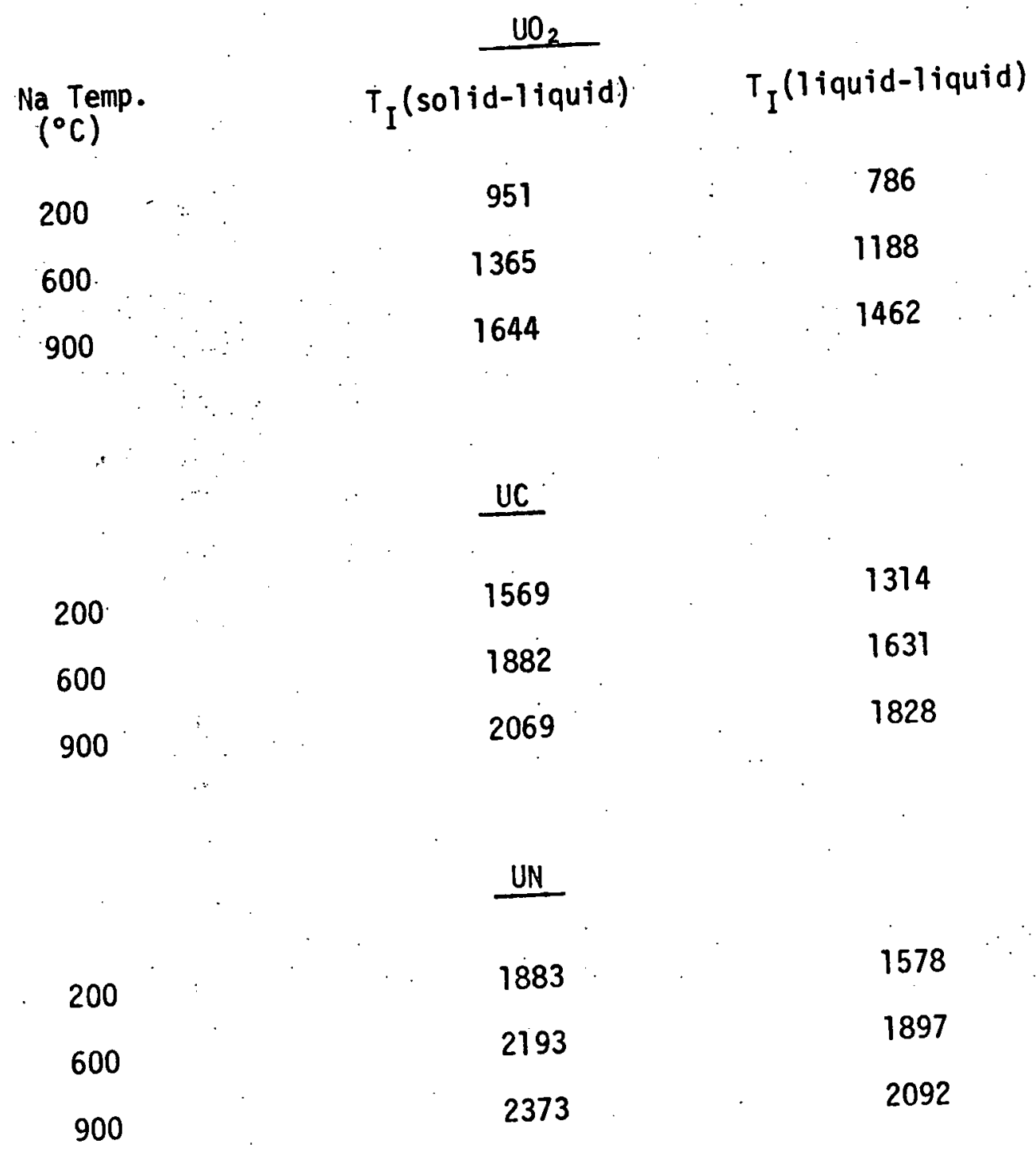


$-149-$

TABLE F.2. Sodium Properties

$$
\begin{aligned}
& 200^{\circ} \mathrm{C} \quad 600^{\circ} \mathrm{C} \quad 900^{\circ} \mathrm{C} \\
& k\left(\frac{\mathrm{cal}}{\mathrm{sec}-\mathrm{cm}^{\circ} \mathrm{C}}\right) \quad 0.196 \quad 0.149 \quad 0.120 \\
& \rho\left(\frac{\mathrm{gm}}{\mathrm{cm}^{3}}\right) \quad \therefore \quad 0.904 \quad 0.809 \quad 0.736 \\
& C_{p}\left(\frac{\mathrm{cal}}{\mathrm{gm}^{\circ} \mathrm{C}}\right) \quad 0.320 \quad 0.300 \quad 0.308 \\
& \alpha\left(\frac{\mathrm{cm}^{2}}{\mathrm{sec}}\right) \quad 0.678 \quad 0.614 \quad 0.529
\end{aligned}
$$


and fuel properties used for the molten and solid conditions are those listed in Appendix D.

\section{F.3 Discussion}

In the present fast reactor designs of the FFTF and the CRBR, the nominal operating temperatures for the sodium range from about $300^{\circ} \mathrm{C}$ to $600^{\circ} \mathrm{C}$. For this range of sodium temperatures with $\mathrm{UO}_{2}$ at its melting point, the corresponding range of fuel-coolant interface temperatures are well below the spontaneous nucleation temperature for liquid sodium at atmospheric pressure. Even if the coolant temperature was to rise to its boiling point of $\sim 900^{\circ} \mathrm{C}$, the calculated interface temperature would still be less than the spontaneous nucleation temperature. [On Figure F.1, two sets of temperatures are given for the critical temperatures and spontaneous nucleation temperatures $(1,7)$. This discrepancy reflects the present uncertainty of the exact values for these sodium properties.]

On the other hand, it appears possible that the interface temperatures calculated for the advanced fuel, UN, can reach the spontaneous nucleation limit for the normal sodium operating temperatures of the reactor systems mentioned. On the other hand, the interface temperatures calculated for UC and Na are not as high as those for UN and Na. However, it is possible that the UC-Na interface temperatures can be considerably above those shown in Figure F.1. This is possible because UC has a much larger temperature difference between its melting point and its boiling 


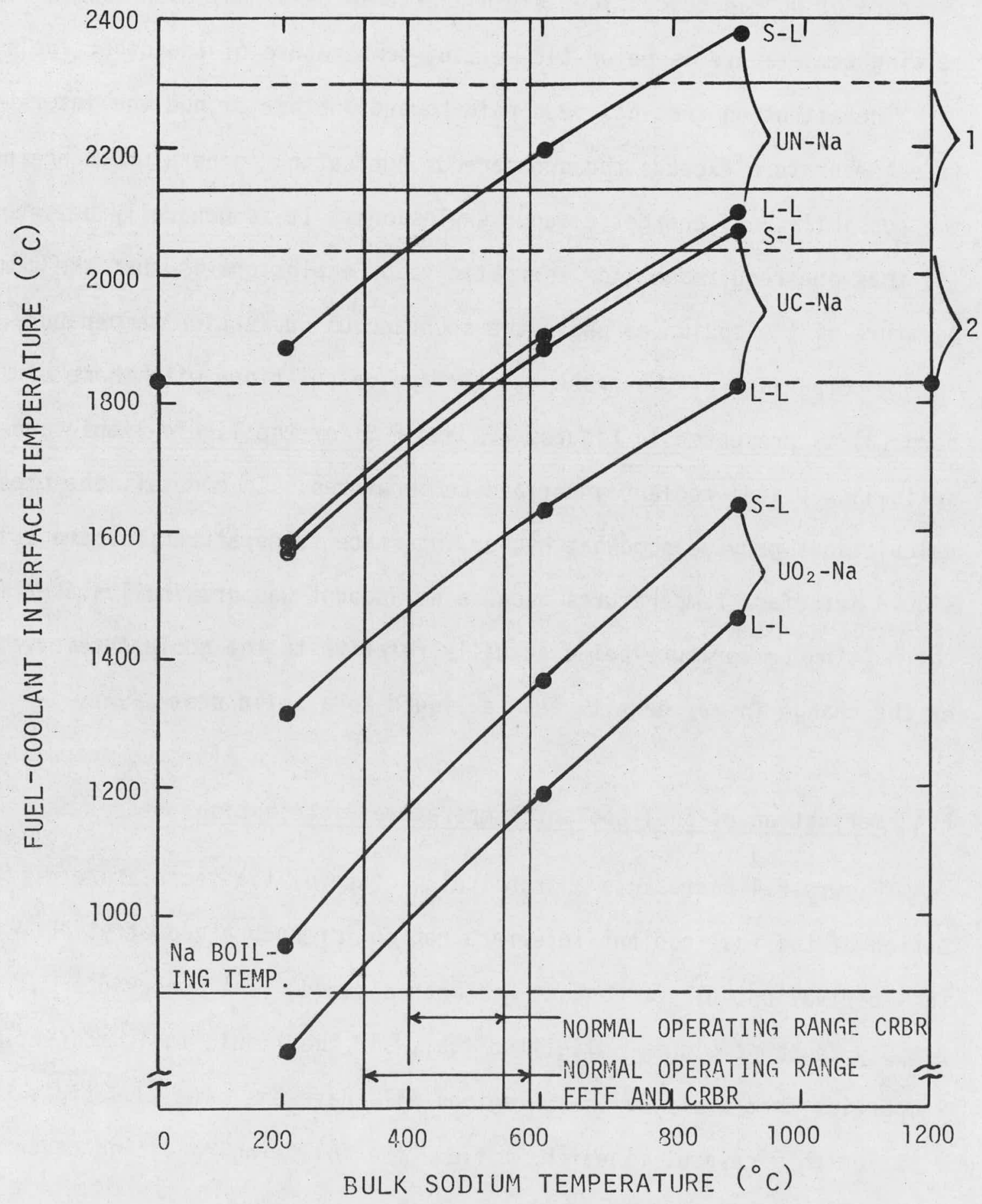

FIGURE F. 1 Fuel-Coolant Interface Temperatures

1. Range of Sodium Critical Temperature

2. Range of Sodium Spontaneous Nucleation Temperatures 
point than either $\mathrm{UO}_{2}$ or UN (see Appendix D). Therefore, the initial temperature of UC can be considerably higher than $U N$ or $\mathrm{UO}_{2}$ even though its melting temperature is below the melting temperature of the other fuels. The attention that has been paid toward whether or not the interface temperature exceeds the spontaneous nucleation temperature concerns the possibility of energetic vapor explosions. It is generally believed (8) that one requirement for energetic vapor explosions is that the temperature of the sodium be above the spontaneous nucleation temperature.

A comparison of the present interface calculations with those of Cronenberg (4) is presented in Figures F.2 and F.3 for the liquid-liquid and the solid-liquid fuel-coolant interface temperatures. In general, the present calculations provide somewhat higher interface temperatures for the solidliquid interface temperatures because no account was originally taken for the melting temperature being actually relative to the coolant temperature or the change in $\mathrm{UO}_{2}$ density from a liquid to a solid state.

\section{F.4 Derivation of Fuel-Coolant Temperature Distribution}

Figure F.4 represents a graphical picture of the temperature distribution of the fuel-coolant interface region for such a geometry. For this derivation, direct contact has been assumed. The subscripts 0,1 , and 2 apply to the coolant, solidified fuel, and the liquid fuel, respectively. Properties that apply to these regions will have the same subscripts. For this case of linear heat flow, the following heat conduction 


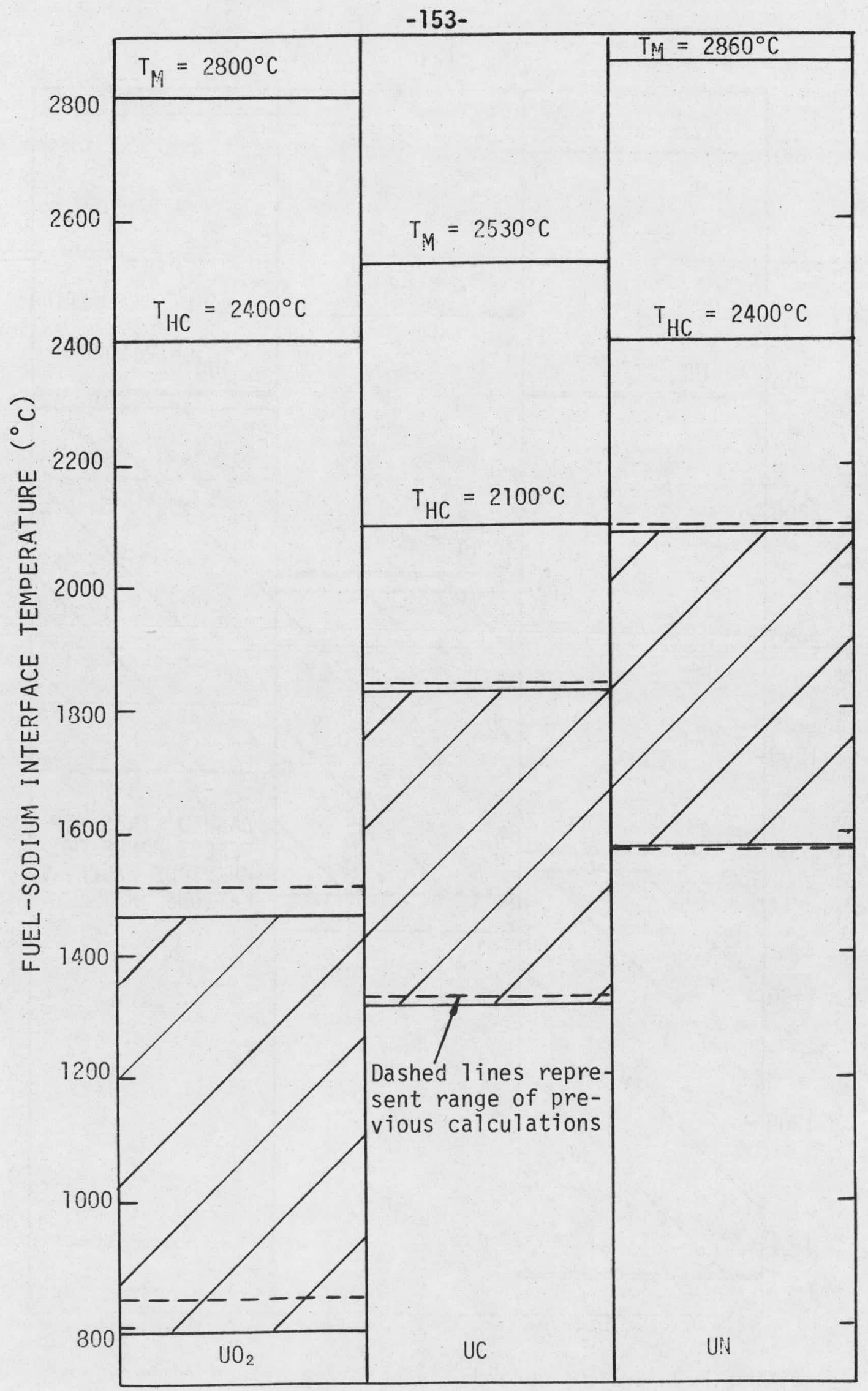

FIGURE F.2 Liquid-Liquid Fuel-Sodium Interface Temperatures 
$-154-$

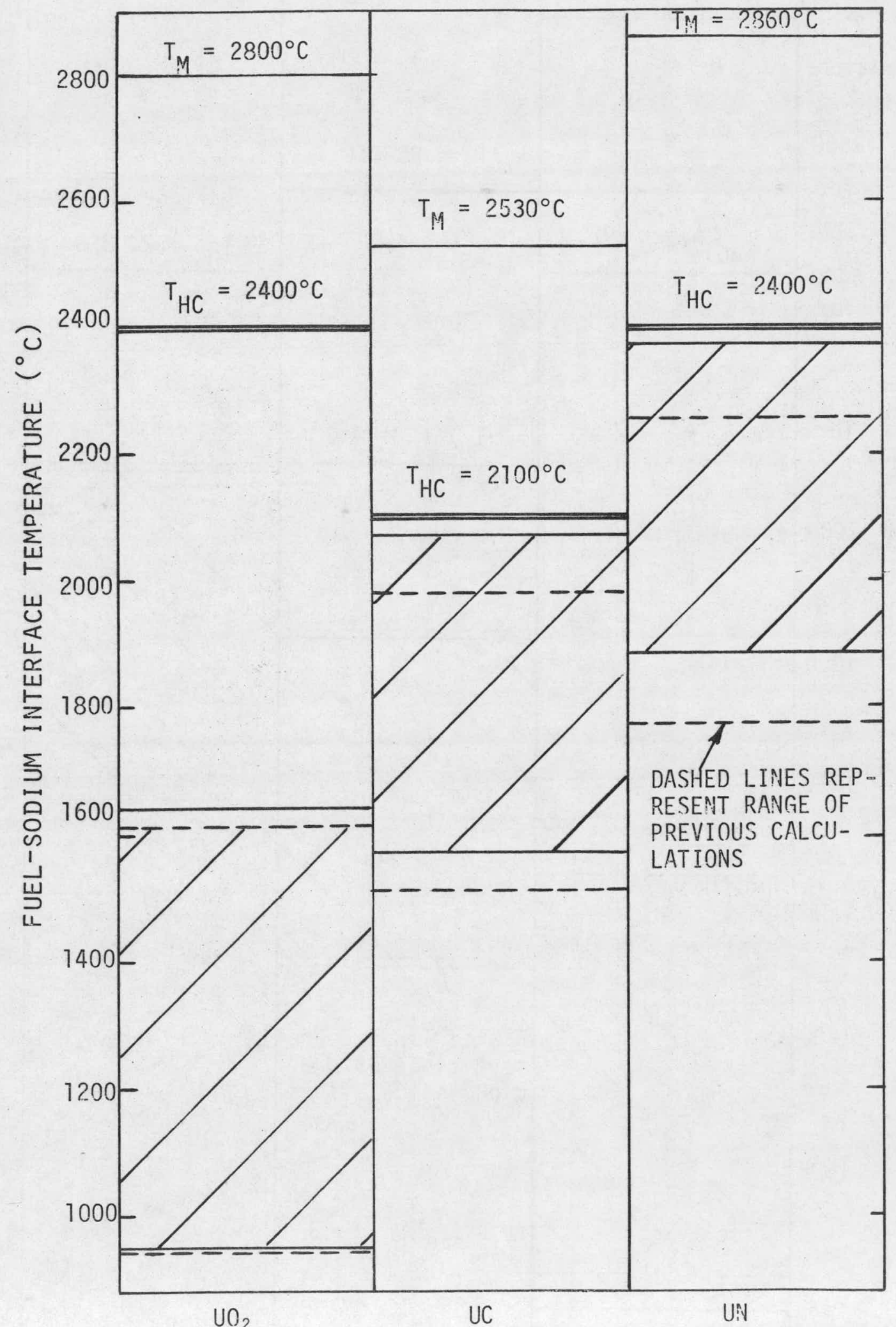

FIGURE F.3 Solid-Liquid Fuel-Sodium Interface Temperatures 
equations must be satisfied within each region:

for $x<0: \frac{\partial^{2} T_{0}}{\partial x^{2}}-\frac{1}{\alpha_{0}} \frac{\partial T_{0}}{\partial t}=0$;

for $0<x<x: \frac{\partial^{2} T_{1}}{\partial x^{2}}-\frac{1}{\alpha_{1}} \frac{\partial T_{1}}{\partial t}=0$;

$$
\text { for } x>x: \quad \frac{\partial^{2} T_{2}}{\partial x^{2}}-\frac{1}{\alpha_{2}} \frac{\partial T_{2}}{\partial t}=0 \text {. }
$$

The two internal boundaries have the following boundary conditions:

(1) $x=0 ; T_{1}=T_{0}$

$$
\left.k_{0} \frac{\partial T_{0}}{\partial x}\right|_{x=0^{-}}=\left.k_{1} \frac{\partial T_{1}}{\partial x}\right|_{x=0^{+}}
$$

These conditions state that (with negligible contact resistance) the interface temperature is the same in both regions and that the heat flow across the interface must be the same on both sides of the interface.

(2) $x=X ; T_{1}=T_{2}=T_{M}^{\prime}$

$$
\left.k_{1} \frac{\partial T_{1}}{\partial x}\right|_{x=X}-\left.k_{2} \frac{\partial T_{2}}{\partial x}\right|_{x=X}=L \rho_{3} \frac{d X}{d t}
$$

These boundary conditions indicate that at the solidifying front, the temperature in both phases is equal to the melting temperature, and that when the solidification surface moves a 
COOLANT

:FUEL

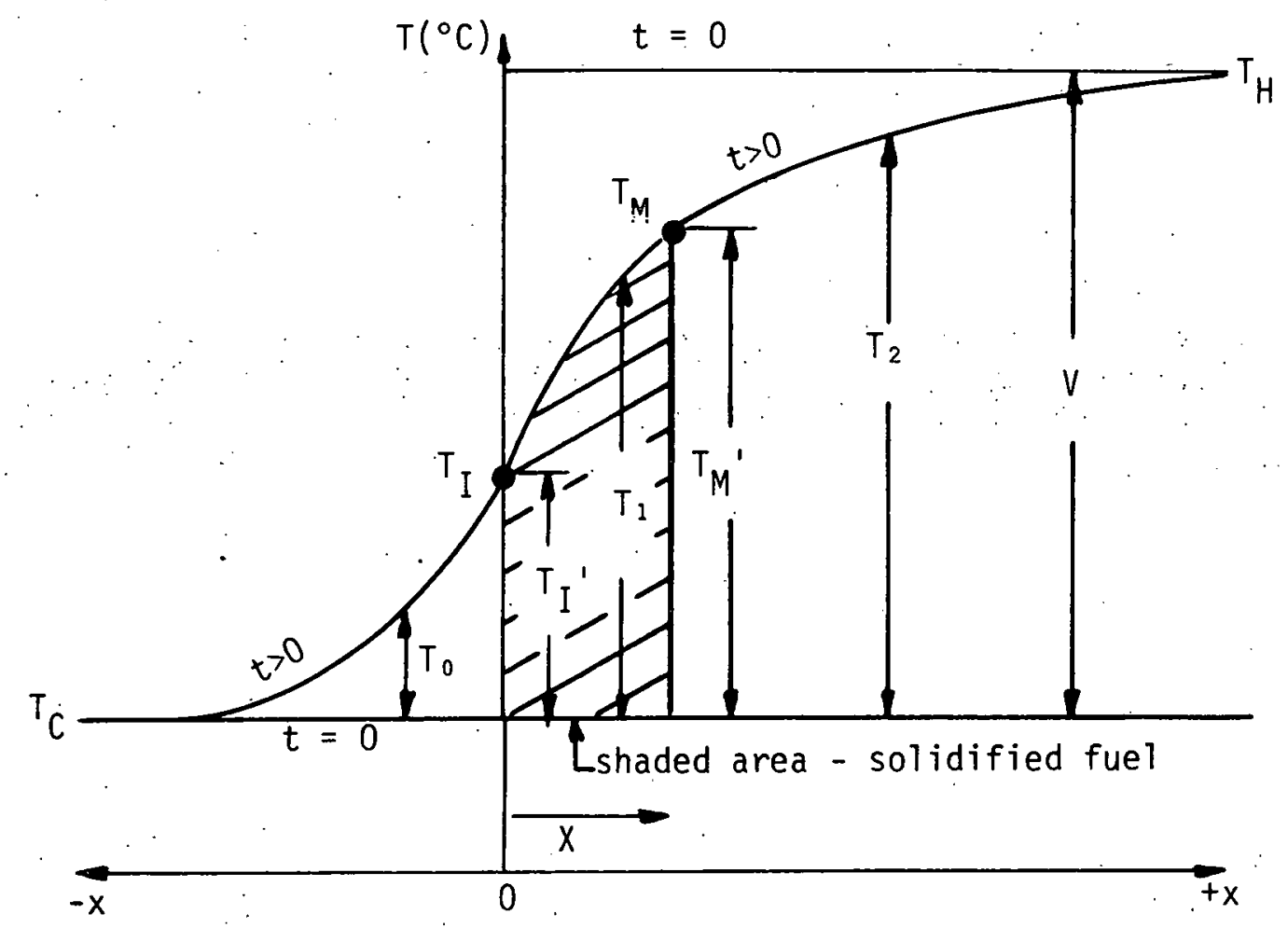

FIGURE F.4 Fuel-Coolant Temperature Distribution

\section{NOMENCLATURE}

$T_{H^{-}}$- initial temperature of hot fuel

$T_{C}$ - initial temperature of cold sodium

$T_{I}$ - interface temperature

$T_{M}$ - melting point of fuel

$V$ - relative initial temperature of fuel $\equiv T_{H}-T_{C}$

$T_{M}{ }^{\prime}$ - relative melting temperature $\equiv T_{M}-T_{C}$

$T_{I}{ }^{\prime}$ - relative interface temperature $\equiv T_{I}-T_{C}$

$x$ - position of solidification front 
distance $d x$, the heat of fusion $\left(L \rho_{1} d x\right)$ is liberated $\left(\mathrm{cal} / \mathrm{cm}^{2}\right)$ and must be removed by conduction.

The only other boundary conditions that must be satisfied are those at $x= \pm \infty$, namely,

$$
\begin{array}{ll}
x=-\infty & T_{0}=0 \quad(t \geqslant 0) \\
x=+\infty & T_{2}=y \quad(t \geqslant 0)
\end{array}
$$

The initial conditions for this problem are

$$
\begin{aligned}
& x \leqslant 0 ; T_{0}=0 \text { at } t=0 \\
& x \geqslant 0 ; T_{2}=T_{1}=V \text { at } t=0 .
\end{aligned}
$$

It has been shown that (9) the error function is a solution to the equations (F-5). Applying this solution to the problem provides general temperature solutions for all three regions:

$$
\begin{aligned}
& T_{0}=A\left(1+\operatorname{erf} \frac{x}{2 \sqrt{\alpha_{0} t}}\right) \\
& T_{1}=B+C \operatorname{erf} \frac{x}{2 \sqrt{\alpha_{1} t}} \\
& T_{2}=V-D \operatorname{erfc} \frac{x}{2 \sqrt{\alpha_{2} t}} .
\end{aligned}
$$

Equations $(F-14),(F-15)$, and $(F-16)$ can be shown to be adequate forms that can satisfy the boundary conditions. For example, the boundary conditions for region 0 are such that as $x \rightarrow-\infty, T_{0} \rightarrow 0$. Putting 
$x=-\infty$ into Eq. $(F-14)$ we find that $T_{0}$ does in fact go to zero. On the other hand, when $x \rightarrow 0, T_{0}$ approaches a fixed value $A$. (The fact that the interface temperature remains fixed with time will, be shown to be true:)

Assuming these forms to be correct, the constants can be determined by utilizing the necessary internal boundary conditions. Plugging Eqs. $(F-14)$ and (F-15) into one of the boundary conditions at the fuel-coolant interface, represented by $E q .(F-6)$, we find

$$
A(1+\operatorname{erf} 0)=B+C \text { erf } 0
$$

or

$$
A=B
$$

Plugging these equations with the above result into Eq. (F-7) produces

$$
\begin{aligned}
& \left.k_{0} \frac{\partial}{\partial x}\left[A\left(1+\operatorname{erf} \frac{x}{2 \sqrt{\alpha_{0} t}}\right)\right]\right|_{x=0}=\left.k_{1} \frac{\partial}{\partial x}\left(A+C \text { erf } \frac{x}{2 \sqrt{\alpha_{1} t}}\right)\right|_{x=0} \\
& \left.\quad \Rightarrow \quad k_{0} A \frac{\partial}{\partial x}\left(\operatorname{erf} \frac{x}{2 \sqrt{\alpha_{0} t}}\right)\right|_{x=0}=\left.k_{1} C \frac{\partial}{\partial x}\left(\operatorname{erf} \frac{x}{2 \sqrt{\alpha_{1} t}}\right)\right|_{x=0} \\
& \left.k_{0} A \frac{2}{\sqrt{\pi}} e^{-\left(x / 2 \sqrt{\alpha_{0} t}\right)^{2}} \cdot \frac{1}{2 \sqrt{\alpha_{0} t}}\right|_{x=0}=\left.k_{1} C \frac{2}{\sqrt{\pi}} e^{-\left(x / 2 \sqrt{\alpha_{1} t}\right)^{2}} \cdot \frac{1}{2 \sqrt{\alpha_{1} t}}\right|_{x=0},
\end{aligned}
$$

which reduces to: 


$$
\frac{k_{0} A}{\sqrt{\alpha_{0}}}=\frac{k_{1} C}{\sqrt{\alpha_{1}}}
$$

or

$$
k_{0} A \sqrt{\alpha_{1}}=k_{1} c \sqrt{\alpha_{0}} .
$$

Using this result in Eq. (F-15), we get

$$
T_{1}=C\left(\frac{k_{1} \sqrt{\alpha_{0}}}{k_{0} \sqrt{\alpha_{1}}}+\operatorname{erf} \frac{x}{2 \sqrt{\alpha_{1} t}}\right)
$$

and from Eq. $(F-14)$,

$$
T_{0}=\frac{k_{1} \sqrt{\alpha_{0}}}{k_{0} \sqrt{\alpha_{1}}} C\left(1+\operatorname{erf} \frac{x}{2 \sqrt{\alpha_{0} t}}\right) \text {. }
$$

To determine the other constants, the boundary conditions at the moving solid-liquid fuel interface are applied. Using Eqs. $(F-19)$ and $(F-16)$ in Eq. $(F-8)$ produces

$$
c\left(\frac{k_{1} \sqrt{\alpha_{0}}}{k_{0} \sqrt{\alpha_{1}}}+\operatorname{erf} \frac{x}{2 \sqrt{\alpha_{1} t}}\right)=V-D \operatorname{erfc} \frac{x}{2 \sqrt{\alpha_{2} t}}=T_{M}^{\prime} \cdot(F-21)
$$

We can see that this equation represents a constant value of the temperature at the liquid-solid interface, $T_{M}^{\prime}$. For this to hold in the above equation, $x$ must be proportional to $t^{\frac{1}{2}}$, that is,

$$
x=2 \lambda \sqrt{\alpha_{1} t},
$$

where $\lambda$ is a numerical constant to be determined from the remaining. boundary condition represented by Eq. $(F-9)$. Before determining $\lambda$, the 
constants $C$ and $D$ can be solved for in terms of $\lambda$ and $T_{M}^{\prime}$ from Eq. $(F-21)$ :

$$
\begin{aligned}
& C=\frac{T_{M}^{\prime}\left(k_{0} \sqrt{\alpha_{1}}\right)}{k_{1} \sqrt{\alpha_{0}}+k_{0} \sqrt{\alpha_{1}} \operatorname{erf} \lambda} \\
& D=\frac{V-T_{M}^{\prime}}{\operatorname{erfc}\left(\lambda \sqrt{\alpha_{1} / \alpha_{2}}\right)} .
\end{aligned}
$$

Using now Eqs. (F-19) and $(F-16)$ in Eq. $(F-9)$ to solve for $\lambda$, we get, at $x=x$,

$$
\begin{gathered}
\left.k_{1} \frac{\partial}{\partial x}\left[C\left(\frac{k_{1} \sqrt{\alpha_{0}}}{k_{0} \sqrt{\alpha_{1}}}+\operatorname{erf} \frac{x}{2 \sqrt{\alpha_{1} t}}\right)\right]\right|_{x=x}-\left.k_{2} \frac{\partial}{\partial x}\left(V-D \text { erfc } \frac{x}{2 \sqrt{\alpha_{2} t}}\right)\right|_{x=x} \\
=L \rho_{1} \frac{\partial}{\partial t}\left(2 \lambda \sqrt{\alpha_{1} t}\right) .
\end{gathered}
$$

This reduces to

$$
\begin{gathered}
k_{1} C \frac{2}{\sqrt{\pi}} e^{-\left(x / 2 \sqrt{\alpha_{1} t}\right)^{2}} \cdot \frac{1}{2 \sqrt{\alpha_{1} t}}-k_{2} D \frac{2}{\sqrt{\pi}} e^{-\left(x / 2 \sqrt{\alpha_{2} t}\right)^{2}} \cdot \frac{1}{2 \sqrt{\alpha_{2} t}} \\
=L \rho_{1} \lambda\left(\sqrt{\alpha_{1} / t}\right) \\
k_{1} C e^{-\lambda^{2}}-k_{2} D e^{-\lambda^{2}\left(\alpha_{1} / \alpha_{2}\right)}\left(\frac{\alpha_{1}}{\alpha_{2}}\right)^{\frac{1}{2}}=L \rho_{1} \lambda \alpha_{1} \sqrt{\pi}
\end{gathered}
$$

Substituting the results of Eqs. $(F-23)$ and $(F-24)$, we get 


$$
\begin{gathered}
k_{1} \frac{T_{M}^{\prime}\left(k_{0} \sqrt{\alpha_{1}}\right)}{k_{1} \sqrt{\alpha_{0}}+k_{0} \sqrt{\alpha_{1}} \operatorname{erf} \lambda} e^{-\lambda^{2}}-k_{2}\left(\frac{V-T_{M}^{\prime}}{\operatorname{erfc}\left(\lambda \sqrt{\alpha_{1} / \alpha_{2}}\right)}\right) e^{-\lambda^{2}\left(\alpha_{1} / \alpha_{2}\right)} \cdot\left(\frac{\alpha_{1}}{\alpha_{2}}\right)^{\frac{1}{2}} \\
=L \rho_{1} \lambda \alpha_{1} \sqrt{\pi} .
\end{gathered}
$$

Dividing Eq. $(F-26)$ by $k_{1}$. and $T_{M}^{\prime}$ and reducing gives

$$
\begin{gathered}
\frac{\left(k_{0} \sqrt{\alpha_{1}}\right) \cdot e^{-\lambda^{2}}}{k_{1} \sqrt{\alpha_{0}}+k_{0} \sqrt{\alpha_{1}} \operatorname{erf} \lambda}-\frac{k_{2}}{k_{1}}\left(\frac{V-T_{M}^{\prime}}{T_{M}^{\prime}}\right) \cdot \frac{e^{-\lambda^{2}\left(\alpha_{1} / \alpha_{2}\right)} \cdot \sqrt{\alpha_{1} / \alpha_{2}}}{\operatorname{erfc}\left(\lambda \sqrt{\alpha_{1} / \alpha_{2}}\right)} \\
\cdots \\
=\frac{\lambda L \sqrt{\pi}}{C_{1} T_{M}^{\prime}}
\end{gathered}
$$

As we can see, the constant $\lambda$ from Eq. (F-22) can be found from the above equation. This completes the determination of all the constants.

Substituting the results of Eqs. $(F-23)$ and $(F-24)$ for the numerical constants $C$ and $D$ into Eqs. $(F-14),(F-15)$, and $(F-16)$, we get for the temperature distributions in all three zones:

$$
\begin{aligned}
T_{0} & =\frac{k_{1} \sqrt{\alpha_{0}}}{k_{0} \sqrt{\alpha_{1}}} \cdot \frac{T_{M}^{\prime}\left(k_{0} \sqrt{\alpha_{1}}\right)}{k_{1} \sqrt{\alpha_{0}}+k_{0} \sqrt{\alpha_{1}} \operatorname{erf} \lambda} \cdot\left(1+\operatorname{erf} \frac{x}{2 \sqrt{\alpha_{0} t}}\right) . \\
& =\frac{k_{1} \sqrt{\alpha_{0}} T_{M}^{\prime}}{k_{1} \sqrt{\alpha_{0}}+k_{0} \sqrt{\alpha_{1}} \operatorname{erf} \lambda}\left(1+\operatorname{erf} \frac{x}{2 \sqrt{\alpha_{0} t}}\right)
\end{aligned}
$$




$$
\begin{aligned}
T_{1} & =\frac{T_{M}^{\prime}\left(k_{0} / \alpha_{1}\right)}{k_{1} \sqrt{\alpha_{0}}+k_{0} \sqrt{\alpha_{1}} \operatorname{erf} \lambda} \quad\left(\frac{k_{1} \sqrt{\alpha_{0}}}{k_{0} \sqrt{\alpha_{1}}}+\text { erf } \frac{x}{2 \sqrt{\alpha_{1} t}}\right) \\
& =\frac{T_{M}^{\prime}}{k_{1} \sqrt{\alpha_{0}}+k_{0} \sqrt{\alpha_{1}} \operatorname{erf} \lambda}\left(k_{1} \sqrt{\alpha_{0}}+k_{0} \sqrt{\alpha_{2}} \operatorname{erf} \frac{x}{2 \sqrt{\alpha_{1} t}}\right) \\
T_{2} & =V-\frac{V-T_{M}^{\prime}}{\operatorname{erfc}\left(\lambda \sqrt{\alpha_{1} / \alpha_{2}}\right.} \operatorname{erfc} \frac{x}{2 \sqrt{\alpha_{2} t}}
\end{aligned}
$$

These results agree with those published eisewhere (9). For the calculation of interface temperature presented earlier in this appendix, the fuel is taken to be initially at its melting point, or

$$
V=T_{M}^{\prime}
$$

This has the effect of simplifying Eq. $(F-27)$ to

$$
\frac{k_{0} \sqrt{\alpha_{1}} e^{-\lambda^{2}}}{k_{1} \sqrt{\alpha_{0}}+k_{0} \sqrt{\alpha_{1}} \operatorname{erf} \lambda}=\frac{\lambda L \sqrt{\pi}}{C_{1} T_{M}^{\prime}}
$$

or to the form used in (2) of

$$
\frac{C_{1} T M^{\prime}}{L \sqrt{\pi}}=\lambda e^{\lambda^{2}}\left(\frac{k_{1} \sqrt{\alpha_{0}}}{k_{0} \sqrt{\alpha_{1}}}+\operatorname{erf} \lambda\right)
$$

The relative interface temperature can be computed using either Eq. (F-28) or $(F-29)$ at $x=0$ to be 


$$
T_{I}^{\prime}=\frac{T_{M}{ }^{\prime} k_{1} \sqrt{\alpha_{0}}}{k_{1} \sqrt{\alpha_{0}}+k_{0} \sqrt{\alpha_{1}} \operatorname{erf} \lambda} \cdots
$$

In terms of $T_{H}$ and $T_{C}$, the absolute interface temperature is therefore

$$
T_{I}=\frac{T_{M}\left(k_{1} \sqrt{\alpha_{0}}\right)+T_{C}\left(k_{0} \sqrt{\alpha_{1}}\right) \operatorname{erf} \lambda}{k_{1} \sqrt{\alpha_{0}}+k_{0} \sqrt{\alpha_{1}} \operatorname{erf} \lambda}
$$

By dividing the numerator and the denominator by $\sqrt{\alpha_{0} \alpha_{1}}$, this is converted again to the form used in this appendix for the interface temperature:

$$
T_{I}=\frac{T_{M}\left(k_{1} / \sqrt{\alpha_{1}}\right)+T_{C}\left(k_{0} / \sqrt{\alpha_{0}}\right) \operatorname{erf} \lambda}{k_{1} / \sqrt{\alpha_{1}}+k_{0} / \sqrt{\alpha_{0}} \operatorname{erf} \lambda} \text {. }
$$




\section{REFERENCES (APPENDIX F)}

1. J.G. Eberhart, "The Wettability of Reactor Fuel by Molten Metal," ANL-RDP-22, November 1973.

2. R.B. Knapp, "Thermal Stress Initiated Fracture as a Fragmentation Mechanism in the $\mathrm{UO}_{2}$-Sodium Fuel-Coolant Interaction," $31-109-38$ 2831 TR, May 1975.

3. A.W. Cronenberg, H.K. Fauske, " $\mathrm{UO}_{2}$ Solidification Phenomena Associated with Rapid Cooling in Liquid Sodium," J. Nucl'. Mat'ls 00 (1974).

4. A.W. Cronenberg, R.L. Coats, "A Comparison of Solidification Phenomena for $\mathrm{UO}_{2}, U \mathrm{C}$, and UN Relative to Quenching in Sodium Coolant," to be published in Nuclear Engineering and Design.

5. Von C. Schwarz, "Zur Rechnerischen Behandlung der Erstarrungsvorgänge beim Giefsen von Metallen," Zeitschrift für Angewandte Mathematik und Mechanik, 13, 202 (1933).

6. G.H. Golden, et al., "Thermophysical Properties of Sodium," ANL-7323, Argonne, 111., August 1967.

7. Personal communication with Michael Corradini, MIT, October 1976.

8. Hans Fauske, "The Role of Energetic Mixed Oxide Fuel-Sodium Thermal Interactions in Liquid-Metal Fast Breeder Reactor Safety," paper presented at 3rd CSNI Specialist Mtg. on Sodium-Fuel Interaction in Fast Reactors, March 1976, Tokyo, Japan.

9. H.S. Carslaw, J.C. Jaeger, Conduction of Heat in Solids, Oxford University Press, London, 1959, p. 288. 
APPENDIX G:

TABULATION OF FCI COMPUTER CASES OF ANL MODEL

\begin{tabular}{|c|c|c|c|c|c|c|c|}
\hline $\begin{array}{l}\text { Run } \\
\text { No. }\end{array}$ & $\begin{array}{l}\text { Reactor } \\
\text { System } \\
\text { (Fue 1) }\end{array}$ & $\begin{array}{l}\text { Fue } 1 \\
\text { Mass } \\
(\mathrm{kg})\end{array}$ & $W$ & $\begin{array}{c}\text { Heat } \\
\text { Transfer } \\
\text { Cutoff }\end{array}$ & $\underset{\text { (msec) }}{t_{m}}$ & $\underset{(\mu m)}{R_{f}}$ & $\begin{array}{l}\text { Expansion Work } \\
\text { at Slug Impact } \\
\text { (MW-sec) }\end{array}$ \\
\hline 1 & FFTF $\left(\mathrm{UO}_{2}\right)$ & 1250 & 6.38 & No & 10 & .117 & 104 \\
\hline 2 & FFTF $\left(\mathrm{UO}_{2}\right)$ & 1250 & 6.38 & No & 10 & 1000 & 38 \\
\hline 3 & FFTF $\left(\mathrm{UO}_{2}\right)$ & 1250 & 6.38 & No & 0.1 & 585 & 69 \\
\hline 4 & FFTF $\left(\mathrm{UO}_{2}\right)$ & 1250 & 6.38 & No & 0.1 & 1000 & 47 \\
\hline 5 & FFTF $\left(\mathrm{UO}_{2}\right)$ & 1250 & 6.38 & No & 5 & 117 & 105 \\
\hline 6 & FFTF $\left(\mathrm{UO}_{2}\right)$ & 1250 & 6.38 & No & 5 & 585 & 61 \\
\hline 7 & FFTF $\left(\mathrm{UO}_{2}\right)$ & 1250 & 6.38 & No & 5 & 1000 & 42 \\
\hline 8 & $\operatorname{FFTF}\left(\mathrm{UO}_{2}\right)$ & 1250 & 6.38 & No & 25 & 117. & \\
\hline 9 & $\operatorname{FFTF}\left(\mathrm{UO}_{2}\right)$ & 1250 & 6.38 & No & 25 & 23.4 & $\begin{array}{l}\text { lear Critical } \\
\text { Point) }\end{array}$ \\
\hline 10 & FFTF $\left(\mathrm{UO}_{2}\right)$ & 1250 & 6.38 & No & 25 & 585 & 47 \\
\hline 11 & FFTF $\left(\mathrm{UO}_{2}\right)$ & 1250 & 6.38 & No & 40 & 117 & 94 \\
\hline 12 & FFTF $\left(\mathrm{UO}_{2}\right)$ & 1250 & 6.38 & No & 40 & 585 & 41 \\
\hline 13 & FFTF $\left(\mathrm{UO}_{2}\right)$ & 1250 & 6.38 & No & 40 & 585 & 41 \\
\hline 14 & FFTF $\left(\mathrm{UO}_{2}\right)$ & 1250 & 6.38 & No & 60 & 585 & 36 \\
\hline 15 & FFTF $\left(\mathrm{UO}_{2}\right)$ & 1250 & 6.38 & No & 60 & 117 & 88 \\
\hline 16 & $\operatorname{FFTF}\left(\mathrm{UO}_{2}\right)$ & 1250 & 6.38 & Yes & 1 & 117 & 109 \\
\hline 17 & $\operatorname{FFTF}\left(\mathrm{UO}_{2}\right)$ & 1250 & 6.38 & Yes & $i$ & 585 & 23 \\
\hline 18 & FFTF $\left(\mathrm{UO}_{2}\right)$ & 1250 & 6.38 & Yes & 20 & 117 & 18 \\
\hline 19 & $\operatorname{FFTF}\left(\mathrm{UO}_{2}\right)$ & 1250 & 6.38 & Yes & 20 & 23.4 & $\begin{array}{l}\text { (Near Critical } \\
\text { Point) }\end{array}$ \\
\hline 20 & FFTF $\left(\mathrm{UO}_{2}\right)$ & 1250 & 6.38 & Yes & 20 & 40 & 85 \\
\hline 21 & FFTF $\left(\mathrm{UO}_{2}\right)$ & 1250 & 6.38 & Yes & 40 & 50 & 38 \\
\hline 22 & FFTF $\left(\mathrm{UO}_{2}\right)$ & 1250 & 6.38 & Yes & 40 & 30 & 76 \\
\hline 23 & FFTF $\left(\mathrm{UO}_{2}\right)$ & 3000 & 11 & Yes & 20 & 64 & 101 \\
\hline 24 & FFTF $\left(\mathrm{UO}_{2}\right)$ & 300 & 10 & Yes & 5 & 64 & 73 \\
\hline 25 & FFTF $\left(\mathrm{UO}_{2}\right)$ & 300 & 10 & Yes & 1 & 64 & 90 \\
\hline
\end{tabular}




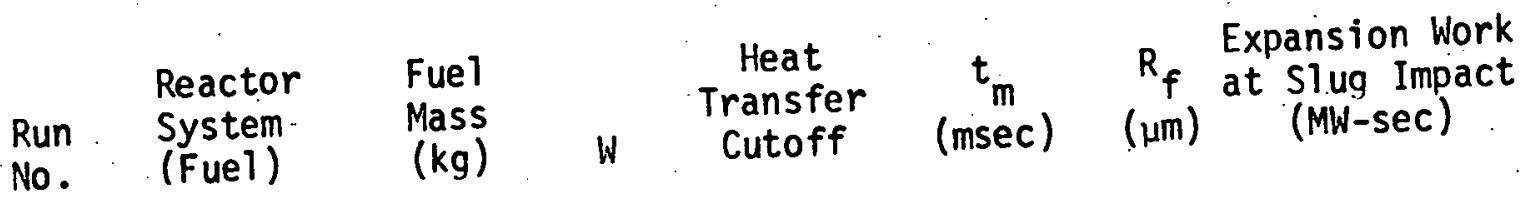
$\begin{array}{llcccccc}26 & \text { FFTF }\left(\mathrm{UO}_{2}\right) & 300 & 11.5 & \text { Yes } & 10 & 64 & 47 \\ 27 & \text { FFTF }\left(\mathrm{UO}_{2}\right) & 300 & 11.5 & \text { Yes } & 15 & 64 & 33 \\ 28 & \text { FFTF }\left(\mathrm{UO}_{2}\right) & 300 & 11.5 & \text { Yes } & 10 & 64 & 109 \star \star \\ 29 & \text { FFTF }\left(\mathrm{UO}_{2}\right) & 3000 & 11 & \text { Yes } & 20 & 64 & \text { (Near Critical Point) } \\ 30 & \text { FFTF }\left(\mathrm{UO}_{2}\right) & 600 & 11 & \text { Yes } & 1 & 64 & \text { (Near Critical Point) }\end{array}$

31. FFTF $\left(\mathrm{UO}_{2}\right) \quad 2000 \quad 12 \quad$ Ye

32 FFTF $\left(\mathrm{UO}_{2}\right) \quad 1250 \quad 11 \quad$ Yes

33 . FFTF $\left(\mathrm{UO}_{2}\right) \quad 1250 \quad 11$

$34 \operatorname{FFTF}\left(\mathrm{UO}_{2}\right) \quad 2000 \quad 12$

35 CRBR $\left(\mathrm{UO}_{2}\right) \quad 7000 \quad 13$

36 CRBR $\left(\mathrm{UO}_{2}\right) \quad 5000 \quad 12$

37 CRBR $\left(\mathrm{UO}_{2}\right) \quad 3000 \quad 12$

$38 \operatorname{CRBR}\left(\mathrm{UO}_{2}\right) \quad 7000 \quad 13$

39 CRPR $\left(\mathrm{UO}_{2}\right) \quad 5000 \quad 12$

40 CRBR $\left(\mathrm{UO}_{2}\right) \quad 3000 \quad 12$

41 CRBR $\left(\mathrm{UO}_{2}\right) \quad 1000 \quad 11$

$42 \operatorname{CRBR}\left(\mathrm{UO}_{2}\right) \quad 1000 \quad 11$

43 FFTF $\left(\mathrm{UO}_{2}\right) \quad 3000 \quad 11.5$

44 FFTF $\left(\mathrm{UO}_{2}\right) \quad 3000 \quad 11.5$

45 FFTF $\left(\mathrm{UO}_{2}\right) \quad 3000 \quad 10$

$46 \operatorname{FFTF}\left(\mathrm{UO}_{2}\right) \quad 3000 \quad 13$

47 CRBR $\left(\mathrm{UO}_{2}\right) \cdot 7000 \quad 12$

48 CRBR $\left(\mathrm{UO}_{2}\right) \quad 7000 \quad 12$

49 CRBR (UC) $5000 \quad 12$

50 CRBR (UC) $5000 \quad 13.5$

51 CRBR (UC) $5000 \quad 10$

52 CRBR (UC) $7000 \quad 15$

53 CRBR (UC) $7000 \quad .15$

54 CRBR (UC) $7000 \quad 15$

Yes 40

40

Yes : 30

Yes 50

Yes 50

Yes 50

Yes $\quad 40$

90

$80: 64$

70.64

$30 \quad 64$

$20 \quad 64$

$60 \cdot 64$

$50 \cdot 64$

$\begin{array}{llll}\text { Yes } & 50 & 64 & 37 \\ \text { Yes } & 50 & 64 & 48\end{array}$

$\begin{array}{llll}\text { Yes } & 50 & 64 & 48\end{array}$

$\begin{array}{llll}\text { Yes } & 70 & 64 & 80\end{array}$

$\begin{array}{llll}\text { Yes } & 80 & 64 & 66\end{array}$

Yes $160: 64: 147$

$\begin{array}{llll}\text { Yes } & 160 & 64 & 155\end{array}$

$\begin{array}{llll}\text { Yes } & 160 & 64 & 135\end{array}$

$\begin{array}{llll}\text { Yes } & 360 & 64 & 154\end{array}$

$\begin{array}{lllll}\text { Yes } & 450 & 64 & 64\end{array}$

Yes 600

64

88

Continued 


\begin{tabular}{|c|c|c|c|c|c|c|c|}
\hline $\begin{array}{l}\text { Run } \\
\text { No. }\end{array}$ & $\begin{array}{l}\text { Reactor } \\
\text { System } \\
\text { (Fuel) }\end{array}$ & $\begin{array}{l}\text { Fue } 1 \\
\text { Mass } \\
(\mathrm{kg})\end{array}$ & W & $\begin{array}{l}\text { Heat } \\
\text { Transfer } \\
\text { Cutoff. }\end{array}$ & $\underset{\text { (msec) }}{t_{\mathrm{m}}}$ & $\begin{array}{c}R_{f} \\
(\mu \mathrm{m})\end{array}$ & $\begin{array}{l}\text { Expansion Work } \\
\text { at Slug Impact } \\
\text { (MW-sec) }\end{array}$ \\
\hline 55 & CRBR (UC) & 4000 & 15 & Yes & 400 & 64 & 103 \\
\hline 56. & CRBR (UC) & 4000 & 15. & Yes & 450 & 64 & 92 \\
\hline 57 & CRBR (UC) & 1000 & 15 & Yes & 50 & 64 & $\star \star \star$ (Uns table) \\
\hline 58 & CRBR (UC) & 1000 & 15 & Yes. & 300 & 64 & $\star \star \star($ Uns table) \\
\hline 59 & CRBR (UC) & 1000 & 15 & Yes. & 150 & 64 & $\star \star \star($ Uns table $)$ \\
\hline 60 & CRBR (UC) & 2000 & 15 & Yes & 300 & 64. & 87 \\
\hline 61 & CRBR (UC) & 2000 & 15 & Yes & $360^{\circ}$ & 64 & 75 \\
\hline 62 & CRBR $\left(\mathrm{UO}_{2}\right)$ & 7000 & 12 & Yes & 80 & 58 & 82 \\
\hline 63 & CRBR $\left(\mathrm{UO}_{2}\right)$ & 7000 & 12 & Yes & 80 & 70 & 53 \\
\hline 64 & CRBR $\left(\mathrm{UO}_{2}\right)$ & 7000 & $\because 12$ & Yes & 80 & 64 & $49\left(T_{f}=3600^{\circ} \mathrm{K}\right)$ \\
\hline 65 & $\operatorname{CRBR}\left(\mathrm{UO}_{2}\right)$ & 7000 & 12 & Yes & 80 & 64 & $85\left(T_{f}=4400^{\circ} \mathrm{K}\right)$ \\
\hline 66 & CRBR $\left(\mathrm{UO}_{2}\right)$ & $7000 \ldots$ & $\ldots 12$ & Yes & 80 & 64 & $58\left(\mathrm{~T}_{\mathrm{Na}}=727^{\circ} \mathrm{K}\right)$ \\
\hline 67 & CRBR $\left(\mathrm{UO}_{2}\right)$ & 7000 & $\ldots 12$ & Yes & 80 & 64 & $75\left(T_{\mathrm{Na}}=889^{\circ} \mathrm{K}\right)$ \\
\hline 68 & CRBR $\left(\mathrm{UO}_{2}\right)$ & $7000^{\circ}$ & 10.8 & Yes & 80 & 64 & 52 \\
\hline 69 & CRBR $\left(\mathrm{UO}_{2}\right)$ & 7000 & 13.2 & Yes & 80 & .64 & 81 \\
\hline 70 & CRBR $\left(\mathrm{UO}_{2}\right)$ & 7000 & 12 & Yes & 72 & 64 & 77 \\
\hline 71 & CRBR $\left(\mathrm{UO}_{2}\right)$ & 7000 & 12 & Yes & 88 & 64 & 57 \\
\hline
\end{tabular}

*Run terminated because equation of state near critical point of sodium is not accurate

$\star \star$ Fuel Temperature $=5000^{\circ} \mathrm{K}$ (All other $\mathrm{UO}_{2}$ runs are at $T_{f}=4000^{\circ} \mathrm{K}$; UC runs are at $T_{f}=5000^{\circ} \mathrm{K}$ )

$\star \star \star$ Code is unstable at this small value of UC fuel mass

Note: Na Temp $=840^{\circ} \mathrm{F}$ (FFTF) unless otherwise noted

$\mathrm{Na}$ Temp $=808^{\circ} \mathrm{F}$ (CRBR) 